University of Tennessee Health Science Center

UTHSC Digital Commons

\title{
MUC13 Modulated Nanomechanical and Biophysical Responses in Pancreatic Cancer Cells
}

Andrew E. Massey

University of Tennessee Health Science Center

Follow this and additional works at: https://dc.uthsc.edu/dissertations

Part of the Pharmacy and Pharmaceutical Sciences Commons

\section{Recommended Citation}

Massey, Andrew E. (https://orcid.org/0000-0001-7688-5501), "MUC13 Modulated Nanomechanical and Biophysical Responses in Pancreatic Cancer Cells" (2020). Theses and Dissertations (ETD). Paper 511. http://dx.doi.org/10.21007/etd.cghs.2020.0496.

This Dissertation is brought to you for free and open access by the College of Graduate Health Sciences at UTHSC Digital Commons. It has been accepted for inclusion in Theses and Dissertations (ETD) by an authorized administrator of UTHSC Digital Commons. For more information, please contact jwelch30@uthsc.edu. 


\title{
MUC13 Modulated Nanomechanical and Biophysical Responses in Pancreatic Cancer Cells
}

\begin{abstract}
Pancreatic adenocarcinoma is one of the deadliest forms of cancer. Even with recent advances in diagnostic tools, chemotherapeutic regimens, and biomarkers for earlier detection, it still has dismal survival rates. Part of the reason for this is the inherent difficulty in detecting and treating this disease. Recent findings suggest that the altered expression of mucins, including MUC13, may be useful molecular signatures for early disease diagnosis, chemotherapy response and predicting patient survival. MUC13, a recently identified transmembrane glycoprotein, is normally associated with forming a protective barrier on epithelial tissues. However, its overexpression/aberrant subcellular localization has been associated with cancer, disease aggressiveness, poorer patient prognosis and drug resistance via alterations of multiple oncogenic signaling pathways. The main objective of this study is to investigate if MUC13 expression influences nanomechanical and biophysical characteristics of pancreatic cancer cells that might contribute to aggressive nature of this disease. To achieve this goal, we performed innovative nanoindentation analyses using atomic force microscopy in conjunction with standard biochemical assays. To combat this malignant disease, multiple approaches have been considered over the years. Recently, a unique biophysical method of cancer detection has been explored in other cancers, whereby an atomic force microscope (AFM) is used to measure the differences in rigidity and adhesion between normal and cancerous cells. AFMs work by using a thin metallic cantilever with a sharp probe which is brought into contact with a sample. Due to the interactions between the probe and the sample, various data can be extracted. AFMs have been used for decades to acquire high resolution, three-dimensional images of a sample, however it is also possible to acquire other types of data. For cancer research, biophysical data can help to differentiate between cancerous cells and their healthy counterparts. Current evidence suggests that normal cells have a greater rigidity than their cancerous counterparts in most malignancies, however literature dealing with pancreatic cancer is limited. In this report, a comprehensive overview of various pancreatic cell lines (both cancerous and non-cancerous) was physically investigated. We noted that there was a significant trend in the reduction of biophysical characteristics associated with differentiation status - namely, poorly differentiated pancreatic cancer cells (MIA PaCa-2, AsPC- 1 and Panc-1) have significantly lower rigidity values as compared to moderately differentiated (BXPC-3), well differentiated (HPAF-II) and normal pancreatic epithelia (HPNE). A positive correlation was seen between the adhesion data and aggregation assays - notably, less aggregation was seen in cancer cells as compared to HPNE cells, and
\end{abstract}

\section{Document Type \\ Dissertation}

\section{Degree Name}

Doctor of Philosophy (PhD)

\section{Program}

Pharmaceutical Sciences

Research Advisor

Subhash C.Chauhan, $\mathrm{PhD}$

\section{Keywords}

Atomic force microscopy, chemotherapeutics, MUC13, nanoindentation, Pancreatic cancer 


\section{Subject Categories}

Medicine and Health Sciences | Pharmacy and Pharmaceutical Sciences 


\section{MUC13 Modulated Nanomechanical and Biophysical Responses in Pancreatic Cancer Cells}

Author:

Andrew E. Massey
Advisor:

Subhash C. Chauhan, $\mathrm{PhD}$

A Dissertation Presented for The Graduate Studies Council of

The University of Tennessee Health Science Center

in Partial Fulfillment of the Requirements for the

Doctor of Philosophy degree from

The University of Tennessee

in

Pharmaceutical Sciences/Pharmaceutics

College of Graduate Health Sciences

May 2020 
Portions of Chapter 4 (C) 2020 by Elsevier.

All other material (C) 2020 by Andrew E. Massey.

All rights reserved. 


\section{DEDICATION}

I dedicate this dissertation to my parents, Clyde and Nanette Massey. It was first and foremost their constant love and support that gave me the strength to get to this point, and for this I am and will be forever grateful to them. 


\section{ACKNOWLEDGEMENTS}

This research would not have been possible without the support of those who guided me throughout my studies during the completion of my dissertation work. I would first like to sincerely thank my advisor, Dr. Subhash C. Chauhan, for giving me the opportunity to work in his laboratory. It was due to his guidance that I was introduced to the application of atomic force microscopy (AFM) to biological research at the University of Tennessee Health Science Center. His mentorship and guidance were instrumental in realizing this project.

I would also like to thank my other committee members - Drs. Hassan Almoazen, Stephen W. Behrman, Clifton Frilot, and Murali M. Yallapu - for their support and guidance of this project during my time at UTHSC.

In addition, I also wish to acknowledge Dr. Bilal Bin Hafeez for assistance with day-to-day experiments during my time in the lab. In addition, I also want to recognize all current and former members of Dr. Chauhan's and Dr. Yallapu's labs for both their camaraderie and their support during my time at UTHSC, especially Kyle Doxtater, for his help on my recent publication as shown in Chapter 4 of this manuscript.

I would also like to thank the Herb Kosten Foundation for providing some of the funding for my research, in addition to the National Institutes of Health as well as UTHSC. Lastly, I want to thank the staff at Bruker, who provided assistance and insight onto the use of the AFM for multiple applications. 


\begin{abstract}
Pancreatic adenocarcinoma is one of the deadliest forms of cancer. Even with recent advances in diagnostic tools, chemotherapeutic regimens, and biomarkers for earlier detection, it still has dismal survival rates. Part of the reason for this is the inherent difficulty in detecting and treating this disease. Recent findings suggest that the altered expression of mucins, including MUC13, may be useful molecular signatures for early disease diagnosis, chemotherapy response and predicting patient survival. MUC13, a recently identified transmembrane glycoprotein, is normally associated with forming a protective barrier on epithelial tissues. However, its overexpression/aberrant subcellular localization has been associated with cancer, disease aggressiveness, poorer patient prognosis and drug resistance via alterations of multiple oncogenic signaling pathways. The main objective of this study is to investigate if MUC13 expression influences nanomechanical and biophysical characteristics of pancreatic cancer cells that might contribute to aggressive nature of this disease. To achieve this goal, we performed innovative nanoindentation analyses using atomic force microscopy in conjunction with standard biochemical assays.
\end{abstract}

To combat this malignant disease, multiple approaches have been considered over the years. Recently, a unique biophysical method of cancer detection has been explored in other cancers, whereby an atomic force microscope (AFM) is used to measure the differences in rigidity and adhesion between normal and cancerous cells. AFMs work by using a thin metallic cantilever with a sharp probe which is brought into contact with a sample. Due to the interactions between the probe and the sample, various data can be extracted. AFMs have been used for decades to acquire high resolution, threedimensional images of a sample, however it is also possible to acquire other types of data. For cancer research, biophysical data can help to differentiate between cancerous cells and their healthy counterparts. Current evidence suggests that normal cells have a greater rigidity than their cancerous counterparts in most malignancies, however literature dealing with pancreatic cancer is limited.

In this report, a comprehensive overview of various pancreatic cell lines (both cancerous and non-cancerous) was physically investigated. We noted that there was a significant trend in the reduction of biophysical characteristics associated with differentiation status - namely, poorly differentiated pancreatic cancer cells (MIA PaCa2, AsPC-1 and Panc-1) have significantly lower rigidity values as compared to moderately differentiated (BxPC-3), well differentiated (HPAF-II) and normal pancreatic epithelia (HPNE). A positive correlation was seen between the adhesion data and aggregation assays - notably, less aggregation was seen in cancer cells as compared to HPNE cells, and most these cell lines also showed significantly lower membrane adhesiveness overall.

The effect of various chemotherapeutics or altered protein expression has not been extensively investigated in this disease state. To address this concern, we investigated the biophysical effect of several chemotherapeutic compounds on pancreatic 
cancer cells with varied levels of differentiation. Of note, the poorly differentiated cells were shown to have the greatest modulus increase, while moderate and well

differentiated cells had only minimal increases. Curcumin was shown to have the greatest biophysical increase of the drugs tested.

Although there is considerable research on the biochemical effects of various mucins, including MUC13, in cancer, there is currently no data detailing the biophysical effects of MUC13 in pancreatic cancer. We for the first time have shown that modulation of MUC13 directly impacts the physical properties of pancreatic cancer cells.

Specifically, overexpression in a Panc-1 transfected model significantly lowered the cell's modulus, which agrees with the literature consensus that aggressive cells are softer than their normal counterparts. Knockdown of MUC13 in HPAF-II cells showed the opposite effect, with a significant increase in both cellular rigidity and adhesion. Once again, the effects on membrane adhesion were confirmed with in vitro aggregation assays, and a positive correlation was noted.

In conclusion, we have for the first time shown a comprehensive biophysical panel of various pancreatic cells and noted differences in their characteristics based on differentiation status, as well as how these cells were affected by chemotherapeutic treatment and modulation of MUC13. Given this method of biophysical analysis, clinicians may be able to measure the effects of various chemotherapeutics more rapidly than with conventional histological tests, or possibly have earlier diagnostic information given changes in tissue properties. 


\section{TABLE OF CONTENTS}

CHAPTER 1. INTRODUCTION AND LITERATURE SEARCH ............................1

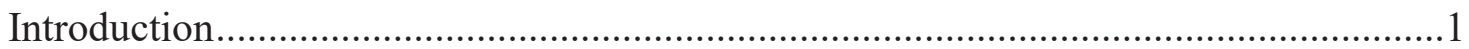

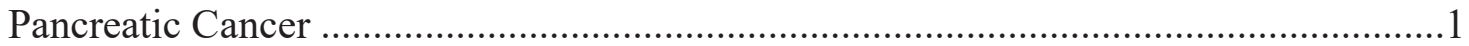

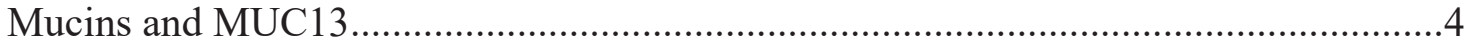

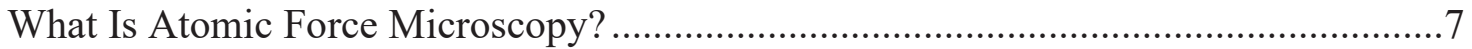

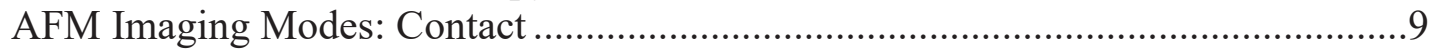

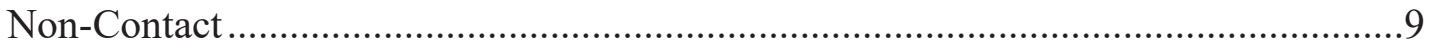

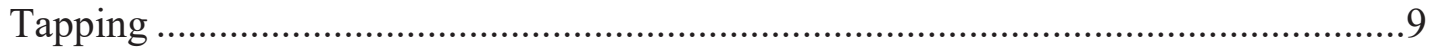

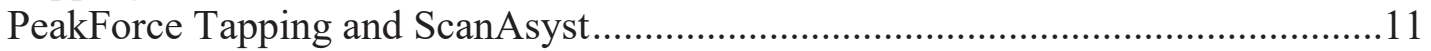

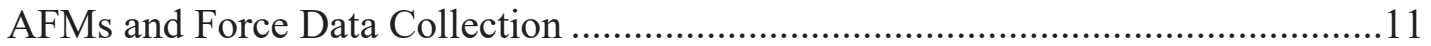

Force Curve Components and Analysis ............................................................... 12

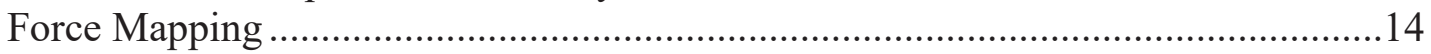

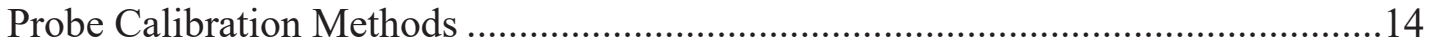

Atomic Force Microscopy and Biological Samples .......................................... 14

Cancer Cells and Mechanical Properties ............................................................... 15

Pancreatic Cancer Cells and Biophysical Analysis................................................. 16

\section{CHAPTER 2. DISCRIMINATION OF NORMAL AND CANCEROUS}

PANCREATIC CELL LINE BIOPHYSICAL PROPERTIES AND THEIR ASSOCIATION WITH DIFFERENTIATION STATUS ...........................................19

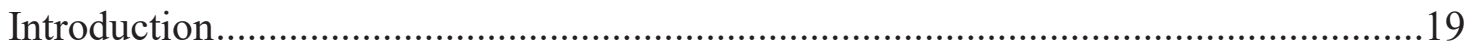

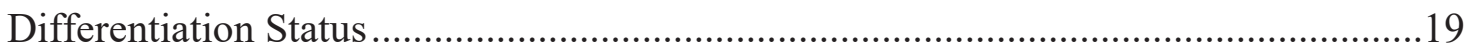

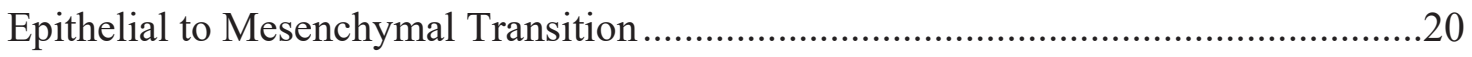

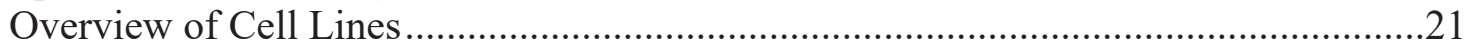

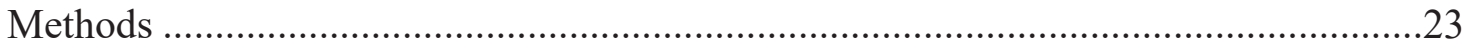

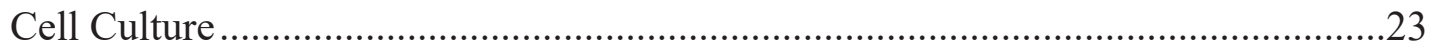

Live Cell AFM Data Analysis ..............................................................................23

Explanation of Settings for Force Map Analysis ..............................................24

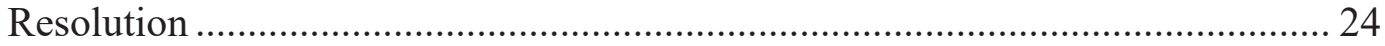

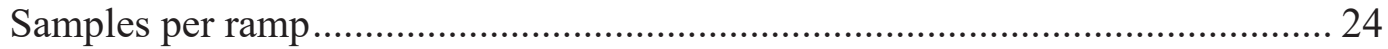

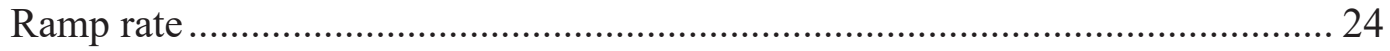

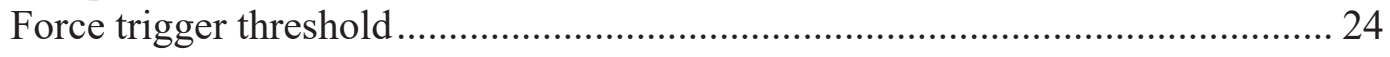

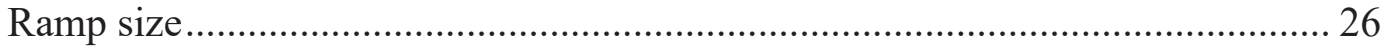

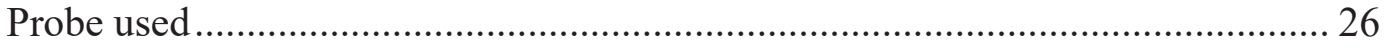

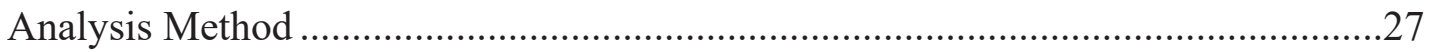

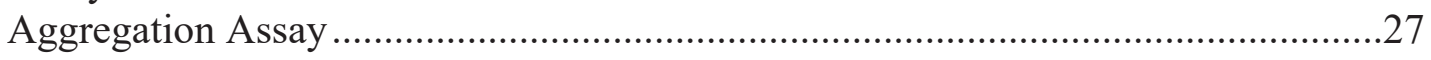

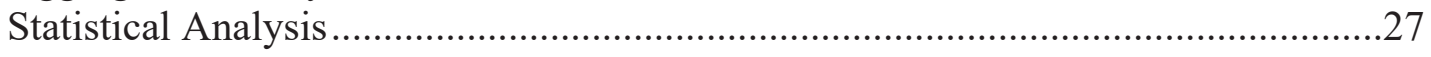

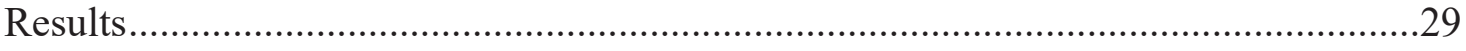

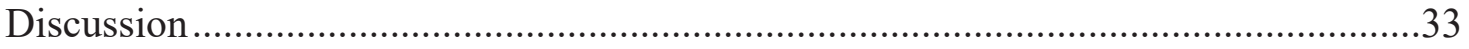




\section{CHAPTER 3. EFFECT OF CHEMOTHERAPEUTICS ON BIOPHYSICAL PROPERTIES OF PANCREATIC CANCER CELLS..............................................38}

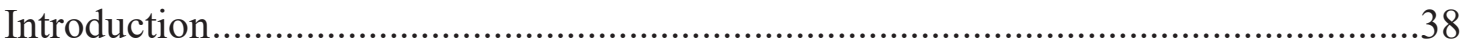

Pharmacological Agents Used and Their Characteristics .........................................38

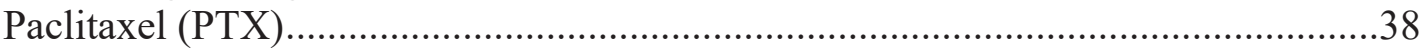

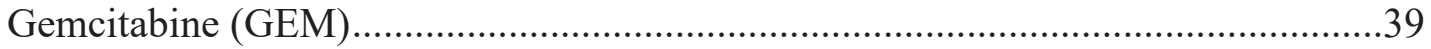

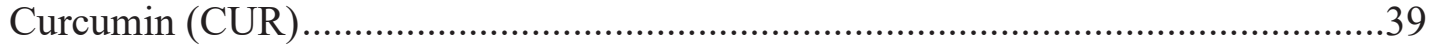

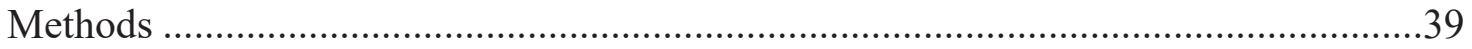

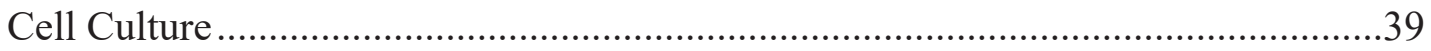

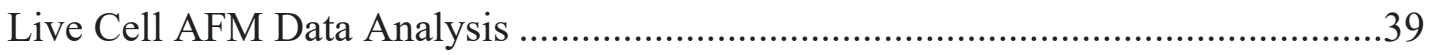

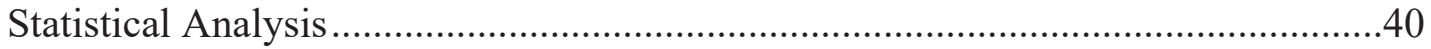

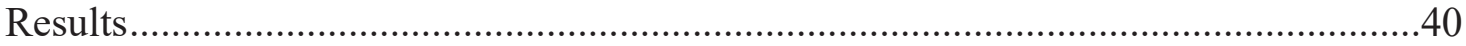

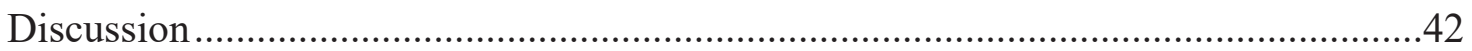

\section{CHAPTER 4. EFFECT OF MUC13 MODULATION ON BIOPHYSICAL}

PROPERTIES OF PANCREATIC CANCER CELLS...........................................52

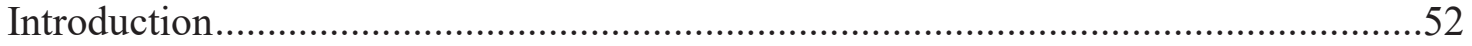

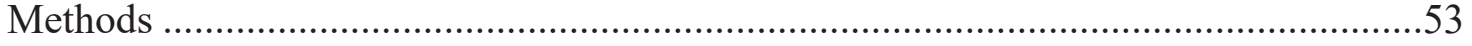

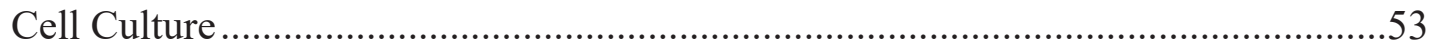

Transfection of PanCa Cells for Altered MUC13 Expression ...................................53

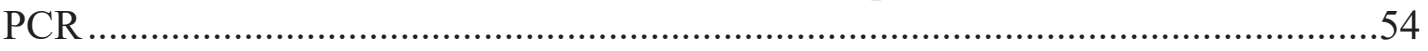

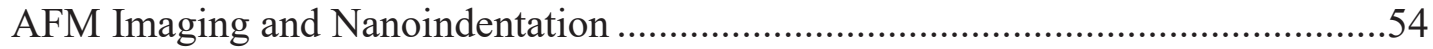

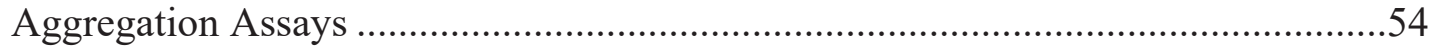

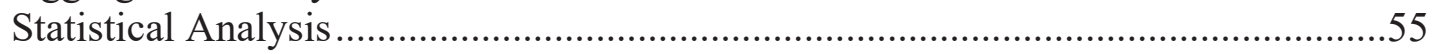

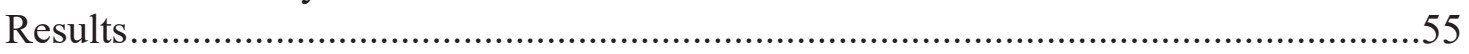

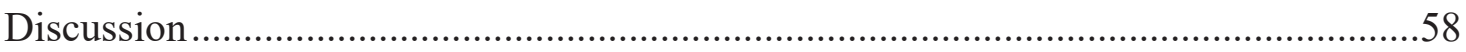

CHAPTER 5. CONCLUSIONS AND FUTURE RESEARCH ...............................62

LIST OF REFERENCES .....................................................................................65

APPENDIX A. SUPPLEMENTARY MATERIAL MENTIONED IN CHAPTER

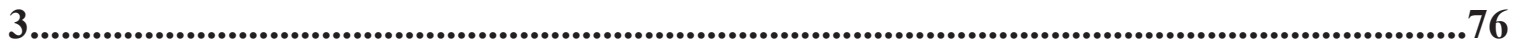

APPENDIX B. SUPPLEMENTARY MATERIAL MENTIONED IN CHAPTER

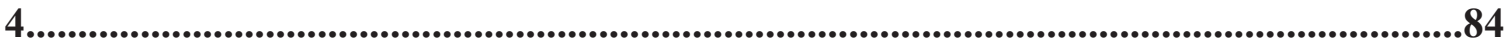

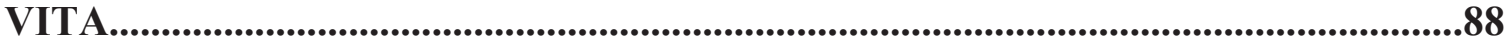




\section{LIST OF TABLES}

Table 2-1. Characteristics of pancreatic cancer cells used in this study....................22

Table 2-2. Summary of previously published studies showing reduced modulus in cancerous cell lines compared to normal reference cells.

Table 3-1. Summary of previously published studies detailing the biophysical effects of PTX and CUR in cancer cell lines. 


\section{LIST OF FIGURES}

Figure 1-1. Summary of the major hallmarks of cancer............................................2

Figure 1-2. Structural overview of transmembrane and secreted mucins. .......................5

Figure 1-3. Structural overview of MUC13 protein. ...............................................6

Figure 1-4. PubMed articles listing "atomic force microscopy" and "atomic force

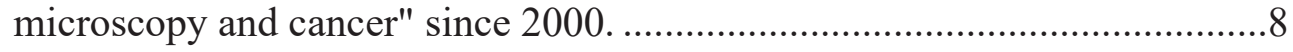

Figure 1-5. Graphical summary of key AFM components and force curve generation.

Figure 1-6. Schematic overview of AFM-based force analysis.

Figure 1-7. Representative force curve generated using Bruker BioScope Resolve on a clean sample in fluid.

Figure 2-1. Representative AFM images of normal HPNE cells. 25

Figure 2-2. Schematic overview of different analysis methods used in this study..........28

Figure 2-3. Schematic overview of aggregation assay.........................................28

Figure 2-4. Characterization of normal and cancerous pancreatic cells........................30

Figure 2-5. Regional cell data showing biophysical differences between normal and cancerous pancreatic cells.

Figure 2-6. Representative 20x images for aggregation assays conducted on normal and cancerous pancreatic cells.

Figure 3-1. Overall biophysical data of pancreatic cancer cells treated with paclitaxel (PTX), curcumin (CUR), and gemcitabine (GEM).

Figure 3-2. Regional biophysical analysis of HPAF-II cells treated with PTX, CUR, and GEM.

Figure 3-3. Regional biophysical analysis of BxPC-3 cells treated with PTX, CUR, and GEM.

Figure 3-4. Regional biophysical analysis of MIA PaCa-2 cells treated with PTX, CUR and GEM.

Figure 3-5. Regional biophysical analysis of AsPC-1 cells treated with PTX, CUR, and GEM. 
Figure 3-6. Regional biophysical analysis of Panc-1 cells treated with PTX, CUR, and GEM.

Figure 4-1. Effect of MUC13 overexpression on PanCa biophysical properties. ...........56

Figure 4-2. Effect of MUC13 knockdown on PanCa biophysical properties..................56

Figure 4-3. Regional nanocmechanical analysis of MUC13-modulated PanCa cells. ....57

Figure 4-4. Effect of MUC13 modulation on cellular aggregation. .............................59

Figure 5-1. Summary of key findings in this study. ..............................................63

Figure A-1. Overall analysis of chemotherapeutic treatments on adhesive properties

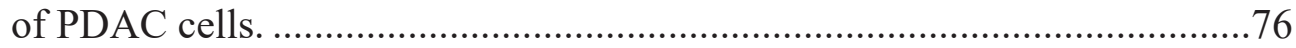

Figure A-2. Biophysical effects of VERU-111 (free drug and PLGA nanoformulations) on Caski cervical cancer cells................................... 77

Figure A-3. Biophysical effects of VERU-111 (free drug and PLGA nanoformulations) on SiHa cervical cancer cells....................................78

Figure A-4. Biophysical effects of curcumin-loaded magnetic nanoparticles on PDAC cells and tissues. 79

Figure A-5. Synthesis and characterization of PLGA-PTX nanoparticles (PPNPs) .......80

Figure A-6. Physical characteristics of living cells after treatment with PPNPs. .82

Figure B-1. Biophysical effects of MUC13 overexpression on SW480 colorectal cells.

Figure B-2. Biophysical effects of MUC13 knockdown on SW620 colorectal cells......85

Figure B-3. Representative aggregation assay results showing effects of MUC13 modulation on aggregative potential in colorectal cancer cells. .86

Figure B-4. Biophysical effects of cellular transfection on pancreatic cancer cells. .87 


\section{LIST OF ABBREVIATIONS}

\begin{tabular}{|c|c|}
\hline AFM & Atomic force microscopy \\
\hline $\mathrm{AKT}$ & Protein Kinase B \\
\hline ATCC & American Type Culture Collection \\
\hline CA19-9 & Carbohydrate antigen 19-9 \\
\hline CEA & Carcinoembryonic antigen \\
\hline $\mathrm{CRC}$ & Colorectal cancer \\
\hline CUR & Curcumin \\
\hline DMEM & Dulbecco's Modified Eagle Medium \\
\hline DMEM/F-12 & Dulbecco's Modified Eagle Medium/Nutrient Mixture F-12 \\
\hline DMSO & Dimethyl sulfoxide \\
\hline EDTA & Ethylenediaminetetraacetic acid \\
\hline EMT & Epithelial to mesenchymal transition \\
\hline ERK & Extracellular signal-regulated kinase \\
\hline FBS & Fetal bovine serum \\
\hline FOLFIRINOX & 5-fluorouracil, leucovorin, irinotecan, oxaliplatin \\
\hline GEM & Gemcitabine \\
\hline Glut-1 & Glucose transporter 1 \\
\hline HER2 & Human epidermal growth factor receptor 2 \\
\hline HPNE & Human Pancreatic Nestin Expressing cell \\
\hline hTERT & Human telomerase reverse transcriptase \\
\hline MET & Mesenchymal to epithelial transition \\
\hline MNP & Magnetic nanoparticle \\
\hline nab-PTX & Albumin-bound paclitaxel \\
\hline NF-kB & Nuclear factor kappa B \\
\hline PAK1 & P21 Activated Kinase 1 \\
\hline PanCa & Pancreatic cancer \\
\hline PanIN & Pancreatic intraepithelial neoplasia \\
\hline PBS & Phosphate buffered saline \\
\hline PDAC & Pancreatic ductal adenocarcinom \\
\hline PFQNM-LC & PeakForce Quantitative Nanomechanical - Live Cell probe \\
\hline PFT & PeakForce Tapping \\
\hline PLGA & Poly-lactic (co-glycolic)acid \\
\hline PTX & Paclitaxel \\
\hline RPMI & Roswell Park Memorial Institute Medium \\
\hline TGF $\beta$ & Tumor growth factor $\beta$ \\
\hline VEGF & Vascular endothelial growth factor \\
\hline ZEB & Zinc finger E-box binding homeobox 1 \\
\hline
\end{tabular}




\section{CHAPTER 1. INTRODUCTION AND LITERATURE SEARCH}

\section{Introduction}

Cancer is, in its most basic form, an uncontrolled growth of cells within the human body. These cells have undergone various genetic alterations that separate them from normal control processes that prevent this type of abnormal growth. These cellular growths, known as tumors, exhibit multiple hallmarks seen in all varieties of cancer. ${ }^{1-4}$

- Growth and division in the absence of normal physiological signals

- Continuous and irregular growth even with regulatory cessation signals

- Avoidance of apoptosis (programmed cell death)

- Limitless replication potential

- Promotion of angiogenesis (formation of new blood vessels)

- Ability to invade into distant tissue site and form metastases

- Promoting inflammation

- Evading immune responses

- Genetic instability and mutations

- Deregulated cellular metabolism

- A heterogeneous microenvironment that promotes abnormal growth

Figure 1-1 gives a visual summary of these hallmarks. Tumors that possess all these properties are considered malignant and present a considerable health risk. As of 2016, cancer ranked the second highest cause of death in the United States, just short of cardiovascular diseases, accounting for $21.9 \%$ of all recorded deaths according to a recent CDC study. ${ }^{5}$

Although prognosis of this disease state depends on many factors, one important factor is the tissue of origin. Even though a metastatic disease is always more difficult to treat and tends to have a lower survival rate, due to advances in either chemotherapy or surgical techniques survival rates have generally improved for certain cancers, such as lung, prostate, colorectal, and breast malignancies. ${ }^{6}$ Although there are still a large number of cases for these disease states, their overall survival has trended upwards in recent years. One cancer however remains dismally poor in terms of survival, with recent survival statistics indicating a less than $10 \%$ five-year survival rate: pancreatic cancer. ${ }^{7}$

\section{Pancreatic Cancer}

Pancreatic cancer $(\mathrm{PanCa})$ is an uncontrolled growth of cells originating in the pancreas, a small, retroperitoneal gland between the stomach and the spine. This organ has two major functions in the body, acting in an exocrine and an endocrine-based method and is principally involved in both macronutrient digestion (e.g., carbohydrates, lipids and proteins) and maintaining blood sugar levels. ${ }^{8} \mathrm{PanCa}$ is divided into two major 


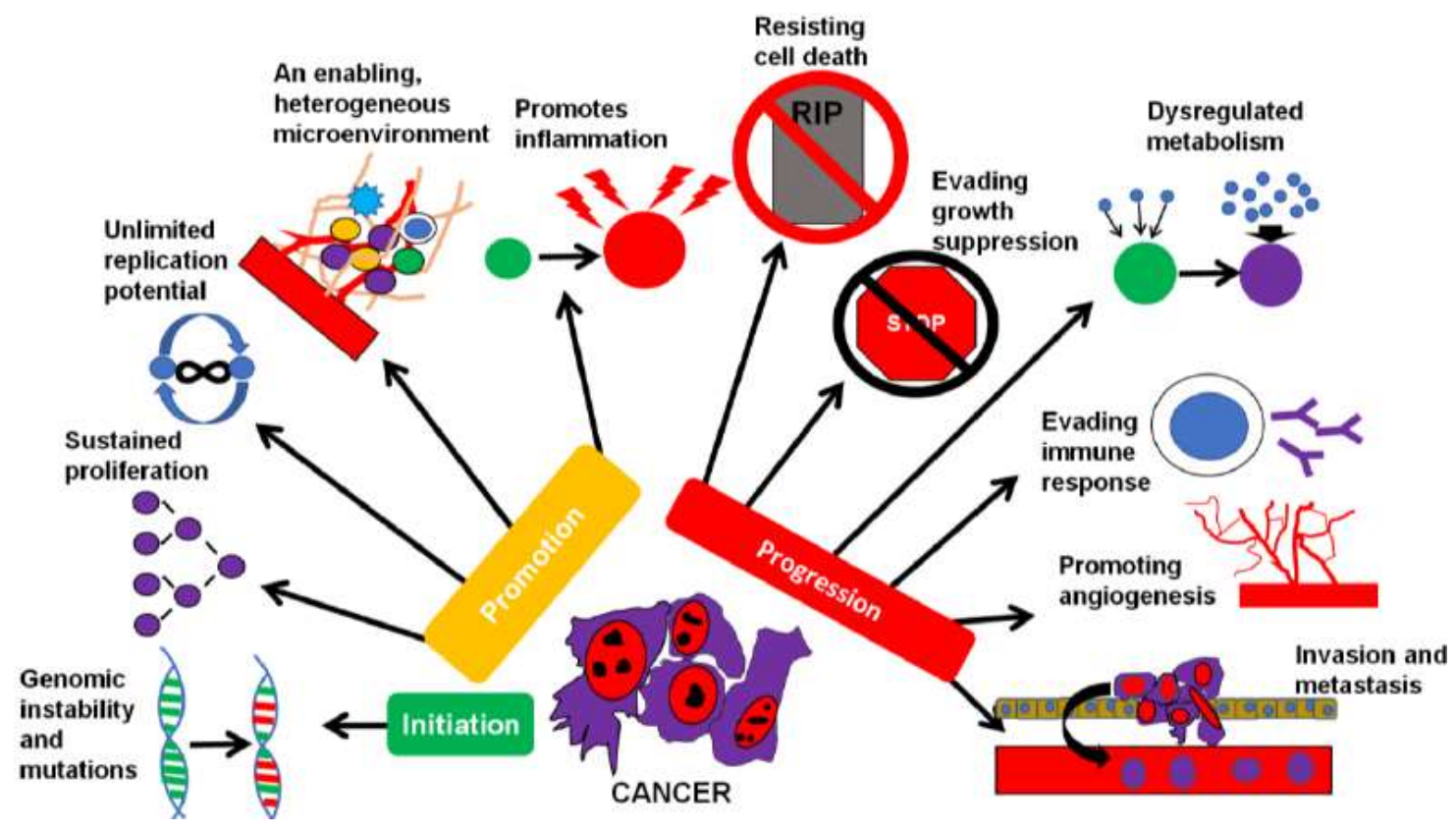

Figure 1-1. Summary of the major hallmarks of cancer.

\section{Data Sources}

Coussens LM, Werb Z. Inflammation and cancer. Nature. 2002;420(6917):860-867. doi:10.1038/nature01322.

Fouad YA, Aanei C. Revisiting the hallmarks of cancer. Am J Cancer Res. 2017;7(5):1016-1036. https://www.ncbi.nlm.nih.gov/pubmed/28560055 Hanahan D, Weinberg RA. Hallmarks of cancer: the next generation. Cell. 2011;144(5):646-674. doi:10.1016/j.cell.2011.02.013.

Hlatky L, Hahnfeldt P. Beyond the Cancer Cell: Progression-Level Determinants Highlight the Multiscale Nature of Carcinogenesis Risk. Cancer Res. 2014;74(3):659664. doi:10.1158/0008-5472.CAN-13-2508. 
types based on the cell of origin - exocrine or neuroendocrine. At least $85 \%$ of all pancreatic malignancies are exocrine - of these, the most common form is pancreatic ductal adenocarcinoma (PDAC). Endocrine tumors are less common, only accounting for approximately $5 \%$ of all cases. ${ }^{9}$ When comparing exocrine cancers to neuroendocrine, a clear difference can be seen in survival rates: exocrine has far lower five-year survival rates, ranging from 14\% (Stage 1A) to only 1\% (Stage 4) as compared to neuroendocrine (61\% at Stage $1 \mathrm{~A}$ to $16 \%$ at Stage 4$).{ }^{9}$ Overall, PanCa remains one of the deadliest forms of cancer in western countries and is projected to become the second leading cause of cancer-related death in the United States by $2030 .{ }^{10}$

According to the American Cancer Society, there will be an estimated 56,770 new PanCa cases in 2019, with an estimated 45,750 deaths. Currently, there is a 5-year survival rate of less than $10 \%$ for PDAC. ${ }^{7}$ This poor survival rate is partly due to an inferior therapeutic response and difficulty in early detection of the disease. Before 2000, the 5-year survival for PDAC was consistently below 10\%; recent advances in detection methods and therapeutic regiments have begun to improve the condition associated with this deadly disease. ${ }^{11}$ Survival rates are typically recorded, as shown in SEER records, into either localized, regional, or distant cancers - in this fashion, 5-year survival range from $37.4 \%$ at the local stage down to only $2.9 \%$ with distant/metastatic cancers. ${ }^{12}$

In terms of a cure, the only option is a surgical resection as a component of treatment sequencing, however at least $80 \%$ of patients are deemed inoperable once diagnosed. ${ }^{13}$ Specifically, only around $15 \%$ of patients are found to have a surgically resectable disease at the time of diagnosis (stages 1 or 2), 35\% have a locally advanced cancer (stage 3), and nearly 50\% have metastatic cancer (stage 4). ${ }^{14}$ Even for those who undergo surgery, recurrence is very common. ${ }^{15}$ In addition, pancreatomy is a complex surgery associated with significant morbidity and has a high risk of procedure related complications. Unfortunately, PDAC is a challenging disease to diagnose and detect for various reasons. Common symptoms of the disease are nonspecific, and include abdominal pain, weight loss, asthenia, anorexia, irregular stools or urine, and sometimes jaundice. ${ }^{16}$ Furthermore, these symptoms are typically only seen with disease progression - in the early stages of PDAC, symptoms may be milder or not present. In addition, these signs can be mistaken for other illnesses, such as pancreatitis or an ulcer., ${ }^{9,17}$

Several serum biomarkers currently exist to measure for PDAC - carbohydrate antigen 19-9 (CA19-9) and carcinoembryonic antigen (CEA) - however, they do not have high sensitivity for PDAC. ${ }^{15}$ Because of this, it is significantly more difficult for pathologists to properly diagnose early stage PDAC, and why when diagnosis is confirmed it is typically already an advanced stage disease. This diagnostic discrepancy indicates a need for further research into potential biomarkers that can be used for earlier detection and diagnosis of PDAC. 


\section{Mucins and MUC13}

As mentioned previously, there are no definitive biomarkers for PDAC. Although several are currently in use, including CA19-9 and CEA, they are not considered sensitive enough to properly detect PDAC. Recently, several promising biomarkers have been investigated for this disease state, including MUC13, a transmembrane mucin protein known to be aberrantly expressed in cancers, including PDAC. ${ }^{18-20}$

Under normal physiological conditions, the mucin family of proteins comprise a significant component of mucosal surfaces lining various body cavities - especially the GI tract. They are important in protecting these cavities from pathogens, proteases, and help to prevent dehydration. ${ }^{21}$ Mucins contain PTS domains, rich in prolines, threonines and serines. ${ }^{22}$ Another common element seen with mucins is extensive O-glycosylation, which plays a role in this protein's barrier function. ${ }^{23}$ They are found in one of two subdivisions, either secreted or transmembrane. Transmembrane mucins (including MUC13) have only one membrane spanning region that generates its protective effect through its highly glycosylated structure. These proteins form rod-like structures that extend far above the cell surface - depending on the specific protein it can extend several hundred nanometers. ${ }^{22}$ Recent evidence suggests that mucins act as "sensors" to the surrounding environment, and under normal circumstances they can trigger pathways such as membrane repair and maintenance. ${ }^{21}$

Mucins have been found to be overexpressed in various cancers, including lung ${ }^{24}$, ovarian, ${ }^{18}$ breast, ${ }^{25}$ and oral cancers ${ }^{26}$ - however there is evidence that they play a considerably larger role in gastrointestinal cancers. In response to various stressors, there is a loss of the normal polarity seen with transmembrane mucins (normally only located on the apical borders), leading to a repositioning of mucins across the entire epithelial surface, allowing them to act on proteins not normally in their immediate vicinity, including various receptor tyrosine kinases. ${ }^{22}$ In cancerous cells, mucins have been implicated in acting as a protective outer barrier which can impact drug uptake and immune surveillance, cell-cell adhesion (partly through its effects on E-cadherin and beta-catenin), proliferation, apoptosis, and metastasis, while intracellular domains can activate pathways involved in differentiation. ${ }^{21,27}$

PDAC has been associated MUC13, a small transmembrane mucin consisting of only 511 amino acids. ${ }^{27}$ This protein is normally expressed at low levels in the large intestine, trachea, kidney, small intestine and gastric epithelium ${ }^{28}$, although it has been seen to be aberrantly expressed in a variety of epithelial carcinomas. ${ }^{24,29,30}$ However, MUC13 has also been shown in a recent study by Khan et al to be expressed in $100 \%$ of pancreatic intraepithelial neoplasia (PanIN) lesions, and almost 95\% of pancreatic ductal adenocarcinoma (PDAC, the most common form of PanCa). By contrast, this same study showed only minimal expression in tumor adjacent tissue and virtually no expression in normal pancreatic tissue ${ }^{31}$, supporting the notion that MUC13 has a strong role in the pathology of PDAC and can be a promising diagnostic marker. Figure 1-2 highlights the major structural components of mucins and Figure 1-3 details MUC13. ${ }^{27,32,33}$ 


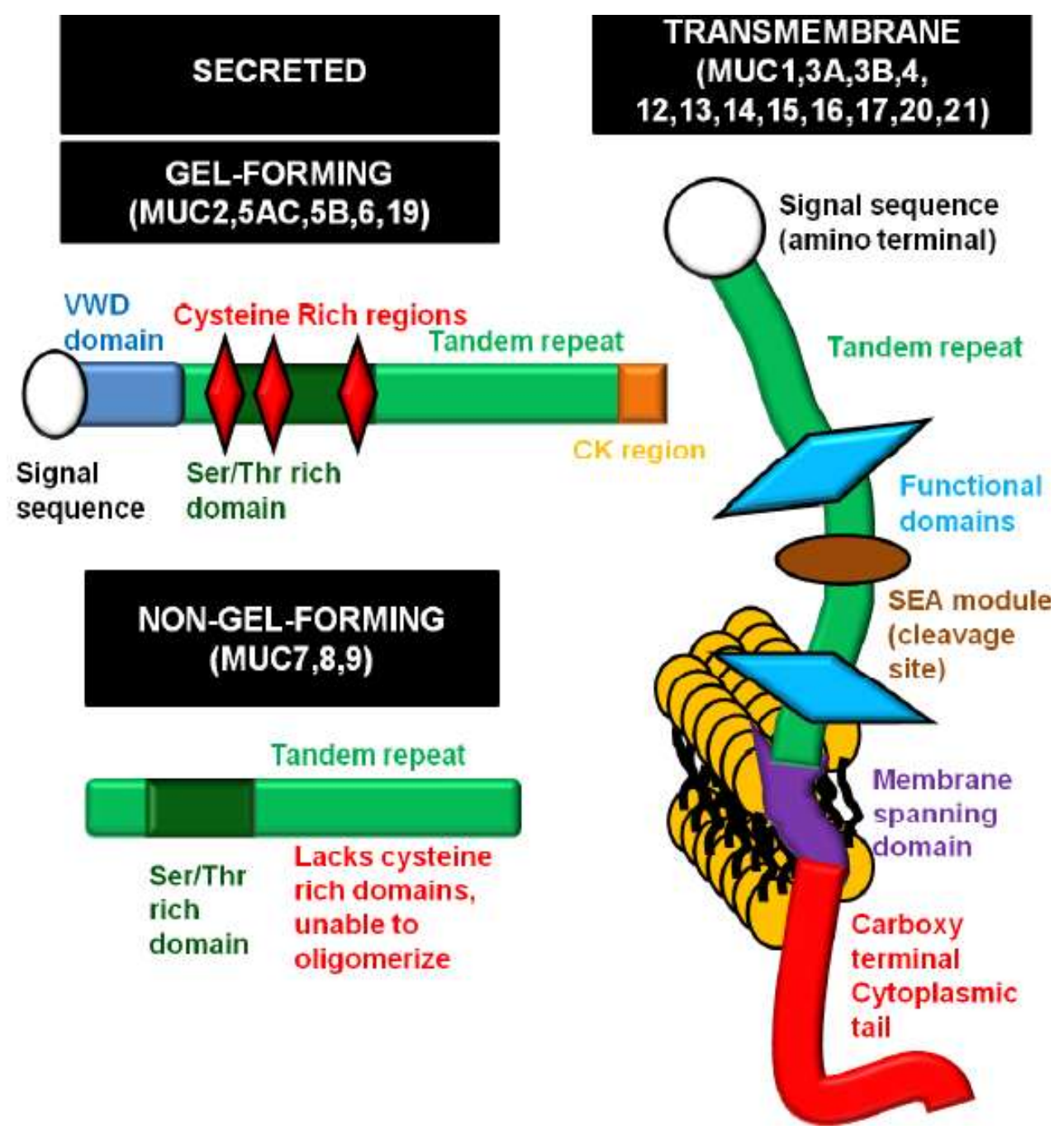

Figure 1-2. Structural overview of transmembrane and secreted mucins.

\section{Data sources}

Andrianifahanana M, Moniaux N, Batra SK. Regulation of mucin expression: Mechanistic aspects and implications for cancer and inflammatory diseases. Biochim Biophys Acta - Rev Cancer. 2006;1765(2):189-222. doi:10.1016/j.bbcan.2006.01.002. Rachagani S, Torres MP, Moniaux N, Batra SK. Current status of mucins in the diagnosis and therapy of cancer. Biofactors. 35(6):509-527. doi:10.1002/biof.64. 


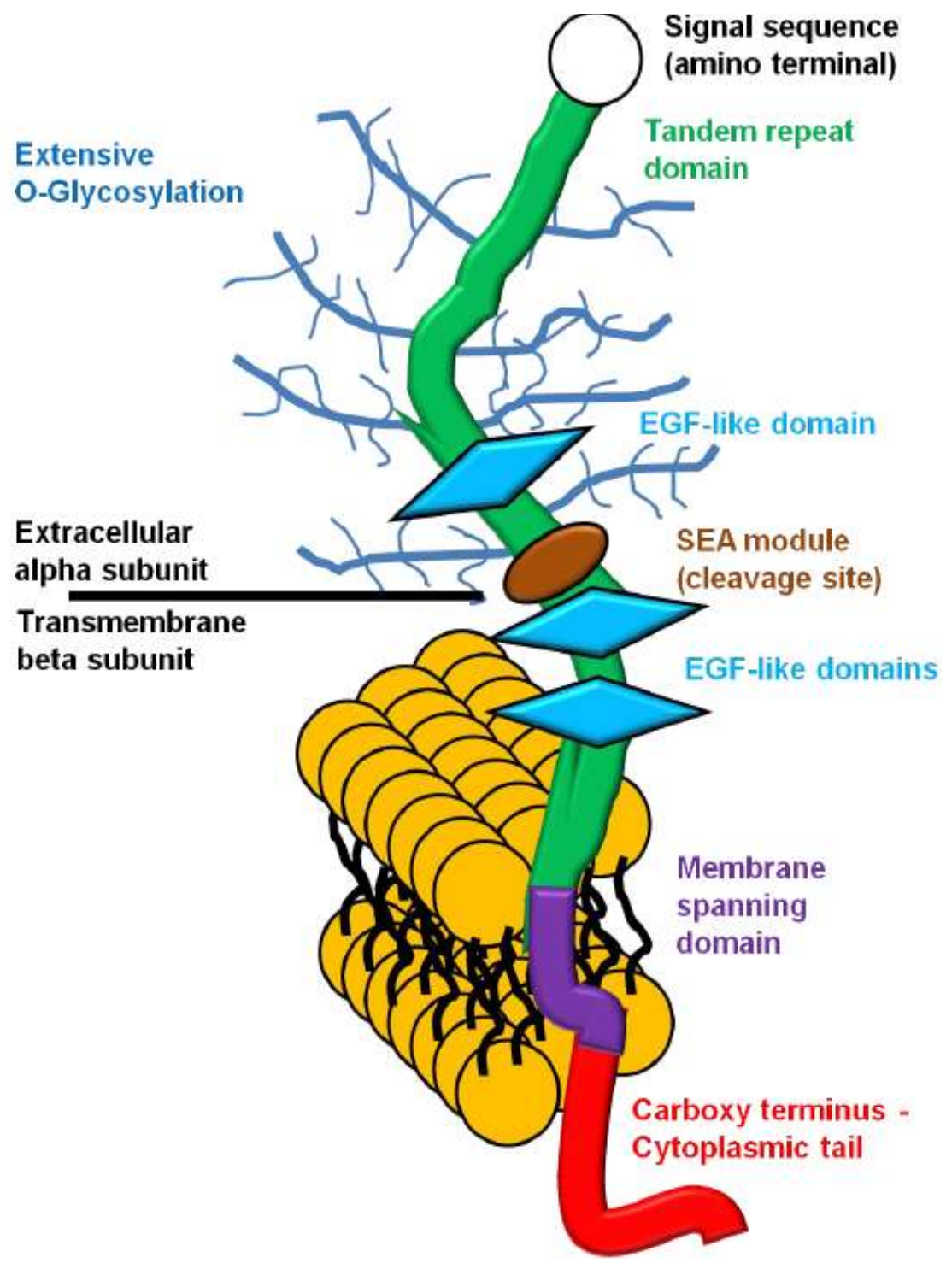

Figure 1-3. Structural overview of MUC13 protein.

\section{Data sources}

Andrianifahanana M, Moniaux N, Batra SK. Regulation of mucin expression: Mechanistic aspects and implications for cancer and inflammatory diseases. Biochim Biophys Acta - Rev Cancer. 2006;1765(2):189-222. doi:10.1016/j.bbcan.2006.01.002. Maher DM, Gupta BK, Nagata S, Jaggi M, Chauhan SC. Mucin 13: structure, function, and potential roles in cancer pathogenesis. Mol Cancer Res. 2011;9(5):531-537. doi:10.1158/1541-7786.MCR-10-0443. Rachagani S, Torres MP, Moniaux N, Batra SK. Current status of mucins in the diagnosis and therapy of cancer. Biofactors. 35(6):509-527. doi:10.1002/biof.64. 
In PDAC, the overexpression of MUC13 was shown to enhance tumorigenic features such as proliferation, motility, invasion and in vivo tumor growth. The suppression of MUC13 was found to have the opposite effects. ${ }^{20}$ Overall, MUC13 expression correlates with the expression and activation of various oncogenic proteins including HER2, PAK1, ERK, AKT and metastasin (S100A4), as well as a reduction in p53. ${ }^{34}$ These effects show that MUC13 expression is strongly correlated with disease progression in PDAC.

Various biochemical assays can be used to elucidate the specific effects of MUC13's effect on cancer cells. In a more general sense, biochemical assays are still a very common method to delineate the function of various proteins, nucleic acids, or other small molecules in cancers or other diseases. In recent years, however, there has been an increasing interest in other methods of measuring cancer cell aggressiveness through different means. One of the most interesting premises involves measuring the biophysical properties of cancer cells to determine how they respond to various stimuli, or in more clinically relevant terms, to see how biophysical data could be used in diagnostic screening or therapeutic monitoring. Over the past few decades, a new methodology has emerged that allows for biophysical characterization of live cells. This is based on the evolution of the relatively recent field of atomic force microscopy. In order to understand the effects of these modulations, it will be important to understand how these physical readings will be acquired. Although there are multiple methods to acquire biophysical data in living cells, this project will specifically focus on the use of atomic force microscopy and provide a comprehensive overview of its workings and how mechanical data is acquired.

\section{What Is Atomic Force Microscopy?}

Atomic force microscopy (AFM) is a type of scanning probe microscopy (SPM) which can obtain high-resolution topography of a sample via interactions between the sample and a sharp probe. These images are obtained using raster scanning, where the pixels of an image are acquired row by row. With AFM imaging, the attractive and repulsive forces between the probe tip and sample surface are used to generate the signal. ${ }^{35}$ The AFM was developed in 1986 by Binnig et al, building upon previous scanning tunneling microscope technology developed earlier in the decade. They showed the potential of this machine in generating images with a lateral resolution of around $30 \AA$ and vertical resolution of less than $1 \AA .{ }^{36}$

There has been a general increase in research interest involving AFMs, especially with a focus on cancer. A recent PubMed search has shown (as outlined in Figure 1-4) an increasing number of articles over the past few years using the search terms "atomic force microscopy" and "atomic force microscopy and cancer" - as of the end of 2019, there are 38950 and 1873 articles in each field, respectively. 
PubMed articles, "Atomic force microscopy"

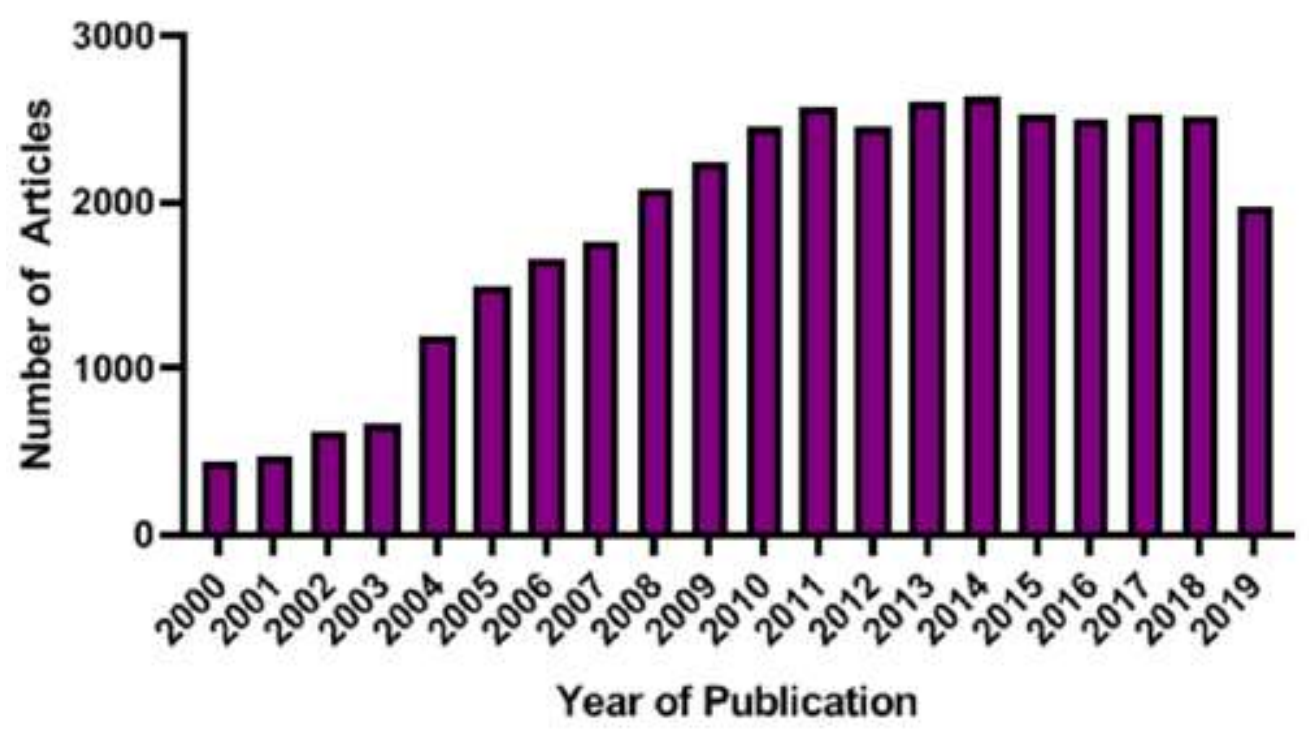

Pubmed articles, "Atomic force microscopy" and "cancer"

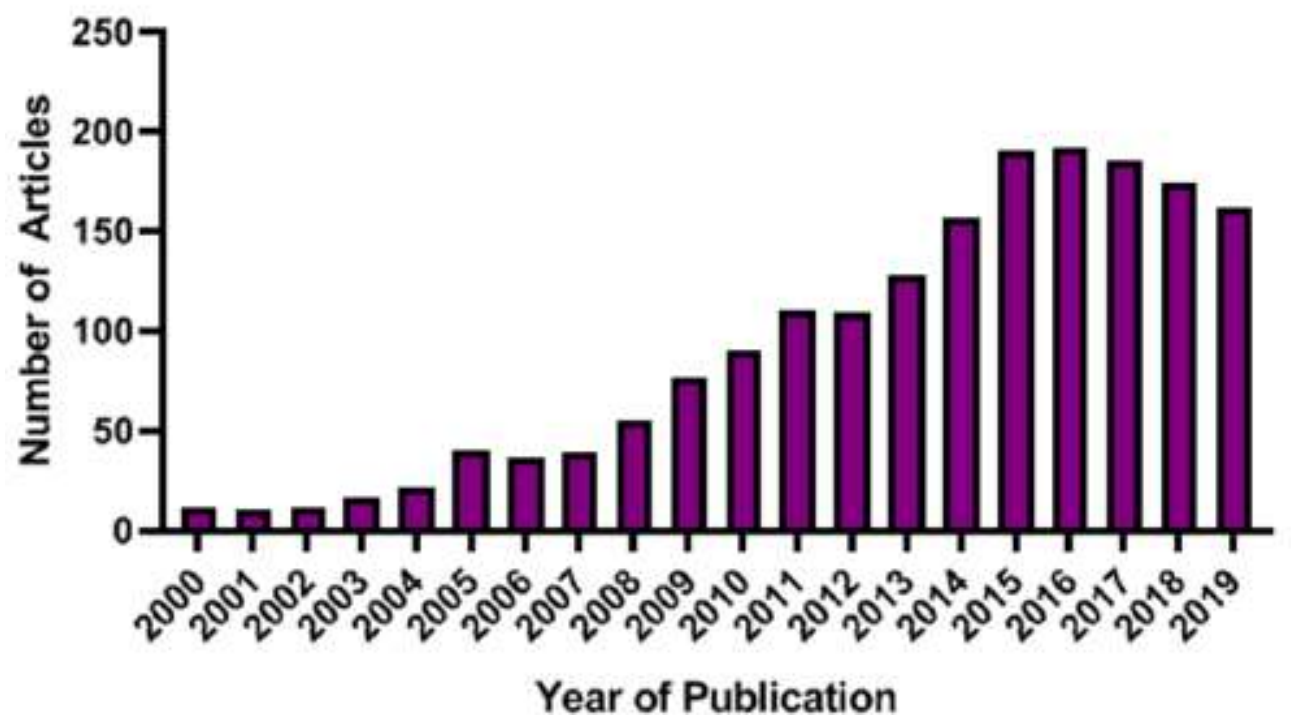

Figure 1-4. PubMed articles listing "atomic force microscopy" and "atomic force microscopy and cancer" since 2000. 
Typically, very sharp probes (with diameters under 10nm) are used for highresolution imaging on flexible metallic cantilevers. The cantilever is attached to a piezoelectric stand which moves the probe in the z-axis. A common method of detecting signal changes involves measuring changes in the reflection of a laser beam that is aimed onto the back of the cantilever and then reflected onto a photodetector. Based on deflections in the cantilever, there is a resultant change in the position of the reflected laser beam - this change is used to generate a voltage signal which can be converted into an image.${ }^{37}$ A general overview of this process is summarized in Figure 1-5.

\section{AFM Imaging Modes: Contact}

Several different modes of imaging samples using an AFM have been developed since the first experiments in the late 1980s. The first imaging method developed on an AFM was known as contact mode, whereby the probe is brought into direct contact with the surface and is held at a constant deflection. In this case, changes in the z-axis are used to generate topographical data. However, since the probe is constantly on the surface, it is important to control the applied force, as this mode can lead to damage for both the sample and the probe tip. Any damage to the probe tip can lead to imaging artifacts and potentially dull the tip, in turn reducing the maximum possible resolution. There is also a high probability for lateral artifacts which can further lead to image and sample issues. ${ }^{38,39}$

\section{Non-Contact}

Shortly after contact mode was developed, non-contact mode was introduced. Here the tip is held several nanometers above the surface of the sample as it is scanned. Attractive van der Waals forces deflect the cantilever and help to generate the image. Since these forces are weak, the probe usually must be oscillated - changes in either amplitude, phase, or frequency of the oscillation can give data on the sample itself. Recently, this mode has shown potential in revealing intra-molecular resolution, visualizing individual bonds within molecules..$^{40,41}$

\section{Tapping}

More recently, tapping mode was implemented, where the cantilever oscillated close to its resonant frequency. This frequency changes when the tip is closer to the sample surface, and changes are typically seen in the oscillation amplitude. Tapping mode greatly reduces the lateral forces applied to the sample and is therefore the preferred imaging technique for biological and other soft or delicate samples. ${ }^{42,43}$ 


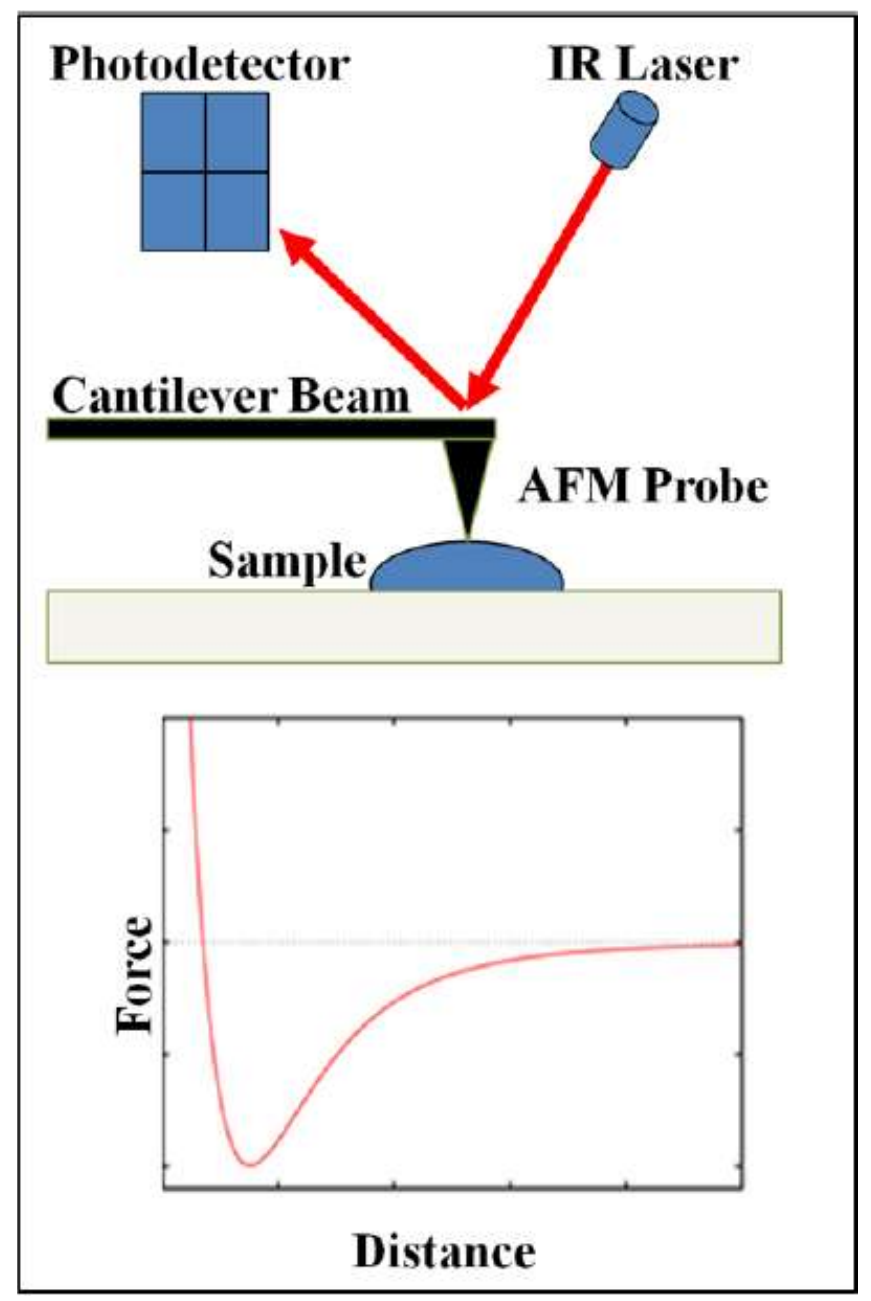

Figure 1-5. Graphical summary of key AFM components and force curve generation. 


\section{PeakForce Tapping and ScanAsyst}

Over the past few years, a unique variation of tapping mode has been developed by Bruker known as PeakForce Tapping (PFT). Unlike standard tapping mode however, PFT generates oscillations at a frequency below the resonant point of the cantilever. This helps overcome some of the dynamic issues usually seen in a resonant system. Using this technique, the AFM probe can indent a sample and acquire multiple force curves at different points, and using real time analysis, multiple types of physical data can be analyzed at the same time. In addition, unique software algorithms were implemented allowing for tight control of the applied force during the imaging process, ensuring that a constant force is always applied even at very high scan rates. ${ }^{44,45}$

Recently, Schillers et al demonstrated that AFMs can, using PFT, acquire highresolution images able to visualize microvilli on the surface of living cells, structures that are typically 1-2 microns in length and up to $100 \mathrm{~nm}$ in diameter. This was accomplished by keeping a mild interaction force with the surface of the cell of around $100 \mathrm{pN}$, a force low enough so that the individual microvilli would not be disrupted. ${ }^{46}$

ScanAsyst, an imaging mode also designed by Bruker, uses PFT in conjunction with various correction algorithms to provide high quality imaging on a sample surface by automatically adjusting various imaging parameters in real time. This allows for automation of a process also called PeakForce Quantitative Nanomechanical Mapping (PF-QNM). Using this process, an image is generated, and for every point of contact, a force curve is generated and analyzed. These imaging systems are capable of operating efficiently in fluids, making them ideal for biological samples. ${ }^{47,48}$

\section{AFMs and Force Data Collection}

The primary use of an AFM is to provide high-resolution, three-dimensional topographical mapping of a sample. Many other uses have been explored: electrical measurements $^{49,50}$, thermal analysis ${ }^{51,52}$, nanolithography ${ }^{53,54}$, nanomanipulation ${ }^{55,56}$, and probe functionalization for various interaction studies ${ }^{45,57,58}$ are just a handful of the various applications of AFM technology.

In addition to being able to collect high-resolution images, the AFM can also collect highly sensitive force measurements on a variety of samples. This is partly due to the cantilever itself, which is typically made of silicon or silicon nitride, allowing for forces in the pico-Newton range to be observed. ${ }^{59}$ Unlike imaging, where the probe is simply scanned over the surface of the sample, in force spectroscopy the probe is moved directly towards the sample until it contacts, presses down to a particular setpoint, then retracts. In this action, several types of mechanical data can be extracted from the sample: once in contact, the probe will indent the sample with a specific force. This will lead to a certain depth of indentation, which can potentially yield information on a sample's elastic modulus or viscoelasticity. ${ }^{35}$ One of the properties this study will focus on is the Young's 
modulus, representing the rigidity or stiffness of a material. This property is defined by Equation 1-1:

$$
\mathrm{E}=\frac{\sigma}{\varepsilon}
$$

Where E is the Young's modulus, $\sigma$ represents stress and $\varepsilon$ represents strain. This value refers to the force applied to an object and its resultant deformation. Put simply, for a constant force, the more a sample deforms, the lower its Young's modulus is (i.e., it is more flexible). Conversely, for the same applied force, a sample with a higher Young's modulus will have a lower deformation and is consequently more rigid.

As the probe is retracted from the surface, the sample may adhere to the probe for a time. This is especially noticeable on softer samples, such as cell membranes. It is also of importance in samples measured in ambient conditions in air, as meniscus forces will play a significant role and need to be considered. Once the retraction generates enough force to separate the sample from the probe, this adhesion force is measured. The adhesive force with the sample is calculated at the point where the probe is fully separated from the sample. ${ }^{60}$ A schematic overview of force data collection on the AFM is outlined in Figure 1-6.

\section{Force Curve Components and Analysis}

One of the most important concepts in AFM data analysis is proper force curve interpretation. Figure 1-7 depicts a representative force curve taken using our lab's recently acquired Bruker BioScope Resolve. The X-axis represents the distance from the surface, and the Y-axis represents the cantilever deflection if uncalibrated, or the force applied if properly calibrated. Here, we can see the basic actions of the probe - normally, there is a small dip in the blue line (the "approach" line) - this represents an attractive van der Waals force when the tip is within a small $(\sim 1-5 \mathrm{~nm})$ distance from the surface. At the trough of this dip is where the probe makes contact and begins to deflect upwards - with proper calibration, this deflection read as a quantifiable force value. Since the force curve shown in Figure 4 was conducted in fluid, the effects of this attractive force were reduced. This is more commonly seen when using the probe to analyze samples in air. The probe will continue pressing down until a pre-determined setpoint (either deflection distance or force applied) is reached. At this point, it is also possible to determine the amount of deflection in the sample. ${ }^{61,62}$

Using these data in conjunction with knowledge about the probe's geometry and physical parameters it is possible to determine the rigidity (Young's modulus) of a sample. Next, the probe will begin to retract from the surface. Even in air, there will be some adhesion to the surface depending on the properties of the sample itself or due to water meniscus formation. ${ }^{60}$ In either case, there will tend to be a difference in the shapes of the blue (approach) and red (retract) curves. Specifically, the red curve tends to go further down than the blue, showing that a specific force is required to detach the probe from the sample surface. 


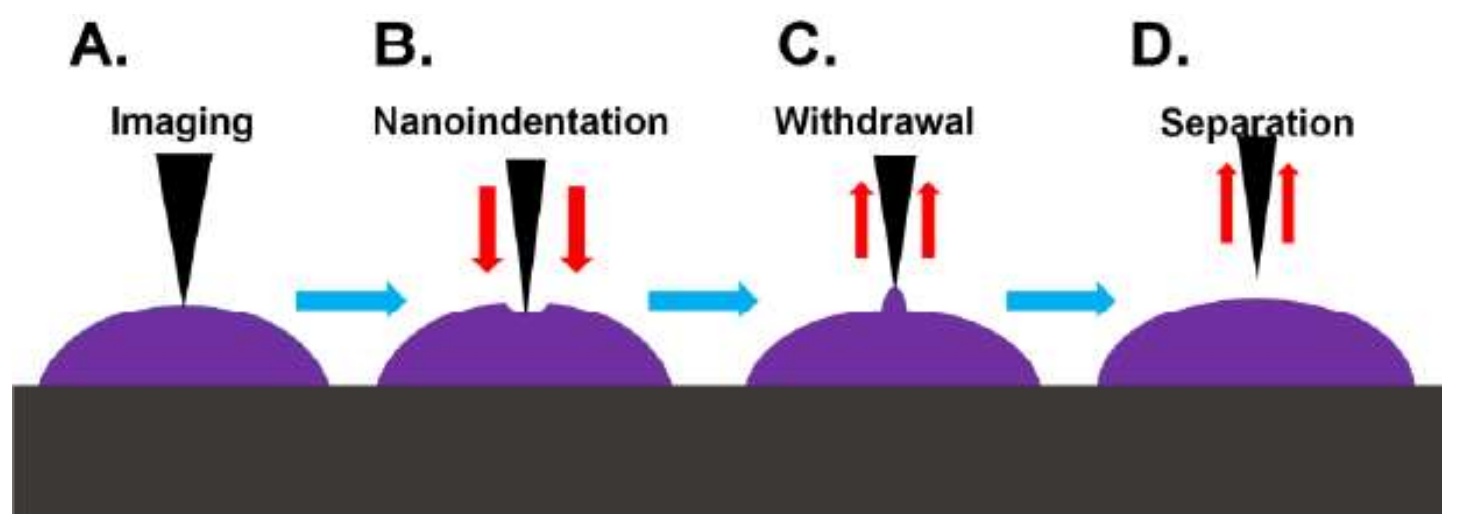

Figure 1-6. Schematic overview of AFM-based force analysis.

(A) Imaging is conducted using ScanAsyst at lower forces to prevent damage to the cell. (B) For force analysis, a higher force is used to generate considerable deformation in the cell membrane. The probe presses down into the cell until the target force is met. (C) After reaching the target force, the probe is retracted from the surface. Depending on the sample, it is possible that a portion can adhere to the tip as it retracts from the surface. (D) As the tip continues to retract from the surface, eventually the force becomes strong enough to overcome the adhesion between the sample and the probe - this point can be used to determine the adhesive force between these two objects.

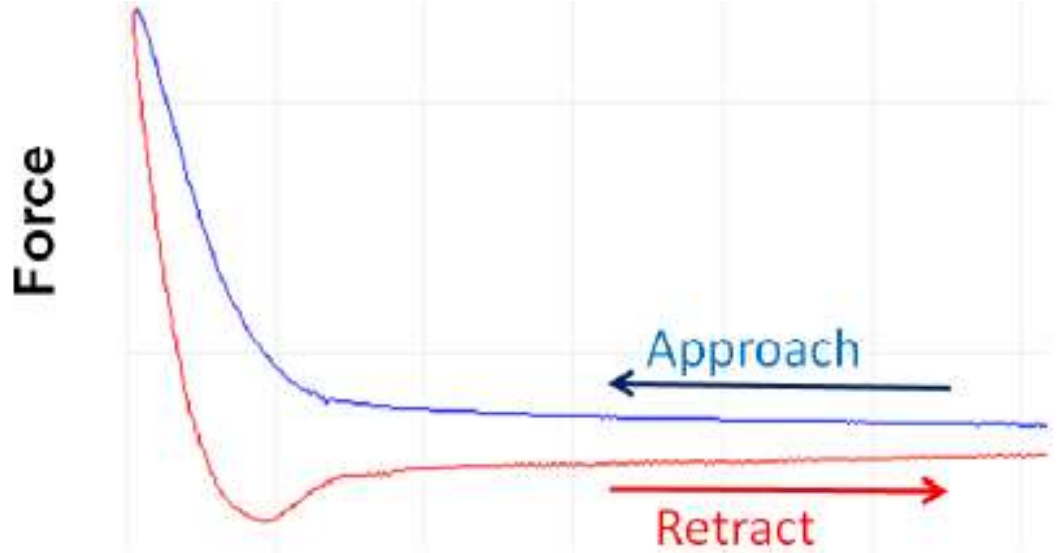

\section{Distance}

Figure 1-7. Representative force curve generated using Bruker BioScope Resolve on a clean sample in fluid.

Note the lack of attractive van der Waals interaction on the approach curve - this is partly due to the probe being immersed in a fluid environment. 


\section{Force Mapping}

In addition to the process described above for force curve generation, AFMs can be used to generate force maps over a defined area to create a pixel map of various physical parameters. For example, a cell or group of cells can be selected, and a series of indentations and retractions is conducted over the surface to create a force map. When analyzed in appropriate software, this map allows one to visualize the intensity of various properties visually - for instance, if measuring the modulus of a cell, brighter regions would indicate more rigid regions, while darker areas would indicate softer ones. These maps can then be quantified to determine the physical properties of the cell overall or at various regions (e.g., nuclear, cytoplasmic, or peripheral).

\section{Probe Calibration Methods}

To properly conduct force analyses, it is important to calibrate the probe being used. Two properties are needed to properly convert the photodetector signal into a quantifiable force value: the deflection sensitivity $(\mathrm{nm} / \mathrm{V})$ and spring constant $(\mathrm{N} / \mathrm{m})$ of the cantilever. The first value can be determined by generating a force curve on a hard, clean surface. This will show how much the tip deflects and its relation to the laser deflection (i.e., the conversion between change in volts on the photodetector to the distance in $\mathrm{nm}$ the cantilever deflects). At the contact region, this relation will be linear on a hard surface, simplifying the calculations. To calculate the spring constant, several methods exist - however for probes generally used with biological samples the thermal tune method is employed. ${ }^{35}$ The thermal tuning method is based on the equipartition theorem, in an effort to link the spring constant of the probe to its thermal motion. Put simply, this theorem states that molecules in thermal equilibrium have the same average energy over all energetically accessible degrees of freedom within a given system. During measurement, air molecules will collide with the cantilever and generate miniscule vibrations. These are measured and then converted into a frequency domain using Fourier transforms to generate a Power Spectral Density (PSD). Integrating the area under this peak indicates the power associated with the resonant peak. Unlike other methods of probe calibration, thermal tune is typically more rapid, and can provide comparable accuracy to other methods. Although other calibration methods (e.g., the added mass method) have the potential to be more accurate, they are much more time consuming and demanding processes. This method is ideal for probes with lower spring constants (typically below $1 \mathrm{~N} / \mathrm{m}) .{ }^{63,64}$

\section{Atomic Force Microscopy and Biological Samples}

Early results with scanning probe microscopes - specifically scanning tunneling microscopes - in the 1980s proved that this imaging system could be used with soft, biological samples. ${ }^{65}$ Such early experiments did run into several issues with image quality and reproducibility however. By contrast, the AFM, which does not require 
conductive materials for imaging, enabled more efficient imaging on biological samples. ${ }^{66}$ AFMs, unlike electron microscopes, can work in a fluid environment and do not require a vacuum, so they are ideally suited for working with biological samples. More specifically, it is not possible to visualize living samples using conventional electron microscopes - particularly scanning electron microscopes (SEM) - due to the high vacuum in the imaging chamber. Because of this, it is necessary to coat such samples in a thin layer of a metal such as gold to properly image biological samples ${ }^{67}$ this requires that cells are fixed with various drying reagents, which can impact their native morphology. ${ }^{68}$

If compared to conventional microscopes, there are certain advantages and disadvantages of AFM imaging. For instance - AFMs can image without the need for any pretreatments, generate high-resolution, three-dimensional data, and is capable of generating such images in physiological conditions. More importantly, because of the interaction between the cantilever and the sample, additional data can be acquired, such as force spectroscopy. ${ }^{45}$ This being said, there are some potential caveats with AFM imaging - conventional imaging is not always fast enough to capture events such as biological or chemical reactions, which can occur within a fraction of a second. Recent fast scanning techniques have been produced to address this concern, and as evident in one recent study demonstrating a technique which was able to show real-time visualizations of CRISPR-Cas9 reactions. ${ }^{69}$ Also, due to the mechanism of imaging, only surface features of a cell can be imaged or analyzed - no data on the cell's interior can be directly assessed. ${ }^{39}$

The primary concern for imaging biological materials, particularly living cells, is how soft the material is compared to conventional materials previously examined using AFMs. Initial contact mode imaging quickly proved that AFM probes can safely image cells without rupturing membranes ${ }^{70,71}$ - however, it was also determined that contact mode can still inflict damage to a cell due to friction forces, potentially deforming the membrane enough to show underlying structures If scanning parameters are not properly calibrated, these forces could even be high enough to rupture the membrane or even detach the cell from the surface of the plate. ${ }^{39}$

It was later found out that this contact mode imaging system could deform the membrane by nearly a full micrometer; if AFM probes pressed this far into a sample image resolution would be drastically affected. By contrast, tapping mode applied to cell imaging virtually removes the concerns associated with friction forces and significant membrane deformation. ${ }^{39}$ In both imaging modes, adjusting the force to the pico-Newton range can yield much smoother images, and gives more information on the structure and complexes seen on the membrane itself. ${ }^{46,72}$

\section{Cancer Cells and Mechanical Properties}

Multiple recent studies have shown that cancer cells, particularly invasive ones, have a reduced modulus compared to their normal, noncancerous counterparts. In 
addition, factors that further enhance aggressive phenotypes have been associated with a reduction in cancer cell rigidity. This is partly thought to be due to changes in the cytoskeletons of cancerous cells compared to their healthy counterparts. To date, the current literature consensus is that cancerous cells tend to be softer than their normal counterparts. ${ }^{43,73-77}$

Given the unique physical characteristics of cancer cells, it is possible to identify cancerous cells in tissue slides given their altered physical properties. In one study by Lekka et al, various cancer cell lines were analyzed with respect to normal cells (e.g., normal PZHPV-7 compared to cancerous PC-3, DU145 and LNCaP prostate cell lines). They noted that the cancerous cells had a reduced modulus compared to the normal cells. Next, patient tissue samples were taken and analyzed at different regions, comparing the modulus of normal and cancerous tissue. again, it was determined that cancerous cells had a lower overall modulus compared to normal cells, even at the tissue level. ${ }^{78}$ Further investigations into the relation between cell stiffness and invasive potential was investigated by Swaminathan et al. In this study, they determined that softer cancer cells had a greater invasive and migratory potential, and various treatments that increased stiffness led to a reduction in invasiveness. This gave credence to an inverse relationship between cell stiffness and migration and invasion. ${ }^{79}$

Over the past three decades, AFMs have emerged as a powerful tool for nanoscale characterization, especially for biological samples. With proper force control, it is now possible to acquire consistent, high-resolution data on living cells and other biological samples under a variety of conditions. These data can even be overlaid with fluorescent data to correlate biochemical, morphological, and even physical data with various alterations (whether pharmacological, genetic, etc). Furthermore, there is some thought that various phenotypes can be assessed physically, such as differentiation status or EMT. which can give an insight as to how a cell changes mechanically due to these processes. One recent example of how cells can be measured for changes in EMT status was investigated by Cascione et al. In this study, they treated hepatocellular carcinoma cells with TGF- $\beta$, a known promoter of EMT. They found that after treatment, the cells had significantly lower modulus values as compared to untreated cells. This implied, with the altered cytoskeletal structures seen with confocal imaging, that the cells had an increased invasive potential. ${ }^{80}$

\section{Pancreatic Cancer Cells and Biophysical Analysis}

Due to various changes in cellular structure, the current consensus in literature is that cancer cells tend to be softer than their normal counterparts. ${ }^{76,81,82}$ AFM force analysis has been extensively used to highlight the differences in cancer cells, as well as their biophysical reactions to various alterations such as genetic alterations or pharmacologic treatment. However, data on PDAC listed in the literature is somewhat limited, and has sometimes been counterintuitive to the consensus - one notable example of this was a recent study by Nguyen et al, where they showed that an increased stiffness was associated with enhanced metastatic potential in PDAC cells. ${ }^{83}$ Several recent studies 
have shown that the treatment of cancer cells with TGF- $\beta$ induces EMT and when analyzed by AFM, these cells are shown to be softer. ${ }^{80,84}$ However, a recent study that was conducted using PanCa associated fibroblast cells indicated an increased modulus with treatment. ${ }^{85}$ This seems to indicate that the effects of EMT induction are cell specific.

At the tissue level, additional studies have been conducted and have shown unique effects in PanCa. In a recent study by Rice et al, cancerous tissue was shown to be significantly more rigid than healthy tissue (PanIN more so than healthy, and PDAC more so than PanIN). This was an assessment of the tissue as a whole - when investigating individual cells, they simulated this increased rigidity by growing cells on surfaces with increasing rigidity - on more rigid surfaces, PanCa cells were shown to have increased EMT markers and drug resistance. ${ }^{86}$ Another recent study has shown a similar effect at the tissue level - cancerous tissue was again found to be significantly more rigid than non-cancerous. ${ }^{87}$ One possible explanation for this was demonstrated in research by Robinson et al using a three-dimensional ECM model - they showed that with an increasing number of cells implanted in the model, the overall rigidity of the structure increased, which is thought to be partly due to matrix remodeling or thickening of collagen fibers within the tissue. ${ }^{88}$ Interestingly, a recent study by Zhao et al further strengthened this notion by showing that PDAC tissues taken from experiments in KPC mice were significantly softer after PTX treatment. ${ }^{89}$ This is of note as these studies seem to contradict the results discussed previously where cancerous tissues in other disease states were softer than their normal counterparts, although this could simply indicate a tissue-specific response.

Furthermore, recent studies have shown that an upregulation of EMT markers (such as vimentin) are associated with a softer cell, while increased levels of E-cadherin, indicating a less metastatic phenotype, are associated with an increased rigidity. ${ }^{79}$ This seems to indicate that the EMT process affects cancer cells in a biophysical manner.

PDAC cells have been analyzed for adhesive properties using AFM studies as well. One notable example of this was indicated in work published by Cao et al detailing the interactions between cancer cells and human endothelial cells. When $\alpha 5$ integrin, an adhesion marker associated with endothelial cells, was blocked, it led to a decrease in the adhesive interactions between cancer cells and HUVEC cells. The authors stipulated that the interaction between $\alpha 5$ integrin and neuropilin- 2 on the surface of cancer cells was responsible for the initial stages of extravasation and metastasis. ${ }^{90}$

As mentioned previously, there is a somewhat limited amount of data regarding the biophysical responses in PDAC cells in comparison to other cancers. In addition, there is significantly less data showing how these cells respond to either chemotherapeutic treatment or genetic alterations. More specifically, it is unclear how MUC13 can affect PDAC cells physically.

In this manuscript, I sought to quantify the biophysical properties of a panel of pancreatic cells and their responses to chemotherapeutic treatment and MUC13 
modulation. To this end, we have generated a protocol designed to measure the biophysical properties of living cells in vitro. This procedure was then used to assess a comprehensive panel of pancreatic cells, both normal and cancerous to create a baseline across various differentiation stages. These cancerous cells were then subjected to various chemotherapeutic treatments to determine if differences in their biophysical responses could be determined. Lastly, a set of MUC13 modulated cells was used to determine if altered expression of this protein could lead to changes in the biophysical properties of these pancreatic cancer cells. Overall, we hypothesize that the use of biophysical properties will allow for a quantitative method of determining whether various alterations (pharmacologic or genetic) can be used to assess either therapeutic efficacy or enhanced oncogenic potential.

To address this hypothesis, we first had to generate a biophysical analysis protocol that could be used to collect the data in this report. This protocol was then used to delineate the biophysical properties of normal and cancerous pancreatic cells and see if any trends could be formed. 


\section{CHAPTER 2. DISCRIMINATION OF NORMAL AND CANCEROUS PANCREATIC CELL LINE BIOPHYSICAL PROPERTIES AND THEIR ASSOCIATION WITH DIFFERENTIATION STATUS}

\section{Introduction}

Although PDAC is not the most common type of cancer, with nearly 57,000 cases anticipated diagnoses for 2019, it is one of the deadliest types of cancer. Of the newly diagnosed cases, nearly 46,000 deaths are estimated for the year. PDAC also accounts for one of the lowest survival rates among cancers, with an estimated $9 \% 5$-year survival rate. ${ }^{7}$ Even with recent advances in diagnostic and therapeutic options, the rates of this cancer incidence and mortality have not changed significantly in the past several decades.

PDAC is commonly diagnosed at a later, more advanced stage as mentioned previously. Diagnosis is typically confirmed with a biopsy, whereby a small section of the pancreas (either normal or cancerous) is extracted for microscopic examination. Pathologists can then stain the tissues and examine them to better understand the disease state. One factor that is typically examined at this point is differentiation status.

\section{Differentiation Status}

In biology, differentiation refers to the ability of cells to gain specialized functions through various phenotypic changes. It is related to the morphological or functional resemblance between cancer cells and normal cells from the same tissue of origin. Differentiation is closely related to tumor grading in PDAC; specifically, the more well differentiated a tumor is, the lower its grade, meaning it tends to be less metastatic and more slow growing. In addition, more well differentiated tumors more closely resemble native, noncancerous tissue of the same organ. This indicates an inverse correlation between differentiation and proliferative capacity in malignant cells. ${ }^{91}$ Higher grade tumors are usually more poorly differentiated, meaning they do not resemble their normal tissue counterparts. In addition, they usually grow more quickly and indicate a poorer prognosis, as this type of tumor is more likely to metastasize. ${ }^{92}$

Differentiation is normally considered a one direction process, however in cancer it is known that cells can dedifferentiate. This process is commonly used in pathology and histology as a prognostic marker to indicate tumor aggressiveness. There is some question as to how strongly tumor cell differentiation overlaps with epithelial to mesenchymal transition (EMT), a process whereby tumor cells transform from an epithelial shape to a more firoblastoid-shaped cell with increased motility and invasiveness. Conceptually speaking, the pathological term of differentiation seems to be strongly related to EMT progression, even if biological examples are difficult to prove. Multiple studies have shown the impact of EMT in various cancers ${ }^{93,94}$, with multiple studies also emphasizing its importance in PDAC. ${ }^{95-99}$ Perhaps most interesting is a recent study by Aiello et al, that suggests a direct correlation between EMT and 
differentiation status, implying that more poorly differentiated PDAC tumors undergo a more thorough EMT process as compared to more well-differentiated ones. ${ }^{96}$

From a pathological standpoint, differentiation status refers to the morphological state of the cancer cells. It is determined using tissue gathered from a biopsy and analyzed by pathologists to discriminate cancerous tissue from surrounding normal tissue. Generally speaking, the more well-differentiated a tumor cell is, the more strongly it resembles its tissue of origin and is typically well organized. More poorly differentiated tumors lose their epithelial properties and may take on mesenchymal characteristics, indicative of EMT. This suggests that more poorly differentiated cancer is associated with a more aggressive phenotype. More poorly differentiated tumors are associated with a poorer prognosis. ${ }^{92}$ As suggested by previous research, differentiation status is closely related to the extent of epithelial to mesenchymal transition (EMT) a cell has undergone. ${ }^{96}$

\section{Epithelial to Mesenchymal Transition}

Epithelial to mesenchymal transition (EMT) is a process through which epithelial cells lose their adhesive properties and take on a fibroblast-like, mesenchymal morphology with increased motility. Although it is a normal process associated with embryogenesis, tissue development, wound healing and stem cell behavior, it is also strongly implicated in fibrosis and cancer metastasis. Specifically, it is thought to play a role via altered gene expression; genes involved in the epithelial state (e.g., E-cadherin) are repressed by of EMT-associated transcription factors, including SNAIL, TWIST, and ZEB. Multiple studies have shown that there is a direct correlation between E-cadherin, EMT markers, and tumor grade in PDAC; specifically, the lower E-cadherin is, the higher the EMT markers and tumor grade, indicating a poorer the prognosis. ${ }^{96,98}$

When the EMT process is initiated, specialized cell-cell adherens junctions are broken down. During this process, epithelial cadherin (E-cadherin) is cleaved and degraded. This degradation, which can be caused by TGF $\beta$, means that $\beta$-catenin is freed from its association with the cadherins and can then move into the nucleus to act as a transcription factor. These catenin molecules are typically stabilized by processes such as WNT signaling, which inhibits glycogen synthase kinase- $3 \beta$ to prevent $\beta$-catenin degradation. ${ }^{96,100}$

EMT is of interest from a clinical standpoint as it can indicate the level of metastatic potential that a cancer has. In fact, there is a high degree of correlation between the pathologic categorization of differentiation and the degree of EMT activation - in tumors with a more thorough activation of the pathway, cells are typically seen to be in a more poorly differentiated state, indicating a poorer prognosis. By contrast, more well-differentiated cells tend to have a reduced level of expressed EMT factors. ${ }^{96}$

Given the disparate characteristics of differentiation status and EMT on different stages of cancer, we ran biophysical analyses on a panel of pancreatic cell lines ranging 
from normal epithelial cells, primary tumor, and metastatic lesion derived cell lines. The cancer cells used in this study were derived from tumors with known differentiation status. We hypothesized that the more poorly differentiated cells, which are known to be more aggressive, should have the lowest overall rigidity and membrane adhesion. We further hypothesized that cells with the lowest measured membrane adhesion would have a lowered ability to aggregate in vitro.

\section{Overview of Cell Lines}

An immortalized human pancreatic epithelial cell line (HPNE) was used as a reference for normal pancreatic tissue. This cell line, acquired from ATCC, had been immortalized using a retroviral transduction (pBABEpuro) containing the human telomerase (hTERT) gene. These cells were made positive for telomerase and failed to senesce. ${ }^{101}$

HPAF-II is a well-differentiated cell line obtained from ascites of a 44-year old male patient with pancreatic adenocarcinoma with metastases to the liver, diaphragm and lymph nodes. These cells were shown to have a very high expression of VEGF. ${ }^{102}$ As shown by results from our lab, these cells express a very high level of MUC13. ${ }^{20}$

BxPC-3 is a moderately differentiated cell line derived from a 61-year old female adenocarcinoma from the body of the pancreas. This cell line was acquired from the primary tumor, and no signs of metastasis were seen upon time of collection. (These cells lack a kRAS mutation, common to most pancreatic cancers - and thus it may not be representative of most PDAC). These cells also have some of the highest expression of COX-2 of a large panel of PDAC cells as shown by Deer et al. ${ }^{102}$ Results from our lab indicate a minimal presence of MUC13 in this cell line. ${ }^{31}$

MIA PaCa-2 was collected from the primary tumor of a 65 -year old male patient with pancreatic adenocarcinoma, and was found to be poorly differentiated. ${ }^{102}$ Results published from our lab also indicate that this cell line is MUC13-null. ${ }^{20}$

AsPC-1 is a poorly differentiated cell line derived from a 62-year old woman with pancreatic adenocarcinoma of the head and metastases to several organs. These cells were acquired from an ascitic culture and were found to produce considerable mucin and carcinoembryonic antigen. ${ }^{102,103}$ The mucin levels were confirmed in our lab, showing moderate levels, although not quite as high as seen with HPAF-II. ${ }^{31}$

Panc-1 is a poorly differentiated cell line acquired from a 56-year old male with adenocarcinoma of the head that invaded the duodenal wall. ${ }^{102}$ Like MIA PaCa-2, Panc-1 was found in previous work from our lab to have little to no MUC13 expression. ${ }^{20}$ Table 2-1 gives a summary of the characteristics of these pancreatic cancer cells. 
Table 2-1. Characteristics of pancreatic cancer cells used in this study.

\begin{tabular}{llll}
\hline Cell line & Differentiation status & Cell type & MUC13 expression \\
\hline HPAF-II & Well & Metastatic (ascites) & High \\
BxPC-3 & Well-moderate & Primary tumor & Minimal \\
MIA PaCa-2 & Poor & Primary tumor & None \\
AsPC-1 & Poor & Metastatic (ascites) & Moderate \\
Panc-1 & Poor & Primary tumor & Low-none \\
\hline
\end{tabular}

\section{Data sources}

Chauhan SC, Ebeling MC, Maher DM, et al. MUC13 mucin augments pancreatic tumorigenesis. Mol Cancer Ther. 2012;11(1):24-33. doi:10.1158/1535-7163.MCT-11$\underline{0598 .}$.

Chen WH, Horoszewicz JS, Leong SS, et al. Human pancreatic adenocarcinoma: in vitro and in vivo morphology of a new tumor line established from ascites. In Vitro. 1982;18(1):24-34. doi:10.1007/BF02796382.

Deer EL, González-Hernández J, Coursen JD, et al. Phenotype and genotype of pancreatic cancer cell lines. Pancreas. 2010;39(4):425-435.

doi:10.1097/MPA.0b013e3181c15963.

Khan S, Zafar N, Khan SS, et al. Clinical significance of MUC13 in pancreatic ductal adenocarcinoma. Hpb. 2018;20(6):563-572. doi:10.1016/j.hpb.2017.12.003. 


\section{Methods}

\section{Cell Culture}

Cell lines (HPNE, HPAF-II, BxPC-3, MIA PaCa-2, AsPC-1, Panc-1) were purchased from the American Type Culture Collection (ATCC, Manassas, VA, USA) and were maintained at $37^{\circ} \mathrm{C} / 5 \% \mathrm{CO}_{2}$ in growth medium with $10 \% \mathrm{FBS}$ (DMEM, Cat. No. 11965092; RPMI-1640, Cat. No. 11875-093; DMEM/Ham's F12, Cat. No. 11320033, Gibco). HPNE, MIA PaCa-2, and Panc-1 cells were grown in DMEM media; BxPC-3 and AsPC-1 cells were grown in RPMI; HPAFII cells were grown in DMEM/F-12 media. Cells were grown in T-75 flasks until at least $70 \%$ confluent. Next, media was aspirated under a flow hood and trypsinized at $37^{\circ} \mathrm{C}$ until cells were detached. The cells were then centrifuged at $1000 \mathrm{rpm}$ for $5 \mathrm{~min}$, counted, and seeded as needed for the various experiments discussed below. ${ }^{1}$

\section{Live Cell AFM Data Analysis}

Cells (HPNE, HPAF-II, BxPC-3, MIA PaCa-2, AsPC-1, and Panc-1) were seeded in $60 \mathrm{~mm}$ dishes $\left(2 * 10^{6}\right.$ cells per dish, $5 \mathrm{~mL}$ media per dish) and attached overnight. Cells were grown in a $37^{\circ} \mathrm{C}$ incubator as mentioned previously until they reached $75 \%$ confluency. Before imaging, the cells were gently washed with PBS three times and fresh media was added. The dish was then promptly taken to the AFM (BioScope Resolve, Bruker) and placed on a heated stage (set to $37^{\circ} \mathrm{C}$ ) and equilibrated for 15 minutes. Using custom-generated probes with an estimated tip diameter of approximately $130 \mathrm{~nm}^{46}$, designed specifically for live cell applications (PFQNM-LC probes, Bruker), the deflection sensitivity was calculated via thermal tune in fluid. This calibration only required one step as each probe had a pre-calibrated spring constant, simplifying the calibration process. For nanoindentation, a force curve was first generated on the center of a cell to confirm contact and to select proper settings for the scan. A force volume scan was then conducted using the ScanAsyst imaging mode using the following settings: $128 * 128$ resolution, 512 samples per ramp, $15 \mathrm{~Hz}$ ramp rate, $400 \mathrm{pN}$ force trigger and $4 \mu \mathrm{m}$ ramp size. This was done to generate a force map over a small group of cells. After collecting multiple sets of data, the nanomechanical properties (elastic modulus, or stiffness, and adhesion) were analyzed. Methods of analysis are described in detail in the "Explanation of Settings for Force Map Analysis" section of this chapter. All force data analysis was conducted using NanoScope Analysis software (Bruker). ${ }^{104}$

\footnotetext{
${ }^{1}$ Reprinted from final submission with permission from Elsevier. Massey AE, Doxtater KA, Yallapu MM, Chauhan SC. Biophysical changes caused by altered MUC13 expression in pancreatic cancer cells. Micron. 2020;130(December 2019):102822. doi:10.1016/j.micron.2019.102822. [104].
} 


\section{Explanation of Settings for Force Map Analysis}

\section{Resolution}

This resolution (128x128) was chosen to break down the resultant images of cells into a force map of 16,384 individual force curves. These curves were converted into a heat map, and the intensity of color corresponds with the intensity of the physical parameter being measured (i.e., for modulus maps, brighter points indicate areas with greater rigidity). Representative images of HPNE cells for reference can be seen in Figure 2-1. These images were then analyzed using NanoScope Analysis software. In the modulus and adhesion maps, brighter regions correspond to higher values (e.g., more rigid or adhesive) while darker regions indicate reduced values.

\section{Samples per ramp}

This value indicates the resolution of the individual force curve (i.e., the number of data points used to make each curve) - for these experiments the default value of 512 was kept.

\section{Ramp rate}

Although these experiments could have been conducted at slower speeds, it was decided to use a higher ramp rate to expedite the experiments. If conducted at $1 \mathrm{~Hz}$ (i.e., one ramp per second), each scan would have taken approximately five hours to complete, given the resolution used in this study. At $15 \mathrm{~Hz}$, they only take approximately 20 minutes. This decision was made in order to conduct multiple scans on a single plate. Moreover, it was necessary to increase the scanning rate to capture as much data as possible within a three-hour time window to ensure the cells were not aberrantly affected by a change in the atmosphere. Although it was potentially possible to scan at even higher rates, preliminary investigations indicated that this increased the hydrodynamic forces applied to the cells, and significantly reduced the resolution of force imaging. This was in conjunction with finding out the importance of making sure the vacuum seal was proper on the plates placed on the AFM stage; if air gaps were present underneath the cell dish, it could lead to feedback oscillations in the probe during scanning, creating artifacts that impacted image quality. Furthermore, higher ramp rates were associated with a higher risk of damaging or detaching cells from the surface of the plate. Therefore, $15 \mathrm{~Hz}$ was chosen to minimize scanning time while also preventing unnecessary damage to the cell from these additional forces. A slower speed would have further reduced this risk, but once again a balance was sought between hydrodynamic forces and experimental throughput.

\section{Force trigger threshold}

Cell membranes can be effectively imaged at forces as low as $50-100 \mathrm{pN}$; lower forces can be used to visualize individual components on the surface of a cell membrane. ${ }^{39}$ For force mapping, forces are typically used around the nano-newton 

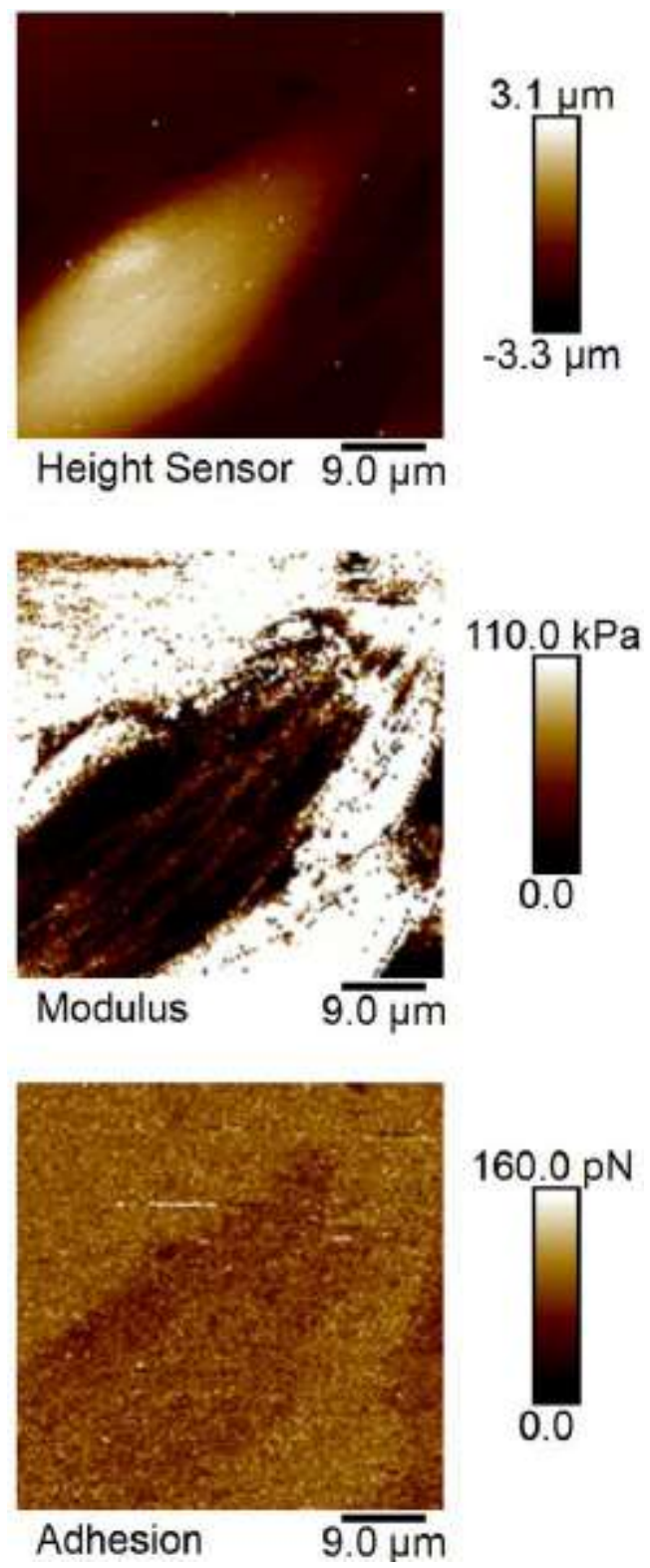

Figure 2-1. Representative AFM images of normal HPNE cells.

These images depict normal cell morphology (top), modulus mapping (middle) and adhesion mapping (bottom). Note the underlying cytoskeletal structure made visible in the modulus mapping image. 
range ${ }^{105}$ however going much higher risks damaging the cell membrane. It was decided to prevent damage to the cell surface to use a lower setpoint which still gave adequate contact and membrane deformation, which was determined through initial calibrations to be $400 \mathrm{pN}$. Using this value yields a factor of safety of at least 2.5 , assuming that membrane ruptures can occur at forces as low as $1 \mathrm{nN}$.

\section{Ramp size}

This value defines the vertical height that the cantilever moves over the entire ramping process (from approach to full retraction). This value needs to be high enough to ensure total separation from the surface of the cell membrane, while at the same time ensuring that the piezomotor is not taken out of range of the machine's detection area. Since the Bruker BioScope Resolve has a maximum Z-range of $21.3 \mu \mathrm{m}$, it was necessary to find a middle ground between these two extremes. PDAC cells can vary in height some cells were measured to be nearly 20 microns in height (this was especially the case with HPAF-II cells). To ensure that all points were properly analyzed while keeping the ramp within range of the piezomotor vertical limits, a ramp size of $4 \mu \mathrm{m}$ was chosen.

\section{Probe used}

For these experiments, a novel, specialized probe was chosen from Bruker - the PFQNM-LC probe. These pre-calibrated probes are specifically designed to work with live cells, and with proper calibration can produce high-resolution images of structures on the surface of a cell. In addition, due to their larger tip diameter (approximately 130nm), there is a reduced concern with potential damage to the cell membrane, as the forces applied will be spread out over a larger area as compared to conventional AFM probes. ${ }^{46}$ Based on this applied force and the average spring constant of around $80 \mathrm{pN} / \mathrm{nm}$, an estimated $5 \mathrm{~nm}$ cantilever deformation is expected with each ramp.

As mentioned previously, PFQNM-LC probes are pre-calibrated. Specifically, their spring constants have already been quantified before being shipped. This simplifies the traditional calibration process to a single step: using these probes, one only needs to place the probe on the AFM, then immerse in fluid, enter the spring constant, and calibrate the deflection sensitivity. The probe is then ready for use.

Although other probes were considered for these studies, it was quickly determined that they did not have appropriate characteristics for whole-cell force analysis. Initial tests were conducted using PEAKFORCE HIRS FA probes, which are typically used for very high-resolution (i.e., molecular) imaging in fluid. However, it was quickly determined that these tips are too sharp (approximate tip radius of 1-2nm) for cell imaging, as they gave images of variable and inconsistent quality. They were switched for MLCT-BIO probes, which are designed for use with biological samples. Although MLCT probes are more well-suited to biological samples than the PEAKFORCE HIRS probes, with a larger tip radius of approximately $20 \mathrm{~nm}$, the tip height was only around 34 microns. This became an issue with whole cell scans, as due to the height of some of the cells scanned, the cantilever itself could come into contact with the cell, leading to an 
increased risk of artifacts in the data acquisition or even potentially detaching cells from the surface of the plate. By contrast, the PFQNM-LC probes have a tip height of almost 17 microns, significantly reducing this concern for whole cell analysis on all but the largest cell lines.

\section{Analysis Method}

In this study, two methods of analysis were used: a whole cell analysis (consisting of an area equal to at least $75 \%$ of the surface area of a cell), and component-based analyses (at the nuclear, cytoplasmic, and peripheral regions). These two methods are highlighted in Figure 2-2. This second method was accomplished by taking equally sized readings ( 25 square microns) randomly at each of the three areas. The nuclear region was defined visually on each cell as the highest point of the cell - this typically correlated with the softest area as well, as the nucleus tends to be the softest region of a cell overall. ${ }^{106,107}$ Approximately midway between the nuclear region and the edge of the cell a random area was selected for the cytoplasmic region, then a random area was selected for the peripheral region of the cell. Data was analyzed using NanoScope Analysis software (Bruker). Multiple biological replicates were conducted to enhance the reproducibility of these results.

\section{Aggregation Assay}

Aggregation assays were performed using a slightly modified variant of a previously described protocol. ${ }^{18}$ In brief, cells were trypsinized using $0.01 \%$ trypsinEDTA (Gibco), centrifuged and counted. They were then resuspended in enough media to give a concentration of 1,000 cells per microliter. Then, $20 \mu \mathrm{L}$ (20,000 cells) of cellcontaining media was pipetted onto the inside surface of a $35 \mathrm{~mm}$ dish lid, and this was suspended over the dish, with $3 \mathrm{~mL}$ of PBS added to prevent evaporation. The dish was placed back into a humidified $37^{\circ} \mathrm{C}$ incubator and kept overnight. The next day, the cells were gently pipetted to break up any loose clumps, and the cells were promptly examined under a microscope at $20 \mathrm{X}$ magnification. A schematic of this experiment is shown in Figure 2-3.

\section{Statistical Analysis}

Analyses were conducted using unpaired, two-tailed Student's T-tests to assess the difference between relevant groups in the various experiments. All error bars used in the attached figures indicate the standard error of mean (SEM). The number of stars used on each graph relates to the level of significance. Items with four stars $(* * * *)$ indicate Pvalues below 0.0001 . 


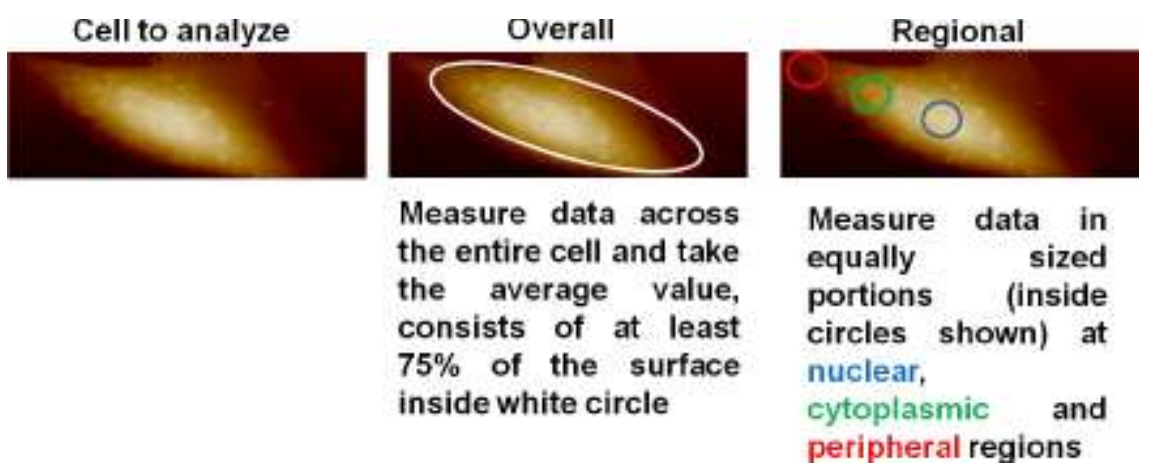

Figure 2-2. Schematic overview of different analysis methods used in this study.

Cells were scanned and analyzed for overall data (taking an average value of at least $75 \%$ of the surface of the cell) or in a compartmentalized manner (measuring data in equally sized, randomly selected portions of the nuclear, cytoplasmic, and peripheral regions).

Reprinted from final submission with permission from Elsevier. Massey AE, Doxtater KA, Yallapu MM, Chauhan SC. Biophysical changes caused by altered MUC13 expression in pancreatic cancer cells. Micron. 2020;130(December 2019):102822. doi:10.1016/j.micron.2019.102822. [104].

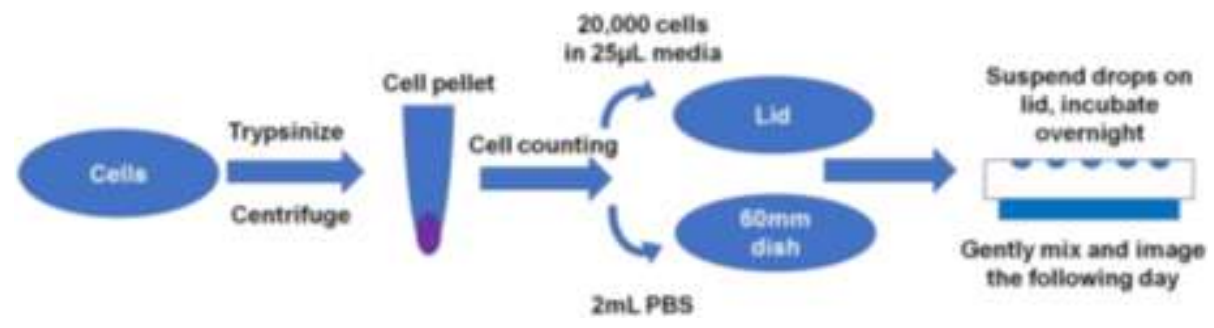

Figure 2-3. Schematic overview of aggregation assay. 


\section{Results}

We first investigated the baseline characteristics on a panel of normal and cancerous pancreatic cells. Figure 2-4 outlines the results of analyzing this panel of cells. All cancerous cells were considerably softer than the reference normal cell line (HPNE). In addition, there is a noticeable trend in the cell lines with reduced differentiation status - a further reduction is seen in MIA PaCa-2, AsPC1 and Panc-1 as compared to HPAF- II and BxPC-3, which are poorly differentiated and more well differentiated respectively. ${ }^{102}$ Some minor differences were also seen in the membrane adhesiveness between these cells, but in comparison to the large changes in membrane rigidity these were relatively minor. Representative force maps for these cells (shown in Figure 2-4 C) clearly show the difference in cellular rigidity and adhesion between these cell lines. ${ }^{2}$

The only set of cells with no significant differences in modulus is HPAF-II and BxPC-3. Overall, these well-differentiated cells are significantly more rigid than the poorly differentiated cells (MIA PaCa-2, AsPC-1, and Panc-1). In addition, both MIA PaCa-2 (primary tumor) and AsPC-1 (metastatic cells) were found to be significantly more rigid than Panc-1 (primary tumor). Overall adhesion data also shows a significant reduction for most pancreatic cancer cells (except for HPAF-II) in comparison to HPNE. There is some significance between the more well differentiated cells and the poorly differentiated cells, however this is a much lower level of significance than what is seen with the modulus data. Also, not all cells are significantly lower.

Figure 2-5 shows the regional data of these cells. The results for the modulus data are very similar across all regions of the cell and are nearly identical in their trends to what was shown in the overall analysis. Perhaps the most notable changes are seen in the adhesion data. Although the values are not significant, trends can still be observed. Of note, BxPC-3 has a noticeably lower adhesion as compared to HPAF-II, and AsPC-1 has a consistently lower value than all other cell lines. If looked overall, however, MIA $\mathrm{PaCa}-2$ seems to have a slightly lower membrane adhesiveness than AsPC-1, although this was not a significant difference. This variation between AsPC-1 and MIA PaCa-2 adhesion may be partly due to the influences of randomly selected regional data as compared to the averaging effect seen with overall analyses. The adhesion data on the AFM also appears to correspond well with the aggregation data shown (Figure 2-6). Specifically, HPNE cells were observed to form small spheroids after only an overnight incubation. HPAF-II and BxPC-3 both seem to form thin sheets of adherent cells. For the poorly differentiated cells, MIA PaCa- 2 shows large clumps of cells, then Panc-1 and AsPc-1 show clumps that are somewhat smaller. This overall indicates a similarity in the AFM's ability to measure cell membrane adhesion and a cell's ability to aggregate in suspension. The more poorly differentiated cells have the lowest values and are also the

\footnotetext{
${ }^{2}$ Reprinted from final submission with permission from Elsevier. Massey AE, Doxtater KA, Yallapu MM, Chauhan SC. Biophysical changes caused by altered MUC13 expression in pancreatic cancer cells. Micron. 2020;130(December 2019):102822. doi:10.1016/j.micron.2019.102822. [104].
} 

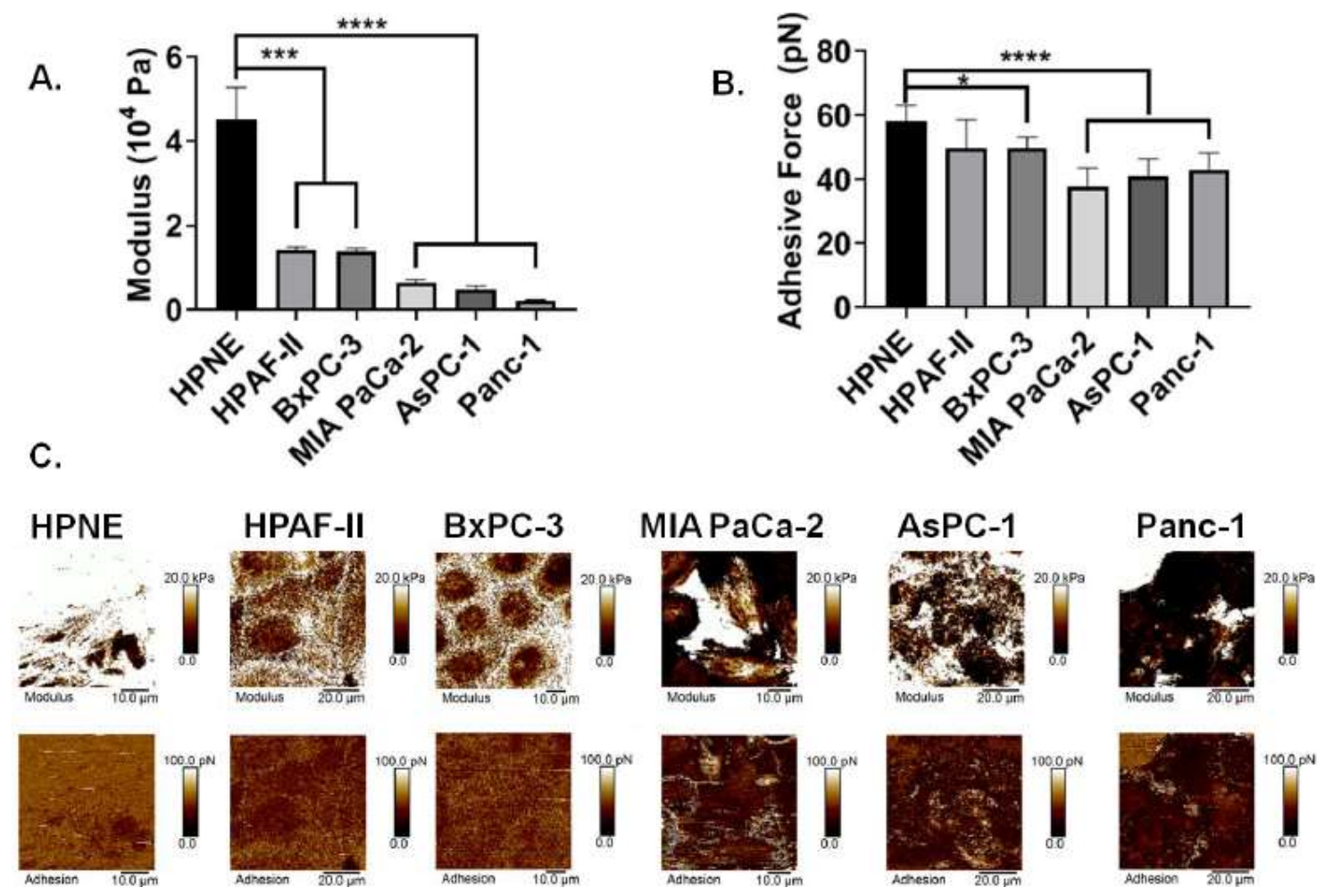

Figure 2-4. Characterization of normal and cancerous pancreatic cells.

(A) Modulus data for a panel of normal and cancerous pancreatic cells. (B) Adhesion data for the pancreatic cell panel. (C) Representative force images showing relative changes in physical parameters between cell lines.

Reprinted from final submission with permission from Elsevier. Massey AE, Doxtater KA, Yallapu MM, Chauhan SC. Biophysical changes caused by altered MUC13 expression in pancreatic cancer cells. Micron. 2020;130(December 2019):102822. doi:10.1016/j.micron.2019.102822. [104]. 

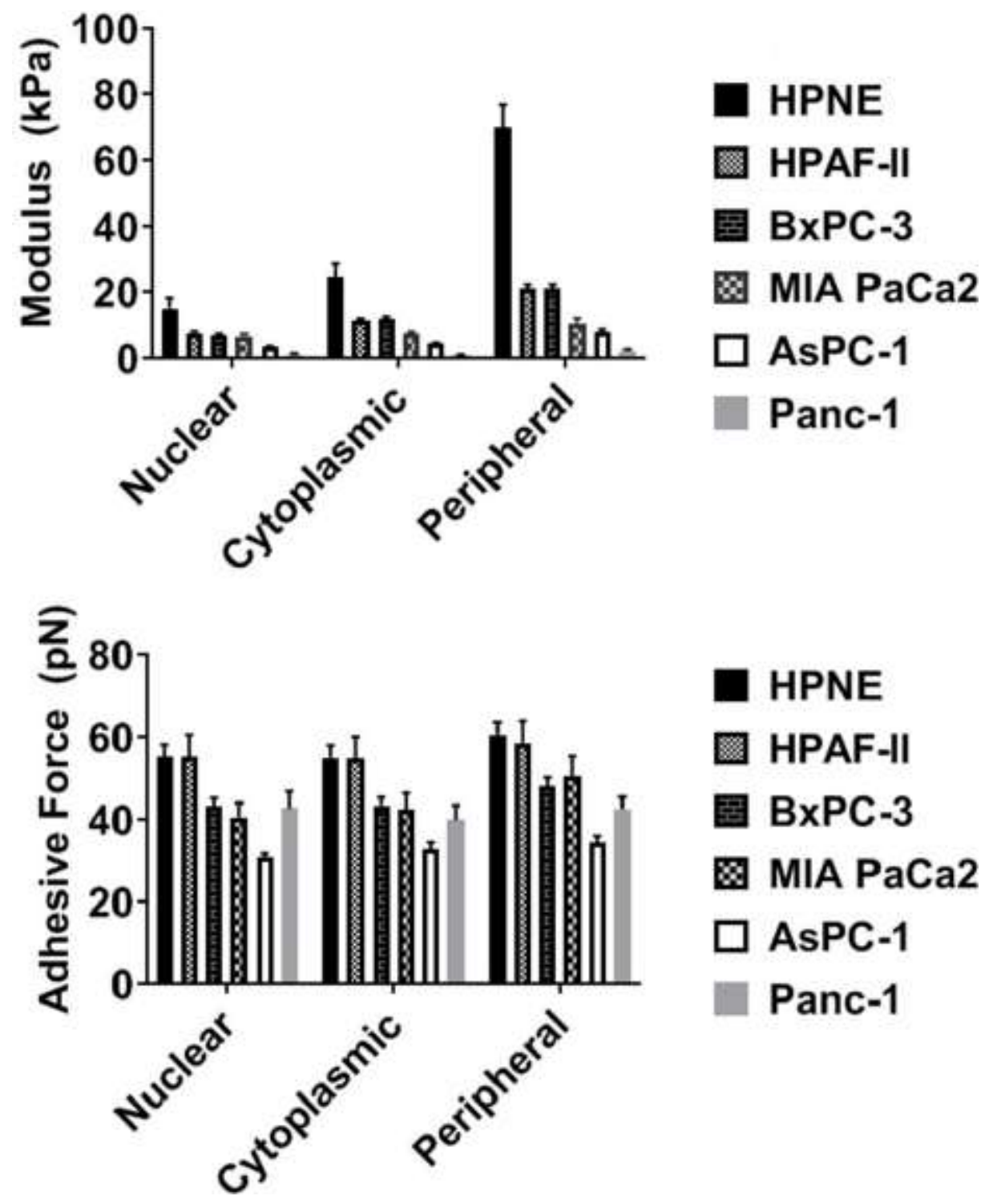

Figure 2-5. Regional cell data showing biophysical differences between normal and cancerous pancreatic cells. 

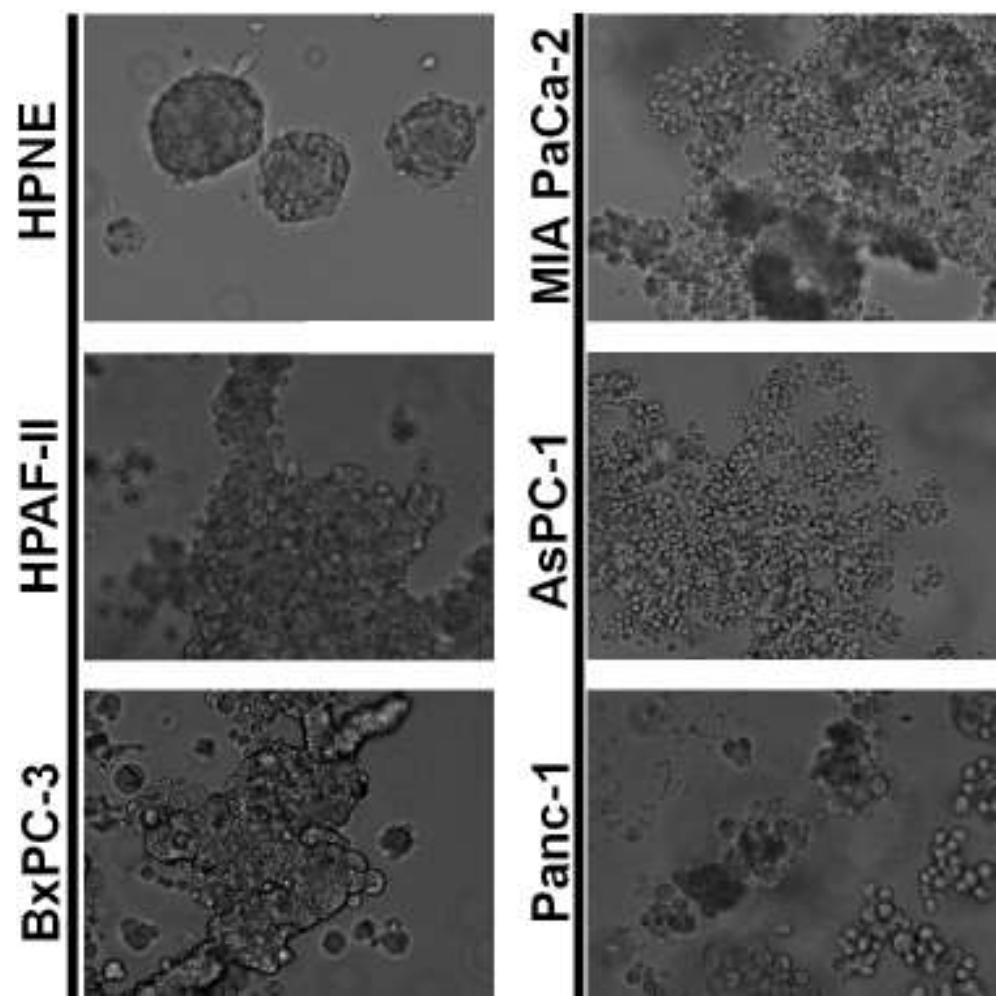

Figure 2-6. Representative 20x images for aggregation assays conducted on normal and cancerous pancreatic cells.

Note the spheroid-like formation present only in HPNE cells, while the more poorly differentiated cells exhibit the lowest aggregative potential. 
least able to aggregate with one another.

\section{Discussion}

This data demonstrates the capability of nanoindentation analyses to clearly discriminate between cancerous and non-cancerous pancreatic cells in vitro. It shows that these measurements can differentiate between cell lines of differing invasive and metastatic potential based on their phenotypic expression. Cells that are more poorly differentiated are clearly less rigid than their more well differentiated counterparts, and all cancerous cells are significantly less rigid than the normal epithelial cell line (HPNE).

The analysis shown in Figure 2-4 brings up some interesting observations. We can clearly see that HPNE cells are much more rigid than all other cells tested. This is in agreement to the previously mentioned literature consensus of reduced cell rigidity seen in cancerous cells compared to healthy ones for a given tissue. ${ }^{108}$ Some examples of previous studies highlighting reduced modulus in cancerous cells is shown in Table 2-2. ${ }^{76,78,82,109,110}$ We can also see a general trend correlating the differentiation status of PDAC cells to rigidity. As mentioned previously, the more well differentiated the cell is, the higher its modulus.

Although not as significant, a similar trend can be seen with adhesion. HPAF-II cells did not show a large (or significant) difference from HPNE cells in terms of membrane adhesion, although BxPC-3 were lower than both of these cell lines. MIA PaCa-2 cells did not have a large difference from BxPC-3, while AsPC-1 and Panc-1 showed somewhat lower membrane adhesiveness, with AsPC-1 showing the lowest when examining the cell compartmentally - with overall analysis, MIA PaCa- 2 cells were slightly less adhesive. Although not as significant as the modulus data, there were still some positive correlations between this adhesion data and a set of aggregation assays. Notably, HPNE cells exhibited the ability to form small spheroids, indicating a high degree of cell-cell adhesion, whereas all other cancerous cell lines tested showed varying degrees of reduced adhesion, with the lowest being observed with the poorly differentiated cells. This is best represented visually by the shift in inherent aggregative capability between more well differentiated cells (HPAF-II and BxPC-3), which show some level of coherent, sheet-like interaction, and the poorly differentiated cells, which at best showed loose clumping. Since it has been shown that metastasis is typically associated with lowered cell adhesion ${ }^{111}$, measuring cell membrane adhesiveness could give an early indicator of a metastatic shift, potentially even at the tissue level.

Regarding the AFM analysis, several points can be brought up with regards to the experimental parameters. It was decided that using a resolution of $128 * 128$ pixels would allow for a greater level of data to be collected on individual cells, and give further insight into physical properties at different regions of the cell. This is clearly visualized in the force maps seen in the figures throughout this report. Although a higher resolution could have been attempted, this value was chosen in an attempt to keep the cells from suffering excessive effects in an atmosphere without constant $\mathrm{CO}_{2}$ influx. Since a 
Table 2-2. Summary of previously published studies showing reduced modulus in cancerous cell lines compared to normal reference cells.

\begin{tabular}{lll}
\hline Cell type & $\begin{array}{l}\text { Average normal cell } \\
\text { modulus (kPa) }\end{array}$ & Average cancer cell modulus (kPa) \\
\hline Liver & L02: 0.174 & HepG2: $0.063 ;$ \\
& & Bel7402: 0.154 \\
Breast & A184: $2.26 \pm 0.560$ & T47D: $1.2 \pm 0.28$ \\
& & MFC7: $1.24 \pm 0.46$ \\
Prostate & PZHPV-7: $3.09 \pm 0.84$ & LNCaP: $0.45 \pm 0.21$ \\
& & Du145: $1.36 \pm 0.42$ \\
& & PC-3: $1.95 \pm 0.47$ \\
Ovarian & IOSE: $2.472 \pm 2.048$ & HEY: $0.884 \pm 0.529$ \\
& & HEY A $8: 0.494 \pm 0.222$ \\
Bladder & HCV29: Approx. 15 & HTB-9, HT-1376, T24: Approx. 4 \\
& (400nm indentation) & (400nm indentation) \\
Melanocyte & HEMa-PL: 14.28 & WM793: 10.18 \\
& & WM1 $15: 9.68$ \\
& & WM239: 6.95 \\
& & WM266-4: 8.84 \\
& & 1205Lu: 7.29 \\
& & A375P: 5 \\
\hline
\end{tabular}

\section{Data Sources}

Bobrowska J, Awsiuk K, Pabijan J, et al. Biophysical and Biochemical Characteristics as Complementary Indicators of Melanoma Progression. Anal Chem. 2019;91(15):98859892. doi:10.1021/acs.analchem.9b01542.

Lekka M. Discrimination Between Normal and Cancerous Cells Using AFM.

Bionanoscience. 2016;6(1):65-80. doi:10.1007/s12668-016-0191-3.

Lekka M, Gil D, Pogoda K, et al. Cancer cell detection in tissue sections using AFM. Arch Biochem Biophys. 2012;518(2):151-156. doi:10.1016/j.abb.2011.12.013.

Pei W, Chen J, Wang C, et al. Regional biomechanical imaging of liver cancer cells. $J$ Cancer. 2019;10(19):4481-4487. doi:10.7150/jca.32985.

Ramos JR, Pabijan J, Garcia R, Lekka M. The softening of human bladder cancer cells happens at an early stage of the malignancy process. Beilstein J Nanotechnol.

2014;5:447-457. doi:10.3762/bjnano.5.52. 
$256 * 256$ image using the previously described parameters would take almost 90 minutes to conduct, it would reduce the throughput of this analytical system by roughly fourfold. The current resolution allows for at least three replicates for every plate used within less than two hours of taking the plate out of the incubator, accounting for cell transport and machine calibration.

An interesting trend can be drawn in the cells with a known MUC13 expression. Of the cells used in this study, Panc-1, BxPC-3 and MIA PaCa-2 are known to have a minimal MUC13 expression, AsPC-1 has a moderate expression and HPAF-II has a high expression. It seems that cells with a higher modulus tend to have a higher MUC13. However, this alone does not explain this increased modulus, otherwise one would expect that $\mathrm{BxPC}-3$ and MIA PaCa-2 cells should be softer than they were recorded to be.

It was originally thought that metastatic cells would have a lower modulus when compared to the primary tumor. However, based on the data shown, that does not appear to be the case. BxPC-3 and HPAF-II are nearly identical in their modulus values, and although AsPC-1 is significantly softer than MIA PaCa-2, it is significantly higher than Panc-1. This comparison should be taken cautiously however, considering that these cells were all collected from separate patients. Furthermore, since the cells show a clear pattern of rigidity based on differentiation status, we can potentially relate this to the overall state of EMT/MET. Cells that are more well-differentiated are typically thought to be closer to an epithelial state, while the more poorly differentiated it is the more mesenchymal it becomes. ${ }^{96,112,113}$ Because of this, we can see the physical differences between these cells as a potential physical marker of its overall aggressiveness. This could potentially be applied to the tissue level, and if an abnormal or unknown tissue section is found to have a considerably different set of physical properties than normal adjacent tissue, it could be an early warning sign of aberrant or cancerous tissue. This could help clinicians to more rapidly diagnose the patient or potentially have ideas on therapeutic options.

Of the cells tested, BxPC-3, MIA PaCa-2, and Panc- 1 are all primary tumors, while HPAF-II and AsPC-1 are metastatic. When comparing some of the metastatic cells to primary tumor cells, we see that overall the metastatic cells have a larger modulus (MIA PaCa 2 notwithstanding). It is possible that this can be related to a cell's EMT/MET state. If these PDAC cells were treated with agents to trigger either EMT or MET, a baseline could be established between these phenotypes and how they affect physical properties. Regarding metastatic cells, it seems likely that if these have already established themselves at a metastatic tumor site, they could have undergone a mesenchymal-epithelial transition (MET) and reversed some of the reductions in modulus that have been previously shown with EMT induction. ${ }^{80}$ However, since these cells are not isogenic this cannot be directly confirmed. It is possible that this comparison is a biophysical representation of the MET process, albeit in a different cancer tissue. Curiously, they showed a lower overall adhesion, although this may be due to differences between the physical properties of CRC and PDAC cells. 
Of interest, in more rigid cells (particularly HPNE), the modulus maps seem to visualize the underlying cytoskeletal structure (see Figure 2-1). This was seen in some of the other cells as well, such as a few MIA PaCa- 2 and AsPC-1 cells, but not across all cell lines.

The results shown in this chapter can be of strong interest in a clinical and diagnostic sense. It is possible that similar tests can be run in the future on patient-derived tumor tissues, and when compared to adjacent normal cells, biophysical differences may be able to assist in expediting tumor grading, and possibly even metastatic risk and an overall prognosis of the disease state. Similar results have already been suggested in other cancers at the tissue level. ${ }^{59,78}$

It should be noted that there is some discrepancy when comparing the results of the regional and overall analyses (Figures 2-3 and 2-4). This is partly due to the amount of the cell that is measured with each method. In the overall analysis, at least $75 \%$ of the entire cell is quantified, and an average value is taken for each individual cell. When using the regional analysis method, only 25 square micron regions are randomly taken at either the nuclear, cytoplasmic or peripheral region. Although they can give a representative idea of these values, especially with multiple replicates, the overall data takes more of the cell surface into effect, and variations across the cell surface (especially regions closer to the nucleus, which tends to be softer as mentioned previously) may lower the overall average value seen at different regions when compartmentalized. Given the heterogeneity of the biophysical properties on a cell surface, the regional method may be less representative when compared to the overall method, and lead to a greater intersample variation than the overall analysis.

The method of analysis (overall cell analysis as compared to analyzing nuclear, cytoplasmic, and peripheral regions separately) seems to have an impact on the results. Of note, the trends in cell rigidity discussed here are virtually identical across both methods of analysis - the same patterns were seen whether the cells were broken up into subcomponents (nuclear, cytoplasmic, and peripheral sections) or analyzed overall. By contrast, there are some minor differences in the membrane adhesion when considered overall and regionally, however neither method of analysis shows considerable significance across any of the cell lines. This is partly due to the lower variation between cell lines in adhesion values as compared to the modulus data. One exception was seen when examining the cells overall - MIA PaCa-2 was found to have the lowest membrane adhesiveness, while when looking at subcomponents, AsPC-1 was lower. AsPC-1 was significantly lower than all other cells at most regions; while MIA PaCa-2 was significantly lower than all cells except AsPC-1 when examined overall. Overall, HPAFII cells show a slightly smaller adhesion when compared to HPNE cells, albeit not significantly. BxPC-3 also shows a significantly lower adhesiveness to HPAF when measured overall, but not compartmentally.

As seen in the subdivision chart, there is a general trend of increasing rigidity the closer the measurements are taken to the periphery of a cell. This may be in part due to structural changes and the underlying cellular components at various regions of the cell. 
By contrast, the cell adhesiveness appears to have minimal if any difference when compared across different regions of the cell surface.

Lastly, it is worth noting that although the probe was calibrated and all values are quantified and consistent over multiple tests, the adhesion data shown on these tests should not be considered quantitative. This caveat is mentioned as the adhesion data in these charts represents the adhesive interaction between the cellular membrane and a bare, unmodified silicon nitride AFM tip. This interaction between the silicon nitride tip and cell membranes is not one that will be found in the body, and the exact mechanisms of membrane attachment to this material is not well understood, although it is known that the adhesive interaction between this material and cellular membranes is relatively weak. ${ }^{114}$ Although it can still give some insight into the base adhesiveness of the membrane, it is not representative of an interaction that a cancer cell would biologically undertake. Therefore, it should only be seen as suggestive as to the adhesive potential of a cell rather than an exact, quantifiable result. 


\section{CHAPTER 3. EFFECT OF CHEMOTHERAPEUTICS ON BIOPHYSICAL PROPERTIES OF PANCREATIC CANCER CELLS}

\section{Introduction}

PDAC has one of the highest mortality rates among cancers, with a poor survival rate of less than $10 \% .{ }^{6}$ Even with recent advances in chemotherapeutics, the overall survival from this disease state has not dramatically improved over the past few decades. ${ }^{115}$ Various chemotherapeutics have been used to address pancreatic cancer current first line agents for PDAC include the combination of gemcitabine and albuminbound paclitaxel (nab-PTX) or the FOLFIRINOX (irinotecan, oxaliplatin, leucovorin, 5fluorouracil) regimen. ${ }^{116,117}$

In this chapter, three agents were selected and used to measure their biophysical effects on PDAC cells: gemcitabine (GEM), a first-line agent; paclitaxel (PTX), a second-line agent that has been shown to enhance the effects of GEM; and curcumin (CUR), a natural product derived from turmeric that has shown promising effects for PDAC therapy. ${ }^{18,119}$ Our aim was to show the biophysical effect of these drugs a panel of PDAC cells to see how varied stages of differentiation respond to treatment biophysically. Initially, we anticipated more poorly cells would be more susceptible to treatment (i.e., exhibit higher changes in their biophysical properties). We also anticipated that, due to its mechanism of action, PTX would lead to the greatest change in these cells.

\section{Pharmacological Agents Used and Their Characteristics}

\section{Paclitaxel (PTX)}

A taxol agent, PTX works by promoting microtubule assembly through enhancing tubulin dimer action, stabilizing existing microtubules, and inhibiting disassembly - this in turn interferes with the $\mathrm{G} 2$ phase of mitosis, inhibiting cell replication. ${ }^{120}$ Although not used as a monotherapy in PDAC, when used as an albumin-bound nanoparticle (e.g., Abraxane), it has been shown to increase the therapeutic efficacy of first-line GEM via inhibiting the enzyme cytidine deaminase, which is involved in breaking down GEM once it enters the cell. ${ }^{121}$ This combination of nab-PTX and GEM is one of the standard first line therapies currently in use. ${ }^{116}$ Given this mechanism of action, PTX was originally considered the positive control, as we expected it would cause the greatest biophysical effect in the cells being analyzed. 


\section{Gemcitabine (GEM)}

A pyrimidine antimetabolite, GEM (Figure 3-2) inhibits DNA synthesis via inhibiting DNA polymerase and ribonuclease reductase. It is phosphorylated intracellularly into a monophosphate form by deoxycytidine kinase. After a further conversion into the diphosphate form, GEM inhibits DNA synthesis via ribonucleotide reductase inhibition, while the triphosphate form incorporates into DNA and inhibits DNA polymerase. ${ }^{122}$ Of note in pancreatic cancer, GEM is seen as a first-line agent, however it is only associated with a marginal increase in patient survival. ${ }^{123}$ There is also concern of rapid resistance to this drug ${ }^{124}$, although combinations, such as the nabPTX/GEM system as mentioned previously, are being investigated to overcome this. ${ }^{125}$

\section{Curcumin (CUR)}

CUR is a yellow pigment derived from turmeric, a spice derived from the homonymous rhizome, Curcuma longa. Multiple studies have shown it to possess antioxidant, anti-inflammatory, and anticancer properties. Recent research has shed light on the actions of this agent in cancer, with effects potentially including modulating cell cycle, apoptotic signaling, protein kinases, NF-kB, proteasome activation, epigenetic regulation and histone modification. There are some concerns over the low bioavailability of the drug, however a recent dosage form (known as THERACURMIN ${ }^{126}$ ) has been developed to help bypass this concern. ${ }^{118,127,128}$

\section{Methods}

\section{Cell Culture}

Pancreatic cancer cells were acquired from ATCC. These cells were grown in a humidified $37^{\circ} \mathrm{C}$ incubator with a 5\% CO2 atmosphere. MIA PaCa-2 and Panc-1 cells were grown in DMEM media. BxPC-3 and AsPC-1 cells were grown using RMPI-1680 media. HPAF-II cells were grown using DMEM/F-12 media. All types of culture media were acquired from Gibco and supplemented with Fetal Bovine Serum (Gibco) and Antibiotic-Antimycotic (Gibco) to final concentrations of $10 \%$ and $1 \%$, respectively. Cells were grown in T-75 flasks until at least 75\% confluent and then trypsinized, counted, and seeded as needed for the experiments discussed in this chapter.

\section{Live Cell AFM Data Analysis}

Cells (HPAF-II, BxPC-3, MIA PaCa-2, AsPC-1, and Panc-1) were seeded in 60 mm dishes $\left(2 * 10^{6}\right.$ cells $)$ and attached overnight. Cells were allowed to grow until they reached $75 \%$ confluency. They were then treated with an approximate 48 -hour IC50 over a 24 hour period. The doses for PTX and CUR were experimentally determined in our 
$\operatorname{lab}^{129-131}$ (10nM for PTX and $15 \mu \mathrm{M}$ for CUR) and 500nM was used for GEM treatments. These doses were selected in order to ensure a therapeutic effect on the cells but not so high as to kill and detach cells from the surface of the plate. The exact dose for this effect in each cell line may have varied, but these values were chosen as an overall baseline. This effect is of particular note in GEM, since certain PDAC cell lines are considerably more resistant to GEM than others, ${ }^{132,133}$ necessitating a high enough dose to affect these without leading to excessive cell death in the more sensitive cell lines. PTX and CUR stocks were made in DMSO, while GEM was dissolved in PBS. Before imaging, the cells were washed with PBS three times and fresh media was added. The dish was taken to the AFM and placed on a heated stage $\left(37^{\circ} \mathrm{C}\right)$ and equilibrated for 15 minutes. Using custom-generated PFQNM-LC cantilevers (tip diameter $\sim 130 \mathrm{~nm}^{46}$ ) designed for live cell applications (Bruker), the deflection sensitivity was calculated via thermal tune. For nanoindentation, a force curve was first generated on the center of a cell to confirm contact, then a force volume scan was conducted (128*128 resolution, 512 samples per ramp, $15 \mathrm{~Hz}$ ramp rate, $400 \mathrm{pN}$ force trigger, $4 \mu \mathrm{m}$ ramp size) to generate a force map of the entire cell. An in-depth explanation for these parameters is mentioned in Chapter 2.

After collecting data on multiple cells, the nanomechanical properties (elastic modulus, or stiffness, and adhesion) were calculated at the nuclear, cytoplasmic, and peripheral regions and averaged. An overall analysis was also conducted. All force data analysis was conducted using NanoScope Analysis software (Bruker).

\section{Statistical Analysis}

Analyses were conducted using unpaired, two-tailed Student's T-tests to assess the difference between relevant groups in the various experiments. All error bars used in the attached figures indicate the standard error of mean (SEM). The number of stars used on each graph relates to the level of significance. Items with four stars $(* * * *)$ indicate Pvalues below 0.0001 .

\section{Results}

Significant changes could be detected using biophysical analyses, but significance was mostly seen only in poorly differentiated cells. For the more well differentiated cell lines, HPAF-II and BxPC-3, there was no significant effect seen at any point on the cell for PTX treatment, although a slight decrease in cell rigidity was still observed. An overview of the overall changes is depicted in Figure 3-1.

Looking at the cells individually, more specific patterns can be seen regionally. With the well-differentiated cells, the overall effect of PTX, CUR, and GEM is relatively similar: in HPAF-II cells, there is a minimal effect with PTX treatment on cell rigidity, while a small yet significant increase was noted with CUR treatment at the periphery of cells. Curiously, GEM treatment reduced the cell modulus, and was significant at the 

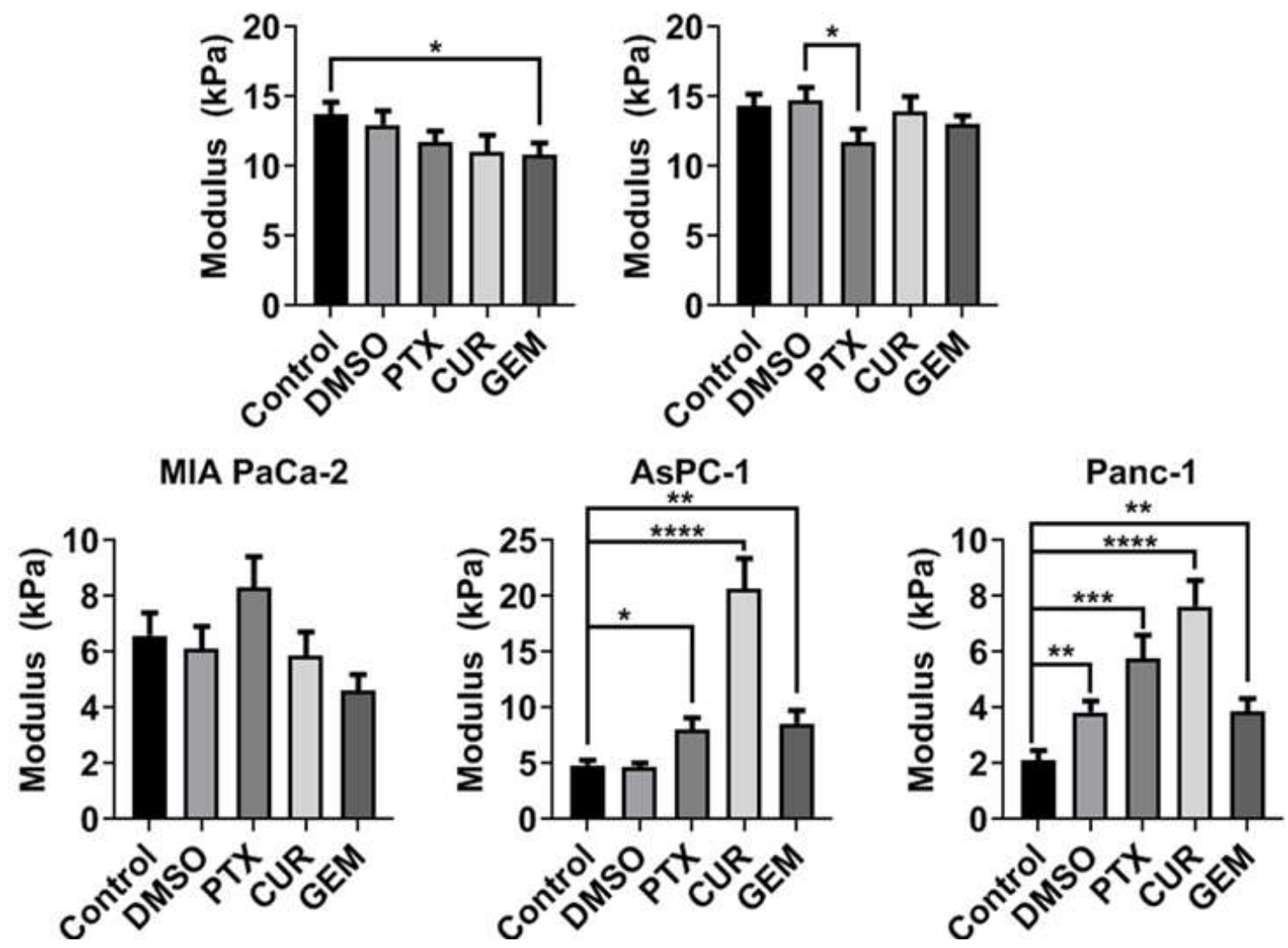

Figure 3-1. Overall biophysical data of pancreatic cancer cells treated with paclitaxel (PTX), curcumin (CUR), and gemcitabine (GEM).

The doses used were 10nM PTX, 15 $\mu$ M CUR and 500nM GEM. 
nuclear region (Figure 3-2). BxPC-3 cells exhibited very few significant changes at the regional level, the most notable being a significant decrease at the periphery with GEM treatment (Figure 3-3).

For poorly differentiated cells, more significant effects were observed. In MIA PaCa-2 cells, no significant effect was observed with PTX treatment, and again a slight decrease was seen with GEM treatment (significant at the periphery). Of interest, CUR treatment led to a significantly higher modulus across the cell surface as compared to vehicle control (Figure 3-4).

Considerably more significant effects were seen in the poorly-differentiated AsPC-1 and Panc-1 cells. With AsPC-1, significant increases were seen across the cell surface with all three treatments, with the largest increase again seen with CUR. PTX had a significant increase at the nuclear and cytoplasmic regions but was not found to be significant at the periphery (Figure 3-5).

Lastly, in Panc-1, noticeably larger increases were noted in all three drugs. All regions of the cell were significantly more rigid than control, and again the greatest overall increase was noted in CUR. In fact, based on these results the greatest effect on increasing cellular rigidity occurs over all regions of AsPC-1 and Panc-1 cells treated with CUR, in each case representing a nearly 4-fold increase (Figure 3-6).

Overall, the largest increase in cell rigidity was noted in CUR treated cells. Also, the greatest physical changes were seen in poorly differentiated cells - particularly in Panc-1 and AsPC-1 cells.

\section{Discussion}

It has been mentioned in past research that poorly-differentiated tumors (i.e., higher grade tumors with an increased proportion of stem-like cancer cells) tend to be more drug resistant as well as being associated with poor prognosis ${ }^{134-138}$, however based on the results shown in this chapter, the poorly-differentiated cancer cell lines show a greater biophysical change as compared to moderate and well-differentiated PDAC cell lines. This is of some interest, as some evidence has supported the notion that the more poorly differentiated a PDAC cell line is, the more thorough the associated EMT markers are expressed. ${ }^{96}$ This gives some insight to the relation between cellular phenotype and the overall mechanics of the cell.

Although it is traditionally considered one of the first-line agents, GEM was shown to have the lowest overall biophysical effect on PDAC cells. Previous studies from our lab have shown that GEM does have an effect on PDAC cell motility and other pathways, however the effect was only marginal at best - it was however shown to be enhanced by the addition of other agents, including CUR and ormeloxifene (ORM). It should be noted however that the doses used in these studies are lower than what was used in this trial - however the effect of these lower doses (100nM and 200nM) also had 

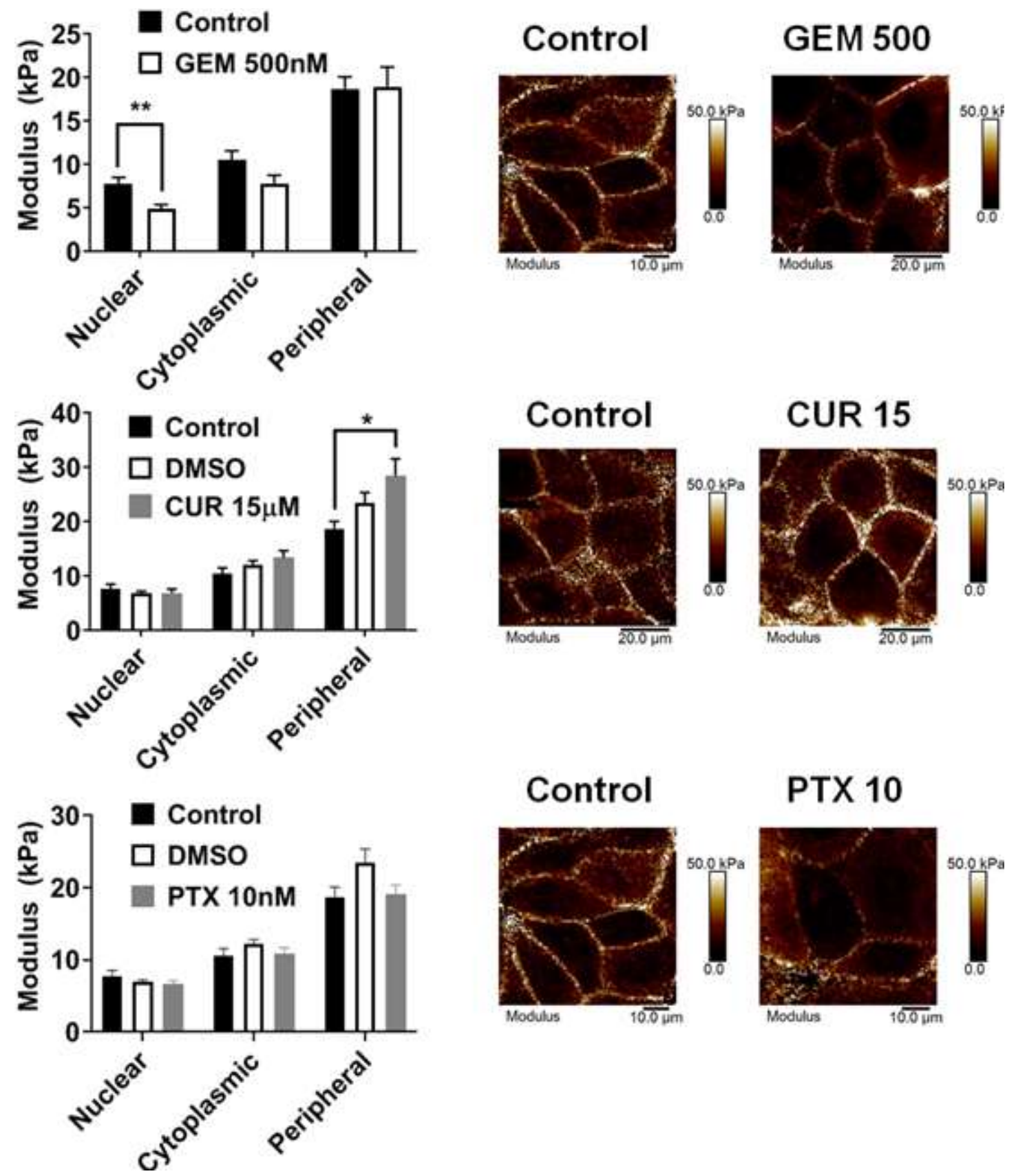

Figure 3-2. Regional biophysical analysis of HPAF-II cells treated with PTX, CUR, and GEM. 

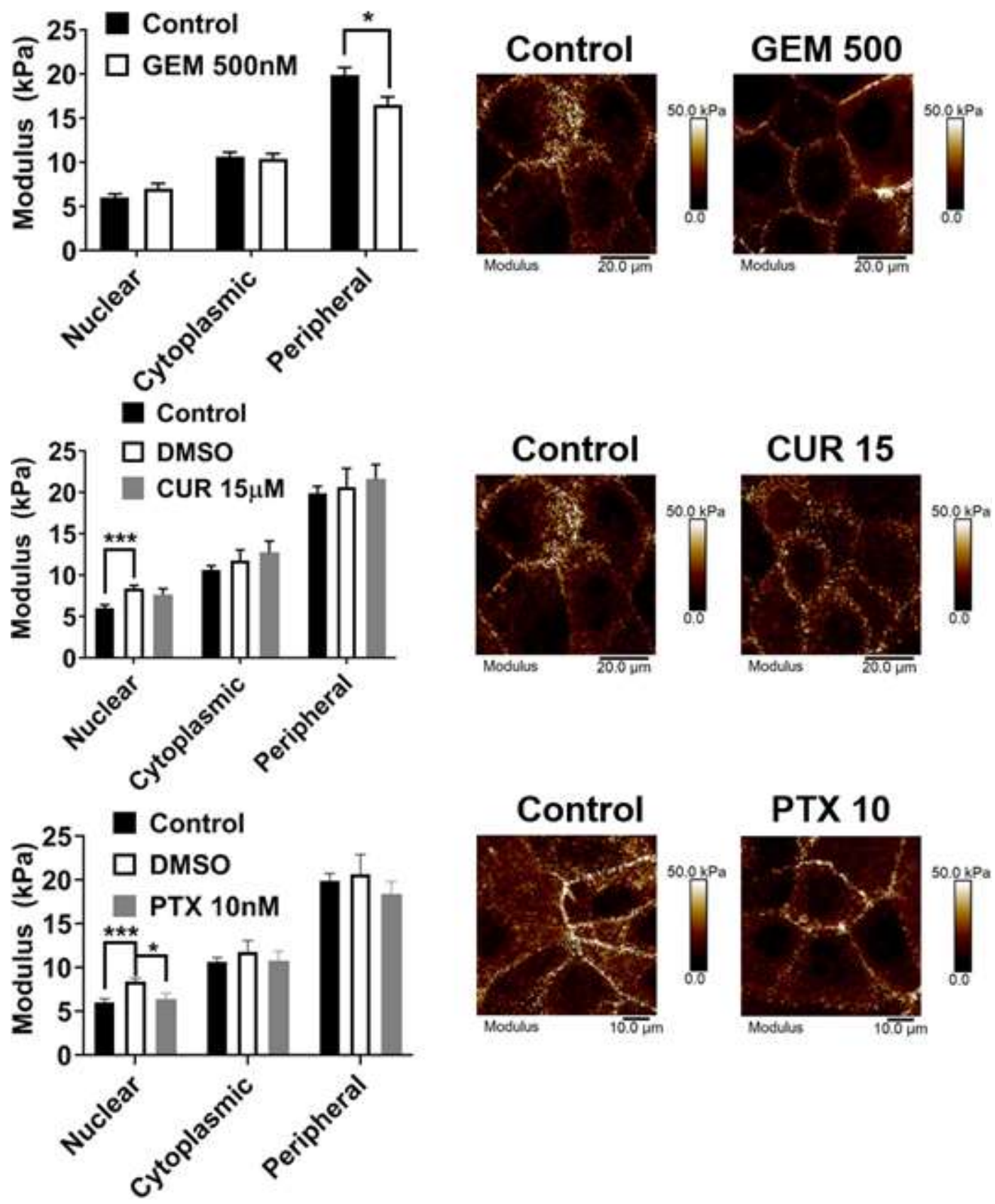

Figure 3-3. Regional biophysical analysis of BxPC-3 cells treated with PTX, CUR, and GEM. 

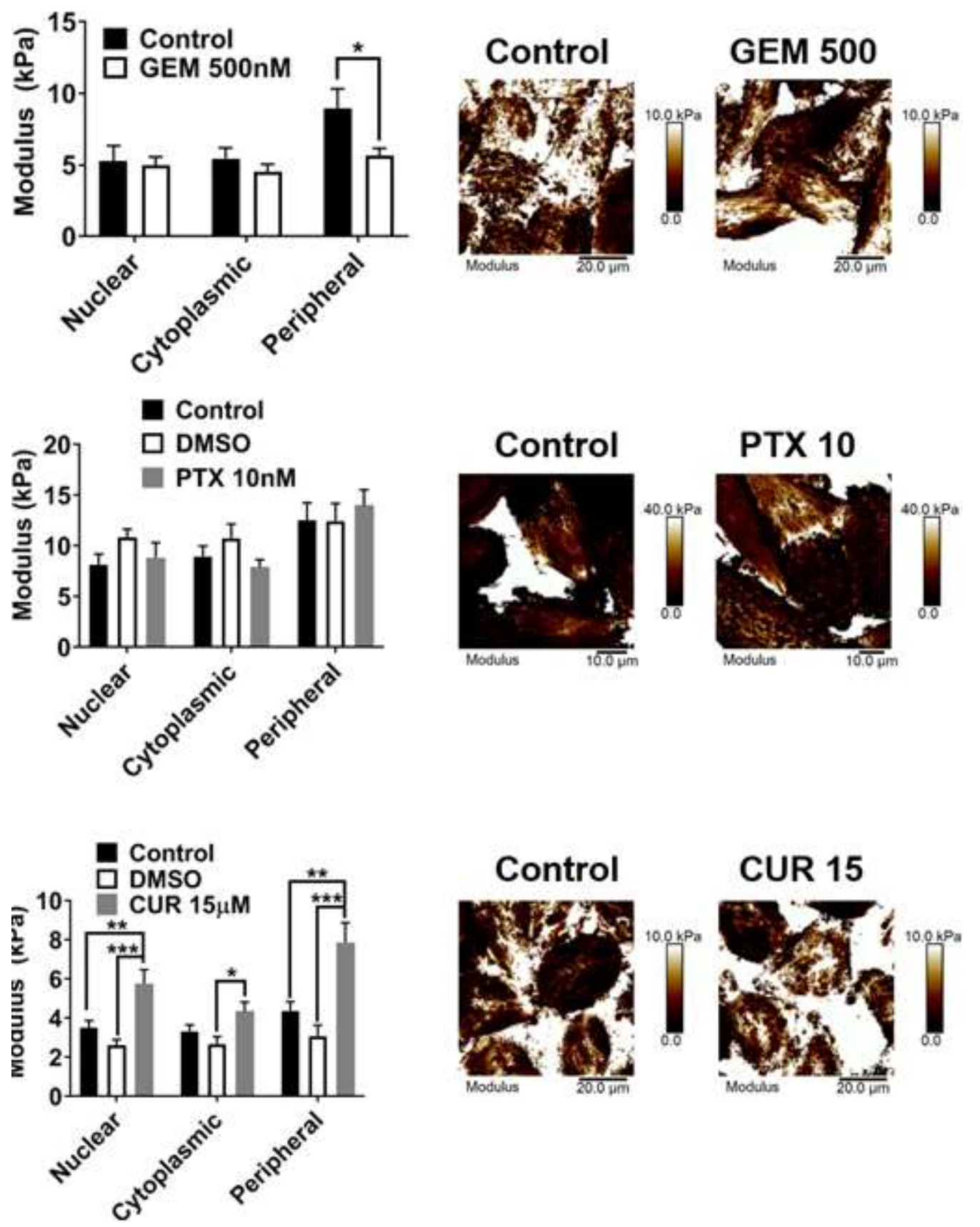

Figure 3-4. Regional biophysical analysis of MIA PaCa-2 cells treated with PTX, CUR and GEM. 

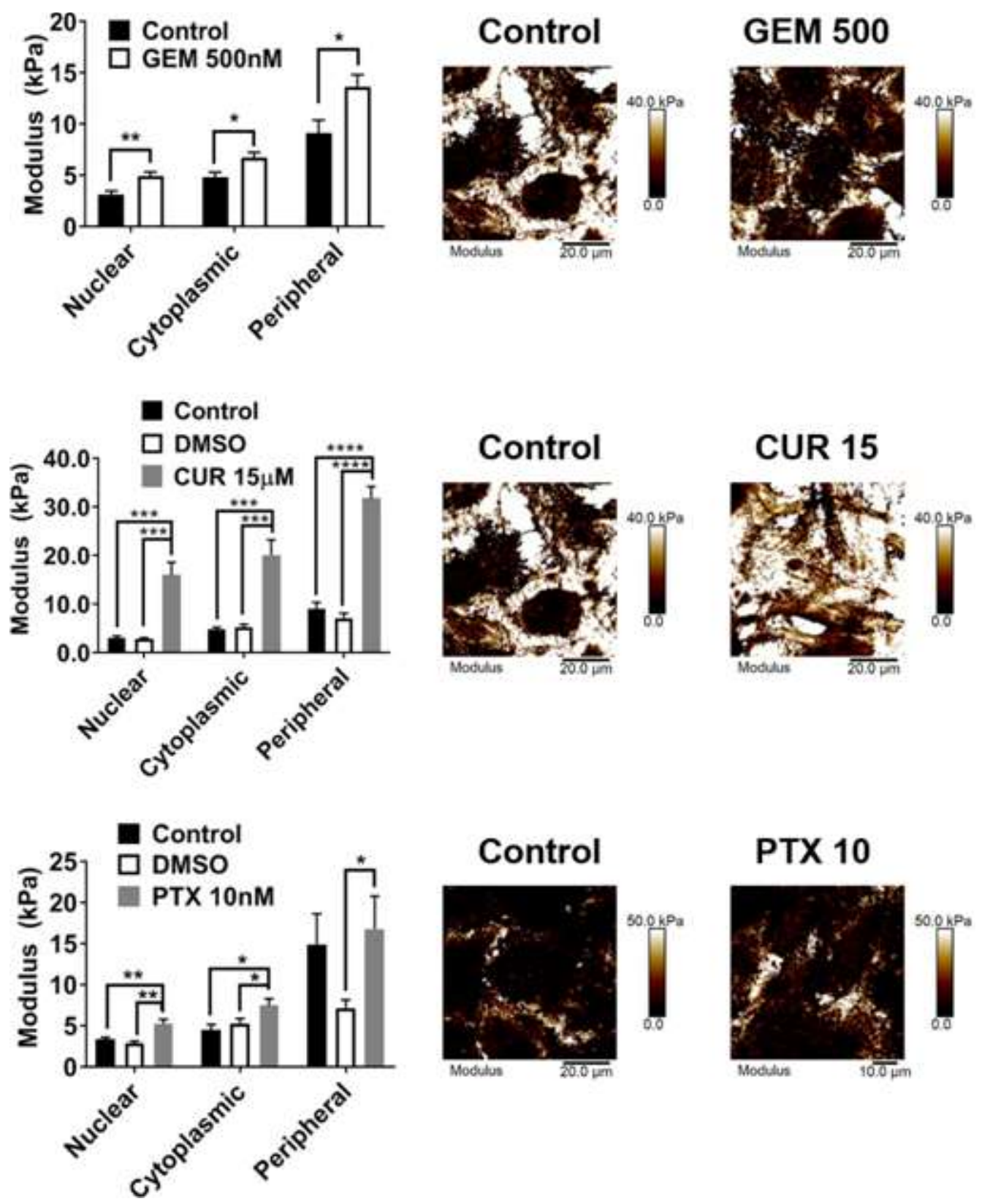

Figure 3-5. Regional biophysical analysis of AsPC-1 cells treated with PTX, CUR, and GEM. 

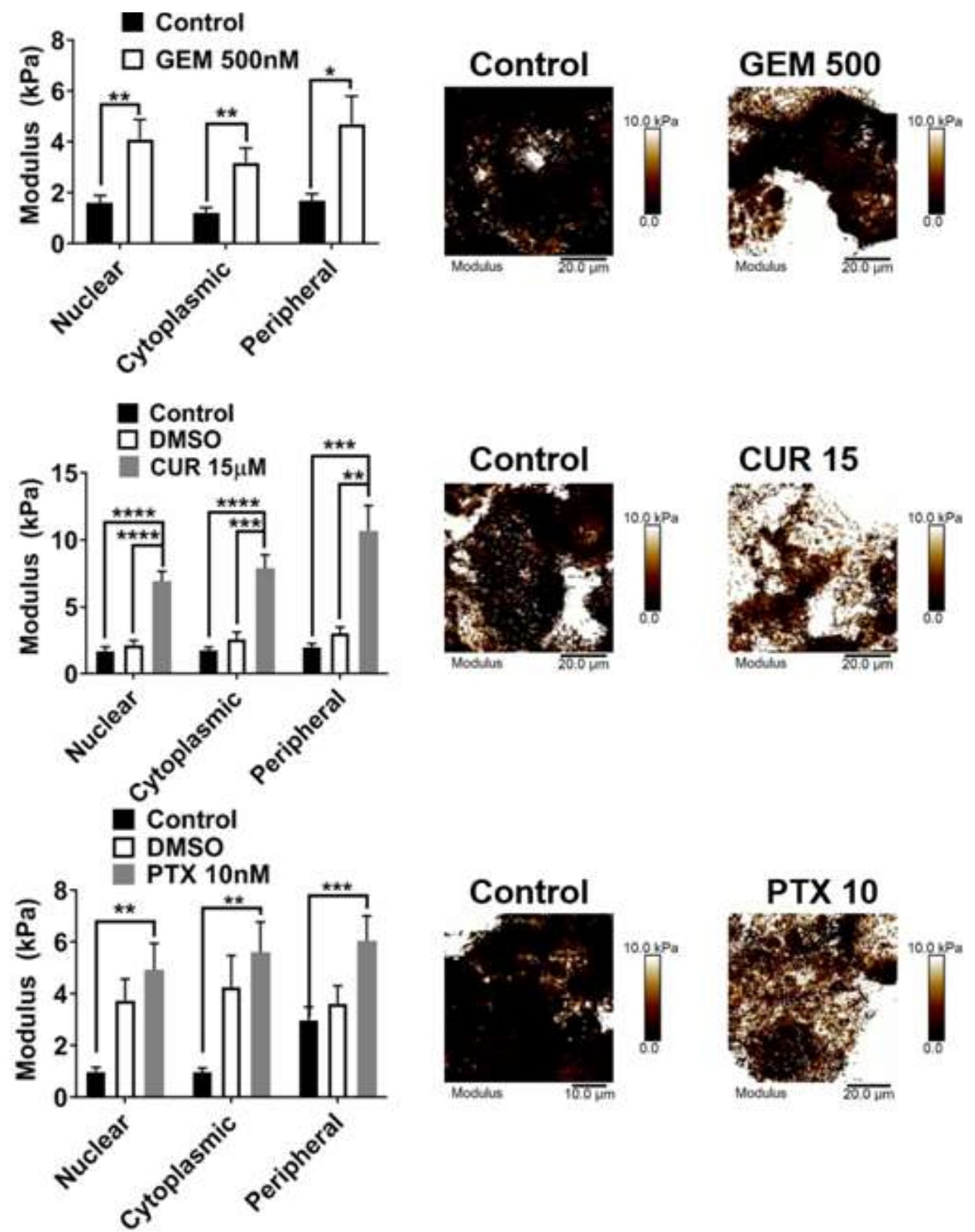

Figure 3-6. Regional biophysical analysis of Panc-1 cells treated with PTX, CUR, and GEM. 
minimal effect on cell toxicity, which may explain why so little effect was seen on cell motility. ${ }^{94,129}$

Interestingly, the greatest biophysical changes appear to be caused by CUR. Originally, we anticipated that PTX, an agent known to hyperstabilize microtubules, would cause the greatest physical change at its respective 48-hour IC50 dose, essentially making it a positive control for the study. However, it appears that CUR has a more significant effect, especially on the more poorly differentiated cell lines. In fact, the relative increased modulus in AsPC-1 and Panc-1 cells was much higher in CUR-treated cells as compared to those treated with PTX. This difference in PTX and CUR was most notable in AsPC-1: while PTX led to an overall increase in modulus of approximately $50 \%$ at its IC50, CUR led to a nearly 4 -fold increase in rigidity.

It should be noted that the doses for these agents were chosen to be as close to the IC50 values of all cell lines. There may be a certain level of variation based on the cell line, and furthermore the therapeutic effect may be more readily observed based on the biophysical change itself - for instance, HPAF-II cells were shown to have a higher IC50 than Panc-1 cells for PTX ${ }^{131}$, and this positively correlates with the increased modulus in Panc-1 cells compared to HPAF-II with PTX treatment.

Although the more poorly differentiated cells have a greater physical effect with the chemotherapeutics, this may not necessarily translate to an increased therapeutic efficacy. As noted in recent research by Khan et al, HPAF-II and Panc-1 cells were treated with CUR at the same dose used in this study $(15 \mu \mathrm{M})$, although their results indicated a greater therapeutic effect on HPAF-II cells, as fewer cells were seen on both MTT and colony formation assays compared to Panc- $1 .{ }^{129}$ This may indicate that the correlation between therapeutic efficacy and physical changes is drug (and cell) specific.

Limited information in the literature could be found as a direct comparison in terms of articles dealing with measuring the biophysical effects of these drugs on other cancer cells, but most of what was available agreed with the consensus that treatment leads to an increased rigidity. A brief summary of previous studies dealing with PTX and CUR can be seen in Table 3-1. ${ }^{139-141}$ Of note, one study indicated a reduced modulus with CUR treatment in breast cancer cells, indicating a possible tissue-specific response. ${ }^{141}$ No studies were found quantifying the biophysical effects of GEM treatment.

Adhesion data for the cell treatments was not as significant when compared to modulus changes. Considering the caveats discussed in Chapter 2, these results should also be taken with caution as they may not be truly representative of the actual effects of these drugs. In addition, the effects noted are somewhat contradictory to the originally expected result - initially, it was thought that most treatments would increase the adhesiveness of cells, which could potentially be related to a reduced metastatic potential. This was seen with HPAF-II cells and PTX treatment, however no modulus increase was noted with this same dose; by contrast, Panc-1 cells actually showed a decreased adhesion with CUR and GEM treatment which was the opposite of our anticipated result. 
Table 3-1. Summary of previously published studies detailing the biophysical effects of PTX and CUR in cancer cell lines.

\begin{tabular}{lll}
\hline Cell line & $\begin{array}{l}\text { Average control } \\
\text { modulus }(\mathbf{k P a})\end{array}$ & $\begin{array}{l}\text { Average treatment } \\
\text { modulus }(\mathbf{k P a})\end{array}$ \\
\hline $\begin{array}{l}\text { HEPG2 } \\
\text { (Liver cancer) }\end{array}$ & $1.33 \pm 0.034$ & $\begin{array}{l}3.4 \pm 0.26 \\
\text { (CUR Treatment, } 1.56 \\
\mu \mathrm{g} / \mathrm{mL})\end{array}$ \\
$\begin{array}{l}\text { PC-3 } \\
\text { (Prostate cancer) }\end{array}$ & Approx. 4 & $\begin{array}{l}\text { Approx. } 8.5(\mathrm{PTX} \\
\text { Treatment, } 2 \mu \mathrm{M})\end{array}$ \\
$\begin{array}{l}\text { MCF7 } \\
\text { (Breast cancer) }\end{array}$ & $9.5 \pm 2.2$ & $\begin{array}{l}5.8 \pm 1.1(\mathrm{CUR} \\
\text { Treatment, } 20 \mu \mathrm{M})\end{array}$ \\
\hline
\end{tabular}

\section{Data Sources}

Olugbami JO, Damoiseaux R, France B, et al. Atomic force microscopy correlates antimetastatic potentials of HepG2 cell line with its redox/energy status: effects of curcumin and Khaya senegalensis. J Integr Med. 2017;15(3):214-230.

doi:10.1016/S2095-4964(17)60337-6.

Ren J, Huang H, Liu Y, Zheng X, Zou Q. An Atomic Force Microscope Study Revealed Two Mechanisms in the Effect of Anticancer Drugs on Rate-Dependent Young's Modulus of Human Prostate Cancer Cells. Dague E, ed. PLoS One. 2015;10(5):e0126107. doi:10.1371/journal.pone.0126107.

Saab M, Bec N, Martin M, et al. Differential Effect of Curcumin on the Nanomechanics of Normal and Cancerous Mammalian Epithelial Cells. Cell Biochem Biophys. 2013;65(3):399-411. doi:10.1007/s12013-012-9443-1. 
In most of the other treatments on other cells, no significant differences in adhesion were noted (Appendix A; Figure A-1).

It should be noted that not all drugs will act to increase the modulus of a cell. This is partly based on the mechanism of action, such as the previously mentioned "positive control" that was PTX, acting to stabilize microtubules leading to an increased cell rigidity. However, previous research has shown that some agents known to destabilize microtubule structure can lead to a decrease in fibroblast cell modulus with treatment. ${ }^{142}$ Similarly, a recently developed anti-tubulin agent, VERU-111, which is a $\beta I I I / \beta I V$ tubulin inhibitor ${ }^{143}$, was shown to lead to signficant reductions in cell rigidity in cervical cancer cells using the same procedures outlined in this study. Nanoformulations were also shown to have superior effects to free drug in other experiments performed in our lab, including nano-VERU on cervical cancer cells. A clear trend was noted in a reduction of the modulus from untreated, free drug, and nano-VERU. (Figures A-2 and A-3). This demonstrates the importance of understanding the mechanism of a drug to ensure that the observed biophysical effect is a cause of the drug or a possible response related to drug resistance.

In a fundamental sense, the biophysical effect of these agents can be ascribed to the action of chemotherapeutics. These drugs tend to act on more rapidly dividing cells, and the fact that the poorly differentiated cells exhibit larger physical changes would agree with this notion.

DMSO (dimethyl sulfoxide), a commonly used solvent in biochemical experiments, is not without its effects on cancerous cells. It has been known for several decades that it can impart effects on various cancer cells - data has suggested that even in PDAC cell lines, at concentrations as low as $2 \%$ it can inhibit colony formation, reduce alkaline phosphatase, and reduce attachment to collagen. ${ }^{144}$ Although the highest DMSO concentration used in these studies was only $0.2 \%$, there is still evidence of some effect on the biomechanics of these cells, at least in the more poorly differentiated cell lines. The most apparent example of this can be seen in Panc-1 cells treated with the DMSO vehicle for PTX. By contrast, the vehicle for CUR treated cells was a concentration of only $0.1 \%$, and the effect was minimal across all cell lines.

The results of this chapter can be of great interest clinically, as it gives a rapid method of determining therapeutic efficacy of various drugs or natural compounds. Similar studies have previously demonstrated the ability to measure biophysical effects in various cancers after being treated. ${ }^{145-149}$ Given a general understanding of their mechanism of action, one can predict the physical effect on a cell and measure it, either at the cellular or tissue level. This level of change (whether an increase or decrease, again partly based on the mechanism of action of the administered agent) can indicate therapeutic efficacy or possibly an indication of drug resistance.

Biophysical analyses can also be used to detect the efficacy of nanoformulations and potentially see whether or not they have superior physical effects on cells as compared to free drug. A recent publication from our lab has shown a significantly 
increased rigidity in both cells and tissue sections with a magnetic nanoparticle formulation of CUR (MNP-CUR). Interestingly, the greatest change occurs in Panc-1 cells, which agrees with the free drug analysis shown in this study. In addition, MNPCUR seemed to show a superior effect in reducing cell aggressiveness by various motility assays and various biochemical tests, as well as an enhanced effect in vivo. Biophysical effects for this formulation could even be seen in excised tissue sections. ${ }^{129}$ (Figure A-4) Further indications of superior therapeutic efficacy can be seen in PDAC with nanoformulations of PTX. Specifically, a recent nanoparticle formulation of PLGA-PTX as made by our lab showed a significant increase in the modulus with nanoparticle treatment. We also used the AFM to help characterize the particles - in agreement with DLS results, we indicated a relatively consistent size for drug loaded and control PLGA nanoparticles. In addition, these particles were shown to have no significant physical changes with drug loading, which seems to support the notion that encapsulation was achieved as seen with FTIR and XRD results. ${ }^{131}$ (Figures A-5 and A-6).

As mentioned in Chapter 2, there may be some variation in the values when comparing regional and overall data. This was noticeable in HPAF-II cells, where some differences were noted in the trends for CUR treatment, albeit not to a significant degree. The trends in both cases are still similar even with the variations - this can be explained in part due to the nature of the overall analysis. Discrepancies were also noted in MIA $\mathrm{PaCa}-2$ cells, however they were somewhat larger. Notably, the effect of CUR was found to be significant at the compartmental level but not overall. Furthermore, it was noted that MIA PaCa-2 cells had significant changes in modulus with successive passaging, leading to larger standard deviations in the mean values. Although this was seen with other cells to a minor extent, the effect was much more pronounced with this MIA PaCa-2. Recent work has demonstrated that cancer cells can have different physical properties over successive passages ${ }^{150}$, however it is unclear as to why only MIA PaCa-2 was so strongly affected in this way. Since more of the cell is being taken into consideration, the average value will be lower since most of the cell has a lower modulus value than the peripheral region. 


\section{CHAPTER 4. EFFECT OF MUC13 MODULATION ON BIOPHYSICAL PROPERTIES OF PANCREATIC CANCER CELLS ${ }^{3}$}

\section{Introduction}

Pancreatic cancer (PanCa) remains one of the deadliest cancers and leading causes of cancer-related death in the United States, requiring additional research to improve quality of life and survival rates. As of 2018, over 44,000 deaths were estimated out of around 55,000 new cases representing a nearly $80 \%$ mortality rate. ${ }^{6}$ Even with recent advances in surgical techniques, chemotherapeutic regimens and radiation therapies, there is a poor 5 -year survival rate of less than $10 \% .{ }^{10}$ One critical factor in this disease is the aberrant expression of various mucins. ${ }^{22}$ These high molecular weight glycoproteins are normally expressed on the exterior of mucosal surfaces to act as a protective barrier with the surroundings. ${ }^{21}$

One mucin of note is MUC13, a transmembrane mucin which is normally expressed at low levels in the large intestine, trachea, kidney, small intestine, and gastric epithelium. Current evidence in the literature suggests an aberrant expression of MUC13 has been associated with ovarian and gastrointestinal cancers. ${ }^{27}$ Our lab has previously shown that the aberrant expression of MUC13 is associated with an enhanced tumorigenesis both in vitro and in vivo in ovarian cancer ${ }^{18}$, colorectal cancer $(\mathrm{CRC})^{19}$, and PanCa. ${ }^{20}$ In all three cancers, MUC13 was associated with an increased cancer cell motility as shown through enhanced proliferation, colony formation, invasion, and migration. In addition, MUC13 was found to be significantly overexpressed in cancerous tissues as compared to their normal counterparts, indicating a singular role in cancer development. ${ }^{18,31,151}$ Results from PanCa and CRC studies seem to indicate that MUC13 expression is higher in both advanced-stage and metastatic tumor tissues. ${ }^{31,151}$

In order to better assess changes in a cell's behavior, various biochemical assays exist to elucidate the specific causes of these changes. There is great interest to understand biophysical information at an ultrastructural level to help judge cellular phenotypes. To accomplish this, over the past few decades a new technology has emerged that allows for biophysical characterization of cells. This technology is based on relatively recent advances in the field of atomic force microscopy. An atomic force microscope (AFM) is a type of scanning probe microscope that works by taking a sharp metallic probe attached to a flexible cantilever and bringing it into contact with or a short distance above the sample's surface and can generate very high-resolution threedimensional topographies. Due to the direct interaction between the probe and the sample's surface, it is possible to use an AFM to perform additional analyses - one of the

\footnotetext{
${ }^{3}$ Portions of chapter from final submission of previously published article; reprinted with permission from Elsevier. Massey AE, Doxtater KA, Yallapu MM, Chauhan SC. Biophysical changes caused by altered MUC13 expression in pancreatic cancer cells. Micron. 2020;130(December 2019):102822. doi:10.1016/j.micron.2019.102822.[104].
} 
most widely used and promising (particularly for biological research) is quantifying physical parameters via nanoindentation. ${ }^{36,152,153}$

With this technique, the probe is brought into contact with the sample and a set deformation is applied. A force curve is generated, and using this, several nanomechanical parameters can be quantified (namely, Young's modulus ${ }^{109,154}$ and adhesion $\left.^{111,155,156}\right)$. Young's modulus, also known as the elastic modulus, is a parameter that defines a material's stiffness, and is defined as stress (a force applied over a given area) divided by strain (the change in a material's length as compared to its original dimensions). Given this parameter, it is possible to determine key physical changes - the more force required to deform a material indicates a higher modulus, and by contrast, a lower force to deform indicates a reduced modulus. ${ }^{35}$

The application of nanoindentation to cancer cells leads to a new and exciting technique to help identify and potentially even diagnose cancer from a purely physical analysis. ${ }^{79}$ The current consensus in scientific literature supports the notion that cancer cells are less rigid (i.e., they have a lower modulus) than their healthy cellular counterparts. In addition, cells with a higher metastatic potential have also generally been seen to have a lower rigidity as well. ${ }^{77,109}$ However, there is limited research on the biophysical role of mucins and virtually none of this applied to PanCa. Therefore, we present our findings on the biophysical effects of MUC13 via genetically modified PanCa cells with over-expressed or knocked down MUC13 levels to determine if any significant biophysical changes can be identified. This will then be compared to the phenotypic effect of MUC13 on cancer cells to see if the expected correlation in literature is met

\section{Methods}

\section{Cell Culture}

Pancreatic cells (HPAF-II and Panc-1) were acquired from ATCC. These cells were grown in a humidified $37^{\circ} \mathrm{C}$ incubator with a 5\% CO2 atmosphere. Panc-1 cells were grown in DMEM media and HPAF-II cells were grown using DMEM/F-12 media. All types of culture media were acquired from Gibco and supplemented with Fetal Bovine Serum (Gibco) and Antibiotic-Antimycotic (Gibco) to final concentrations of $10 \%$ and $1 \%$, respectively. Antibiotic selection was used on transfected cells with every passage. Cells were grown in T-75 flasks until at least $75 \%$ confluent and then trypsinized, counted, and seeded as needed for the various experiments discussed in this chapter.

\section{Transfection of PanCa Cells for Altered MUC13 Expression}

Transfected models of MUC13 modulated cells for PanCa cells were generated using previously described protocols. ${ }^{20}$ In brief, overexpressing models were generated 
using Panc-1 cells transfected with Lipofectamine 2000 per manufacturer's directions (Invitrogen). Knockdown cell lines were created with HPAF-II transfected with MUC13 specific shRNA lentiviral particles per manufacturer's instructions (Sigma).

\section{PCR}

Cells were collected and RNA was isolated using TRIzol reagent. Reverse transcription was then conducted using High-Capacity cDNA reverse transcriptase kit (ThermoFisher) according to manufacturer's protocol. After collecting cDNA, it was amplified using MUC13 and GAPDH-specific primers. Quantitative real-time PCR was done using SYBR Green Master Mix on a Roche LightCycler.

\section{AFM Imaging and Nanoindentation}

Cells were seeded in $60 \mathrm{~mm}$ dishes (Sarstedt, Model No. 83.3901, Numbrecht, Germany) and grown to $75 \%$ confluency. The cells were then gently washed with Phosphate Buffered Saline (PBS, 1X, pH 7.4) three times and fresh media was added. Cells were taken to the AFM (BioScope Resolve, Bruker; Billerica,MA,USA) and placed on a heated stage $\left(37^{\circ} \mathrm{C}\right)$ and allowed to equilibrate for $10-15$ minutes. During this time, the probe (PFQNM-LC, Bruker) was calibrated via thermal tune. These probes are custom-made for live cell applications and have pre-calibrated spring constants, allowing for a simple, one-step calibration. Once calibrated, the probe was brought into contact with a cell and a ramp test was run to confirm proper contact. A force volume scan was then conducted over a small group of cells $(128 * 128$ resolution, $15 \mathrm{~Hz}$ scan rate, $400 \mathrm{pN}$ force setpoint, $4 \mu \mathrm{m}$ ramp size) and repeated on several groups. All data was collected within a two-hour window for each plate. Force data was then analyzed in two separate ways: firstly, over the whole cell using at least $75 \%$ of the surface of each cell, and then a regional analysis was conducted, taking equally sized $25 \mu \mathrm{m}^{2}$ regions randomly selected at the nuclear, cytoplasmic, and peripheral regions. The data was averaged for each group from multiple cells in each group using NanoScope Analysis software (Bruker). These experiments were repeated in triplicate.

\section{Aggregation Assays}

To determine the effect of MUC13 on cell-to-cell adhesion, aggregation assays were conducted. The original protocol can be found in one of our lab's previous publications. ${ }^{18}$ The protocol was slightly modified for use in these experiments: briefly, 20,000 cells were suspended in a small bead of media $(\sim 25 \mu \mathrm{L})$ which was deposited onto the lid of a petri dish. The base of the petri dish was filled with PBS to prevent

evaporation. The lid was then placed on the dish and incubated overnight at $37^{\circ} \mathrm{C}$. The next day the lid was inverted, and the bead was gently pipetted to disperse any larger aggregates. Photos were then promptly taken using optical microscopes (20x images 
taken on EVOS® FLoid Cell Imaging System, Cat. No. 447136; ThermoFisher, Waltham, MA, USA).

\section{Statistical Analysis}

Analyses were conducted using unpaired, two-tailed Student's T-tests to assess the differences between relevant groups in the various experiments. All error bars used in the attached figures indicate the standard error of mean (SEM). The number of stars used on each graph relates to the level of significance - i.e., one star $\left(^{*}\right)$ indicates P-values below 0.05 , two stars $(* *)$ values below 0.01 , three stars $(* * *)$ for values below 0.001 , and items with four stars $(* * * *)$ indicate all P-values below 0.0001 .

\section{Results}

MUC13 modulated cells were generated using the protocols outlined in the Methods section. Using PCR analysis, altered MUC13 expression was confirmed in these cell lines. Of the cell lines analyzed in Chapter 2, HPAF-II was chosen for the knockout model as our lab has previously shown it has extensive MUC13 expression, while Panc-1 has shown minimal to no MUC13 expression, making it an ideal candidate for an overexpression model. ${ }^{20}$

Overexpression of MUC13 in Panc-1 cells (Figure 4-1) gave results that theoretically agreed with the expected trends in literature, specifically that genetic changes that cause enhanced invasive or migratory potential reduce the cellular modulus. ${ }^{97,157}$ Panc-1 MUC13 OE cells were significantly softer than their vector counterparts. Overall, there was no significant change in membrane adhesion.

A set of HPAF-II cells with MUC13 knockdown (Figure 4-2) showed the opposite effect, i.e., an overall significant increase in was noted in the modulus as well as a highly significant increase in membrane adhesiveness.

As discussed in the Methods section and shown in Figure 2-2, the MUC13 modulated cells were analyzed in an overall method (as seen in Figures 4-1 and 4-2) as well as a regional method, where data was collected in equally sized regions at the nuclear, cytoplasmic and peripheral regions. When looking at the regional data for Panc-1 MUC13 overexpressing cells, a significant reduction in the modulus was noted in the nuclear and cytoplasmic regions, and a significant reduction was noted in adhesion but only at the nuclear region. For HPAF-II MUC13 knockout cells, the modulus was found to be significantly increased at the cytoplasmic and peripheral regions, and the cell has significantly higher membrane adhesion at all regions of the cell (Figure 4-3). The data in Figures 4-1 through 4-3 shows that the trend between the overall and regional analyses are similar. 

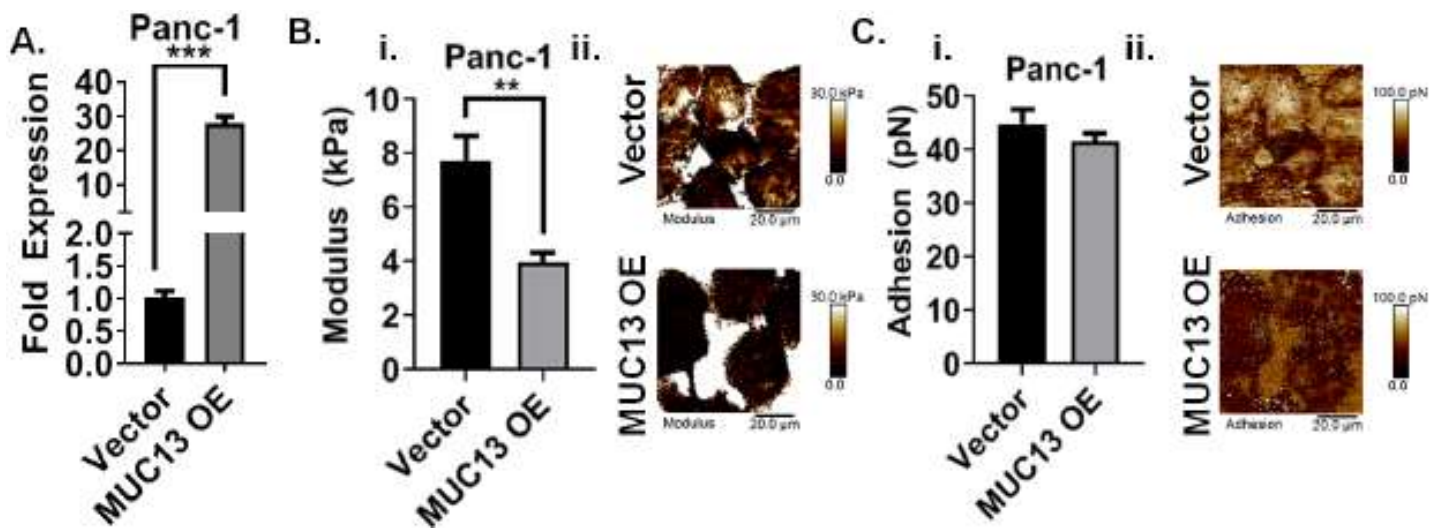

Figure 4-1. Effect of MUC13 overexpression on PanCa biophysical properties.

(A) PCR data showing increased mRNA with MUC13 overexpressed cells. (B) Effect of MUC13 overexpression on modified Panc-1 cell rigidity (i). Representative force maps show changes in modulus across the surface of the cell (ii). (C) Effect of MUC13 overexpression on modified Panc-1 adhesiveness (i). Representative force maps show changes in adhesion across the surface of the cell (ii).

A.

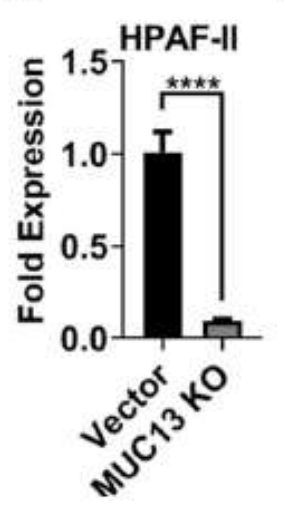

B. i.

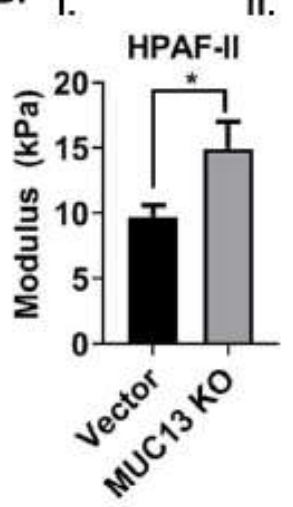

c. i.

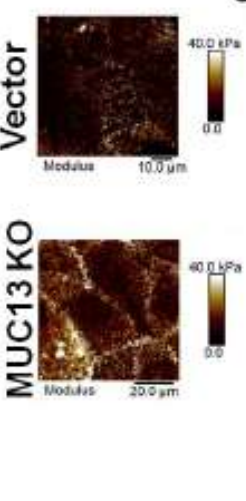

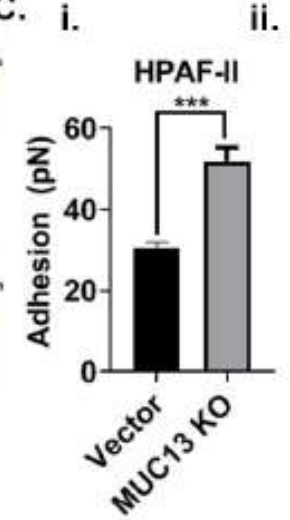

ii.
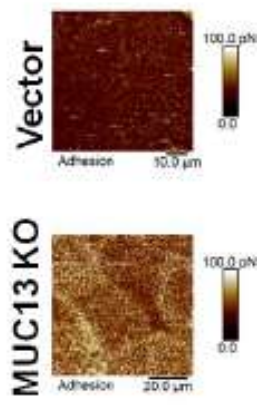

Figure 4-2. Effect of MUC13 knockdown on PanCa biophysical properties.

(A) PCR results showing reduced mRNA levels with MUC13 knockdown. (B) Effect of MUC13 knockdown on rigidity of modified HPAF-II cells (i). Representative force maps showing changes in rigidity across the surface of the cell (ii). (C) Effect of MUC13 knockdown on adhesion of modified HPAF-II cells (i). Representative force maps showing the changes in adhesion across the surface of the cell (ii). 
A.
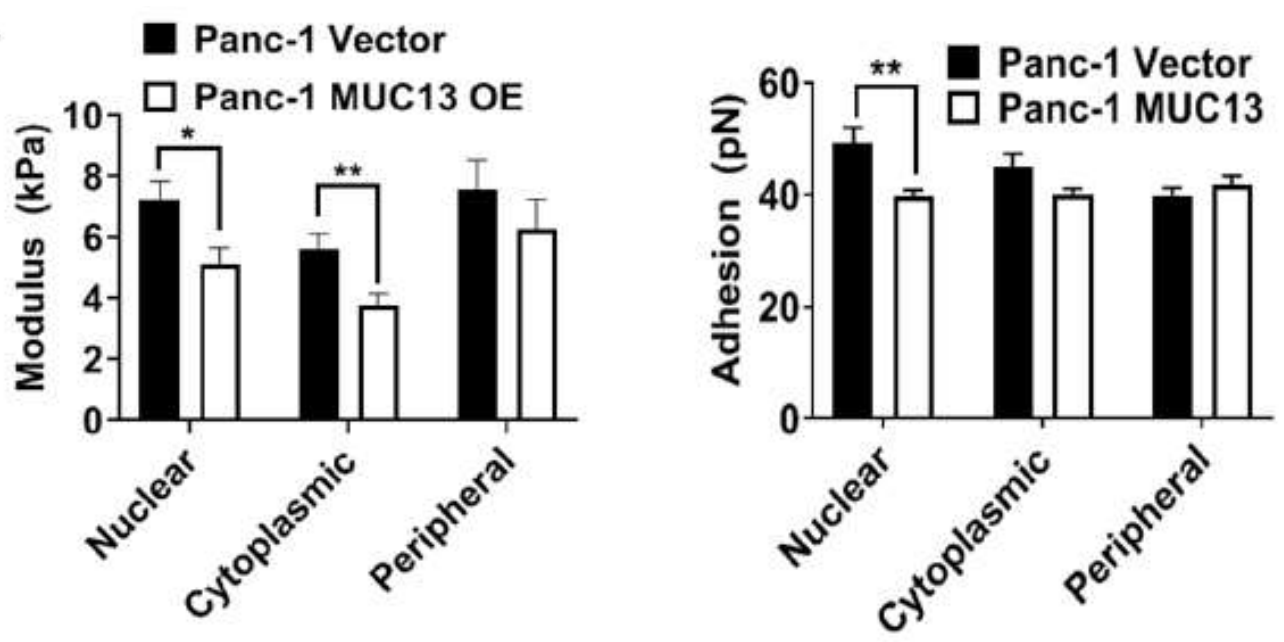

B.
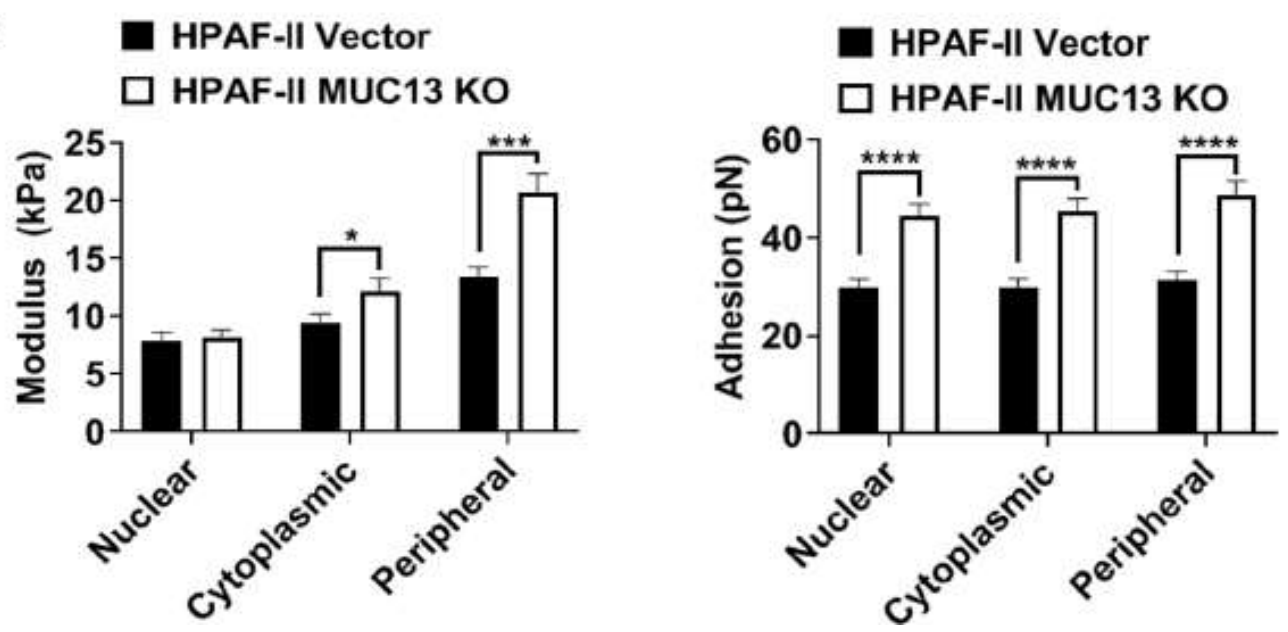

Figure 4-3. Regional nanocmechanical analysis of MUC13-modulated PanCa cells.

(A) Regional nanoindentation data for Panc-1 MUC13 overexpressed cells showing localized changes at the nuclear, cytoplasmic, and peripheral regions of the cell surface. (B) ) Regional nanoindentation data for HPAF-II MUC13 knockdown cells showing localized changes at the nuclear, cytoplasmic, and peripheral regions of the cell surface. 
Aggregation assays were conducted on these cell lines to determine the effect of MUC13 on cell-to-cell cohesion. The results of these tests indicate that MUC13 plays a potent role in affecting this intercellular adhesion (Figure 4-4). It was shown that Panc-1 cells with overexpressed MUC13 were only loosely grouped to one another, while the vector control consistently stayed in tight clusters. HPAF-II vector cells did show some inherent adhesiveness; however, it was observed to be in loosely connected clumps with several detaching cells. With MUC13 knockdown, there appeared to be a greater interconnectivity between the cells, and a clear sheet-like layer of cells was observed.

\section{Discussion}

Multiple previous studies have shown that cancer cells have a reduced modulus when compared to their normal and noncancerous counterparts. ${ }^{43,78,109}$ In addition, factors that enhance oncogenic phenotypes have also led to reductions in cancer cell rigidity. ${ }^{74,75,97}$ It is thought that these changes are in part due to changes in the cytoskeleton of the cell. ${ }^{73,76}$ Due to this, several studies have been conducted investigating the biophysical differences in cancerous and normal tissue as a means of rapid identification and diagnosis of cancer. ${ }^{78,108,158}$

Although various studies have been published detailing the biophysical effects of various genetic alterations or treatment with various compounds in both $\mathrm{PanCa}^{97,148,159}$ and other gastrointestinal cancers such as $\mathrm{CRC}^{160}$, there has been no study to date investigating the biophysical effect of MUC13 expression in these cancers. Based on the nanoindentation and additional supporting data discussed in this section, we can conclude that differential MUC13 expression has significant biophysical effects on PanCa cells.

When observing the effect of MUC13 on the biophysical properties in these cells, PanCa cells gave the initially anticipated result. MUC13 overexpression led to a significant reduction in the cell modulus (Figure 4-1), which is expected for changes leading to an increased oncogenicity. HPAF-II cells also showed the anticipated effect with MUC13 knockdown in the form of significant increases in both modulus and adhesion (Figure 4-2).

Similar results were also seen in other gastrointestinal cancers. Specifically, recent results published our lab have shown that, in a similar manner to PanCa cells, overexpression and knockdown of MUC13 cells in colorectal cancer leads to either an increase or decrease in various motility-based assays, respectively. ${ }^{19}$ Curiously, nanoindentation on these cells indicated an opposite trend than what was seen in PanCa cells - namely, with overexpression of MUC13 in SW480 cells, an increased modulus was noted, but with knockdown in SW620 cells, a reduction was seen. The trends seen in CRC are the opposite of the expected result of this study. Although the effects on cellular motility were the same, this difference in biophysical changes seems to indicate that the manner in which MUC13 affects cancer cells is tissue specific. Furthermore, similar adhesion results were seen in aggregation assays conducted with these CRC modulated cells. Notably, SW480 MUC13 overexpressing cells had a lower overall aggregation 
A.

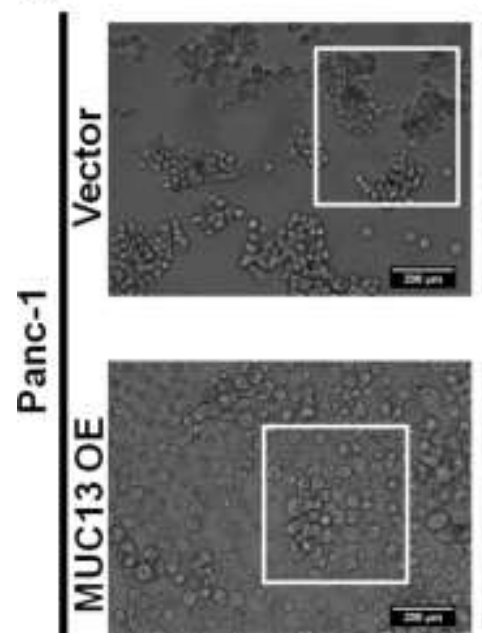

B.
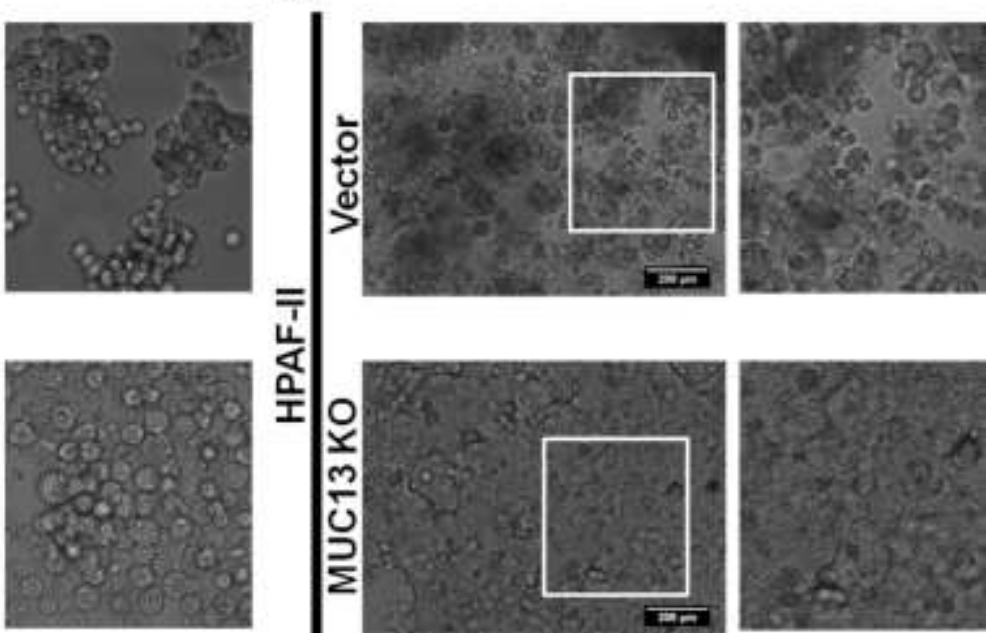

Figure 4-4. Effect of MUC13 modulation on cellular aggregation.

(A) Panc-1 cells show decreased cell-cell adhesion with MUC13 overexpression. (B) HPAF-II cells show increased cell-cell adhesion with MUC13 knockdown. Cells were imaged at 20x magnification. Representative groups of cells are highlighted with white squares and magnified images are detailed on the right of each image to show detailed effect of MUC13 on cellular aggregation. 
compared to the vector cell line, whereas SW620 cells had more association with MUC13 knockdown (Appendix B. Figures B-1 through B-3).

Of note, there is a considerable change in the base rigidity of Panc-1 and HPAF-II after transfection has occurred. Specifically, the average rigidity of Panc-1 raised from approximately $2 \mathrm{kPa}$ to nearly $8 \mathrm{kPa}$ after transfection with the vector plasmids. In addition, HPAF-II dropped from around $14 \mathrm{kPa}$ to approximately $10 \mathrm{kPa}$. It is unclear as to the exact mechanism behind this biophysical change; however, we speculate that the effects of stable transfection and antibiotic selection have caused considerable change in the cell which led to significant physical changes as well. Of note, at least one study has shown that transient transfection with siRNA led to minimal changes in biophysical properties ${ }^{97}$, however this may be due to a lack of antibiotic selection pressure on the cells. (Figure B-4)

As mentioned previously, the trends in the overall and regional analyses are similar. Regional data examining the nuclear, cytoplasmic, and peripheral regions individually may provide a clearer insight into some of the effects of MUC13 modulation on cancer cell phenotypes, especially when looking at changes at the periphery of the cell. Changes at this region may be more closely related to changes in the motility and adhesive properties in a two-dimensional culture, but all regions of the cell should need to be considered for three-dimensional effects, as evident by alterations in aggregation.

MUC13 seems to directly impede the ability of cells to aggregate with one another in vitro. This may be in part to its ability to impede with the association of cadherins between cells, impacting cell to cell adhesion and facilitating the dissociation and invasion of cancer cells from the primary tumor. Similar results previously published from our lab indicated a similar effect on MUC13 modified ovarian cancer cells; specifically, a reduced aggregation was seen with MUC13 overexpression as compared to the vector. ${ }^{18}$ In addition, our lab has previously published data indicating an interaction between MUC13 and HER2 in PanCa cells, leading to an upregulation of its downstream pro-oncogenic pathways. This in turn is implicated in affecting various facets of oncogenicity, including disruption of integrins at the cell membrane, which can lead to a reduced interaction with the extracellular matrix. ${ }^{161}$

Furthermore, previous studies have shown an interaction between MUC13 and HER2 in PanCa cells. This is of note as HER2 is thought to be activated by MUC13, and in turn reduce the function of E-cadherin which would lower cell-cell adhesion. ${ }^{18,20,161}$ This may partially explain why cells with overexpressed MUC13 have been shown to have enhanced motility, as removing E-cadherin from the surface of the cell frees $\beta$ catenin, which could then act as a transcription factor to propagate the EMT cycle. ${ }^{93}$

As shown from previously published data from our lab, knockdown of MUC13 in HPAF-II cells is associated with a reduction in clonogenic, invasive, migratory, and proliferative phenotypes. This supports the notion of reduced aggressiveness with an increased cellular modulus noted in MUC13 KO cells compared to their vector. By contrast, the overexpression of MUC13 in Panc-1 has the opposite effect, leading to an 
increase in proliferation and clonogenic potential ${ }^{20}$ - this helps to support the notion that MUC13 increases cancer cell aggressiveness and leads to a reduction in cellular rigidity. Recently, our lab showed that in PanCa cells, MUC13 was associated with an increased glucose uptake and metabolism via stabilizing the Glut-1 protein, allowing cancer cells to utilize more glucose for various functions. ${ }^{162}$

Clinically, MUC13 has been shown to be associated with a poorer prognosis in PanCa. This was shown in recent research by Khan et al, where tissue samples showed a positive correlation between later stage disease and increased MUC13 expression. In addition, MUC13 was more pronounced in cancerous tissue compared to normal adjacent, and especially concentrated in higher stage (Stage III-IV) or metastatic tissue as demonstrated in one of our lab's previous reports. ${ }^{31}$ This effect does not appear to be limited to gastrointestinal cancers - as shown in our lab's previous work on ovarian cancer, MUC13 expression led to significant changes in cellular motility. ${ }^{18} \mathrm{We}$ can therefore hypothesize that based on the results from this study, a significant biophysical effect would occur, but studies would need to be run to see how MUC13 affects ovarian cancer cells.

Our results indicate the potential of AFM-based nanoindentation for use as a clinical tool for cancer assessment. Using only the physical changes observed in tumor samples, it may one day be possible for pathologists to determine the course of a disease state by measuring physical changes over time and using these changes as prognostic indicators of disease progression.

Overall, MUC13 seems to impart significant biophysical changes associated with a promotion of increased metastatic potential. In this paper, we assessed the biophysical effects of MUC13 modulation on PanCa cells. These cells were first scanned in their native configuration to determine their baseline physical characteristics. With MUC13 modulation, significant changes were seen in the biophysical parameters for PanCa cells (modulus and adhesion) which correlated with previous phenotypic data produced from our lab. When taken together, these data help to show that MUC13 leads to an increased metastatic potential, which in turn softens the cell leading to an increase in its overall motility and reduction in cell-cell adhesion. 


\section{CHAPTER 5. CONCLUSIONS AND FUTURE RESEARCH}

Pancreatic cancer remains one of the deadliest cancers with dismal prognosis rates. Early detection of this disease may be one of the keys to improving these survival rates. As discussed in this report, I investigated the use of biophysical analysis as a method of describing different effects on a panel of pancreatic cancer cells. Overall, I found that the biophysical changes seen in PDAC cells positively correlate with phenotypic expressions, namely changes in cell aggregation. This can potentially give insights into various biochemical pathways, such as effects on cell stemness, differentiation, EMT, and various other pro-oncogenic systems. A brief summary of the findings of this report are highlighted in Figure 5-1.

In Chapter 2, we examined a panel of cells in their native configuration including HPNE as a reference for normal, non-cancerous pancreatic epithelia. The results of this study clearly showed that the normal cell line (HPNE) had a significantly higher modulus as compared to all other cancerous cells, and a clear delineation of rigidity and adhesion between various stages of differentiation. The same trend was observed for membrane adhesion, but to a lesser extent. More poorly differentiated cells were found to have the lowest overall rigidity, and generally lower adhesion. This adhesion trend was confirmed with aggregation results, indicating that nanoindentation results can give an indication to a cell's biophysical state.

The results shown in Chapter 2 give perhaps the most promising potential use for the AFM in a clinical sense for PDAC - we hope that these results may one day lead to the use of biophysical analysis as a facile, alternative assay to staging, diagnosing, or determining a prognosis for patients with PDAC. Although there are multiple methods that can be considered for diagnosis or early detection, most of these methods rely on biochemical means, which can be time-consuming and delay critical diagnostic decisions. For this biophysical analysis to be conducted, we anticipate that physicians would first extract patient tumor samples, as well as adjacent normal tissue for comparison. These could then be rapidly attached to a substrate such as a glass slide and measured on an AFM shortly after surgical extraction to measure physical parameters of the tissue. These same sections could then be analyzed biochemically for various markers to confirm the results of the nanoindentation studies. We propose that in this way, the AFM can provide a more rapid tool to potentially acquire clinical information about a patient's disease state based only on physical parameters in the sample.

In Chapter 3, we investigated the effect of several chemotherapeutic agents (GEM, PTX, and CUR) and their biophysical effects on PDAC cells. Interestingly, the relatively novel agent CUR was shown to have the greatest overall effect, and GEM had the lowest. Poorly differentiated cells were seen to have significantly larger biophysical changes as compared to the more well differentiated cell lines. These results help to indicate how effective different chemotherapeutics are on differing types of PDAC cell lines, but our long-term goal is to examine these effects at the tissue level. We anticipate 


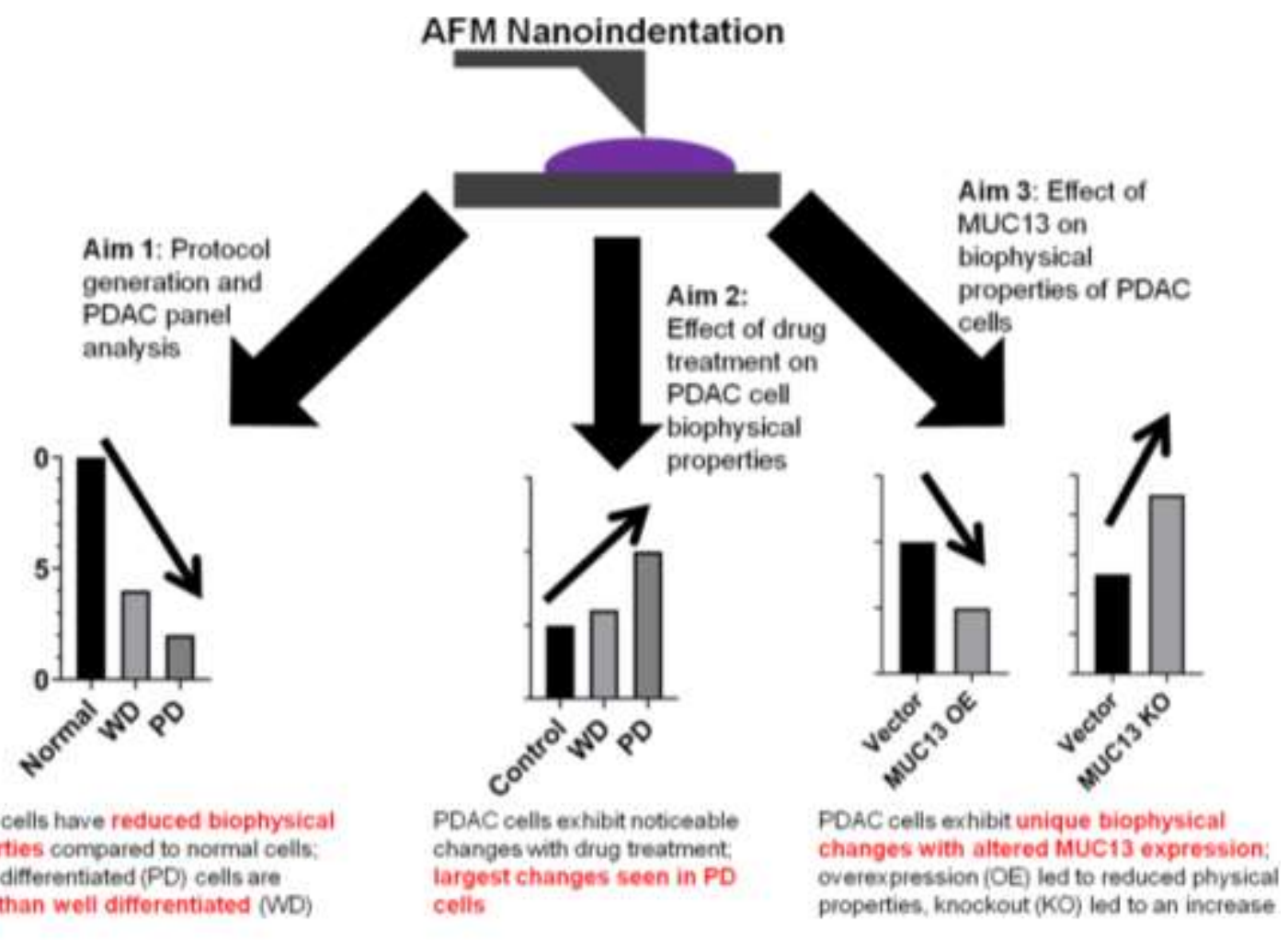

Figure 5-1. Summary of key findings in this study. 
using similar techniques on patient-derived tissue sections in the future, and based on the intensity of the biophysical change in tissues or cells after treatment we predict that pathologists could more rapidly determine the therapeutic efficacy or even drug resistance of a tumor to more rapidly determine a prognosis or it altered therapy is required for a patient.

In addition, it should be noted that not all drugs cause an increase in the modulus of a cell. Although the three drugs in this study tended to do so, particularly in the more poorly differentiated cell lines, there are other agents that have caused significant reductions in a cellular modulus. One notable example is outlined in the Appendices: VERU-111, a novel tubulin inhibitor.

In Chapter 4, MUC13 modulated cells were generated and analyzed using various biophysical studies. It was found that MUC13 overexpression in Panc-1 cells led to a decrease in both the modulus and adhesion of the cells, and that knockdown in HPAF-II cells led to the opposite effect, indicating that MUC13 has a significant biophysical impact on cancer cells. This leads to the observation that MUC13 is associated with biophysical changes involved in a promotion of increased metastatic potential. A positive correlation was noted between membrane adhesion data as measured with the AFM studies and a series of aggregation assays, indicating the ability of the AFM to predict phenotypic characteristics of the cells with genetic modification. In a similar manner to what was discussed about the results with therapeutic treatment, it is conceivable that many other genetic alterations will lead to physical differences. Again, based on the intensity of this change it may be possible to determine the overall prognosis or staging of the disease.

Overall, our data indicate that biophysical parameters as measured by atomic force microscopy can detect the effects of various changes in PDAC cells in vitro. Using this knowledge, it is our long term goal that this knowledge be used in patient derived tissue samples, as a facile method of determining cancer grades, therapeutic efficacy, and potentially even prognosis of the disease state, comparing cancerous tissue to its normal counterpart or treated tissue over a particular timeframe. We believe that in the proper setting, this can give a rapid and straightforward analysis to pathologists to more quickly determine the disease course without having to rely completely on immunohistochemistry or other biochemical tests.

Such physical changes can potentially be useful to determine various oncogenic processes, including EMT, metastasis, or maybe even determining how susceptible or resistant a tumor is to a given therapy. Our data help to prove the predictive power of biophysical analyses in measuring the effect of various modifications to the cell. 


\section{LIST OF REFERENCES}

1. Hanahan D, Weinberg RA. Hallmarks of cancer: the next generation. Cell. 2011;144(5):646-674. doi:10.1016/j.cell.2011.02.013.

2. Fouad YA, Aanei C. Revisiting the hallmarks of cancer. Am J Cancer Res. 2017;7(5):1016-1036. https://www.ncbi.nlm.nih.gov/pubmed/28560055.

3. Coussens LM, Werb Z. Inflammation and cancer. Nature. 2002;420(6917):860867. doi:10.1038/nature01322.

4. Hlatky L, Hahnfeldt P. Beyond the Cancer Cell: Progression-Level Determinants Highlight the Multiscale Nature of Carcinogenesis Risk. Cancer Res. 2014;74(3):659-664. doi:10.1158/0008-5472.CAN-13-2508.

5. Heron M. Deaths: Leading Causes for 2016. Natl Vital Stat Rep. 2018;67(6):1-77. http://www.ncbi.nlm.nih.gov/pubmed/30248017.

6. Siegel RL, Miller KD, Jemal A. Cancer statistics, 2018. CA Cancer J Clin. 2018;68(1):7-30. doi: 10.3322/caac.21442.

7. Siegel RL, Miller KD, Jemal A. Cancer statistics, 2019. CA Cancer J Clin. 2019;69(1):7-34. doi: 10.3322/caac.21551.

8. Shih HP, Wang A, Sander M. Pancreas organogenesis: from lineage determination to morphogenesis. Anпu Rev Cell Dev Biol. 2013;29:81-105. doi:

10.1146/annurev-cellbio-101512-122405.

9. Rawla P, Sunkara T, Gaduputi V. Epidemiology of Pancreatic Cancer: Global Trends, Etiology and Risk Factors. World J Oncol. 2019;10(1):10-27. doi:10.14740/wjon 1166 .

10. Cavanna L, Stroppa EM, Citterio C, et al. Modified FOLFIRINOX for unresectable locally advanced/metastatic pancreatic cancer. A real-world comparison of an attenuated with a full dose in a single center experience. Onco Targets Ther. 2019;12:3077-3085. doi: 10.2147/OTT.S200754..

11. Siegel R, Naishadham D, Jemal A. Cancer statistics, 2013. CA Cancer J Clin. 2013;63(1):11-30. doi:10.3322/caac.21166.

12. Noone AM, Howlader N, Krapcho M et al. SEER Cancer Statistics Review, 19752015. National Cancer Institute. https://seer.cancer.gov/archive/csr/1975_2015/. Published 2018.

13. Sclafani F, Iyer R, Cunningham D, Starling N. Management of metastatic pancreatic cancer: Current treatment options and potential new therapeutic targets. Crit Rev Oncol Hematol. 2015;95(3):318-336. doi: 10.1016/j.critrevonc.2015.03.008.

14. Stathis A, Moore MJ. Advanced pancreatic carcinoma: Current treatment and future challenges. Nat Rev Clin Oncol. 2010;7(3):163-172. doi: 10.1038/nrclinonc.2009.236.

15. Zhang L, Sanagapalli S, Stoita A. Challenges in diagnosis of pancreatic cancer. World J Gastroenterol. 2018;24(19):2047-2060. doi: 10.3748/wjg.v24.i19.2047.

16. Keane MG, Horsfall L, Rait G, Pereira SP. A case-control study comparing the incidence of early symptoms in pancreatic and biliary tract cancer. BMJ Open. 2014;4(11):e005720. doi: 10.1136/bmjopen-2014-005720. 
17. Freelove R, Walling AD. Pancreatic cancer: diagnosis and management. Am Fam Physician. 2006;73(3):485-492. http://www.ncbi.nlm.nih.gov/pubmed/16477897.

18. Chauhan SC, Vannatta K, Ebeling MC, et al. Expression and functions of transmembrane mucin MUC13 in ovarian cancer. Cancer Res. 2009;69(3):765774. doi: 10.1158/0008-5472.CAN-08-0587.

19. Gupta BK, Maher DM, Ebeling MC, et al. Functions and regulation of MUC13 mucin in colon cancer cells. J Gastroenterol. 2014;49(10):1378-1391. doi: 10.1007/s00535-013-0885-Z.

20. Chauhan SC, Ebeling MC, Maher DM, et al. MUC13 mucin augments pancreatic tumorigenesis. Mol Cancer Ther. 2012;11(1):24-33. doi: 10.1158/15357163.MCT-11-0598.

21. van Putten JPM, Strijbis K. Transmembrane Mucins: Signaling Receptors at the Intersection of Inflammation and Cancer. J Innate Immun. 2017;9(3):281-299. doi: $\underline{10.1159 / 000453594}$.

22. Kufe DW. Mucins in cancer: function, prognosis and therapy. Nat Rev Cancer. 2009;9(12):874-885. doi: 10.1038/nrc2761.

23. Suh H, Pillai K, Morris DL. Mucins in pancreatic cancer: biological role, implications in carcinogenesis and applications in diagnosis and therapy. Am J Cancer Res. 2017;7(6):1372-1383. http://www.ncbi.nlm.nih.gov/pubmed/28670497.

24. Lakshmanan I, Ponnusamy MP, Macha MA, et al. Mucins in lung cancer: Diagnostic, prognostic, and therapeutic implications. J Thorac Oncol. 2015;10(1):19-27. doi: 10.1097/JTO.0000000000000404.

25. Burchell JM, Beatson R, Graham R, Taylor-Papadimitriou J, Tajadura-Ortega V. O-linked mucin-type glycosylation in breast cancer. Biochem Soc Trans. 2018;46(4):779-788. doi: 10.1042/bst20170483.

26. Kohli M, Shivam AK, Ahuja P, Dutta J. Mucin-4: A novel marker for oral cancer. J Oral Maxillofac Pathol. 23(1):49-53. doi: 10.4103/jomfp.JOMFP 17516.

27. Maher DM, Gupta BK, Nagata S, Jaggi M, Chauhan SC. Mucin 13: structure, function, and potential roles in cancer pathogenesis. Mol Cancer Res. 2011;9(5):531-537. doi: 10.1158/1541-7786.MCR-10-0443.

28. Williams SJ, Wreschner DH, Tran M, Eyre HJ, Sutherland GR, McGuckin MA. MUC13, a Novel Human Cell Surface Mucin Expressed by Epithelial and Hemopoietic Cells. J Biol Chem. 2001;276(21):18327-18336. doi: 10.1074/jbc.M008850200.

29. Filippou PS, Ren AH, Korbakis D, et al. Exploring the potential of mucin 13 (MUC13) as a biomarker for carcinomas and other diseases. Clin Chem Lab Med. May 2018. doi:10.1515/cclm-2018-0139.

30. Sheng Y, Ng CP, Lourie R, et al. MUC13 overexpression in renal cell carcinoma plays a central role in tumor progression and drug resistance. Int J cancer. 2017;140(10):2351-2363. doi:10.1002/ijc.30651.

31. Khan S, Zafar N, Khan SS, et al. Clinical significance of MUC13 in pancreatic ductal adenocarcinoma. Hpb. 2018;20(6):563-572. doi: 10.1016/j.hpb.2017.12.003.

32. Rachagani S, Torres MP, Moniaux N, Batra SK. Current status of mucins in the diagnosis and therapy of cancer. Biofactors. 35(6):509-527. doi:10.1002/biof.64. 
33. Andrianifahanana M, Moniaux N, Batra SK. Regulation of mucin expression: Mechanistic aspects and implications for cancer and inflammatory diseases. Biochim Biophys Acta - Rev Cancer. 2006;1765(2):189-222. doi:10.1016/j.bbcan.2006.01.002.

34. Rao C V., Janakiram NB, Mohammed A. Molecular pathways: Mucins and drug delivery in cancer. Clin Cancer Res. 2017;23(6):1373-1378. doi: 10.1158/10780432.CCR-16-0862.

35. Gavara N. A beginner's guide to atomic force microscopy probing for cell mechanics. Microsc Res Tech. 2017;80(1):75-84. doi: 10.1002/jemt.22776.

36. Binnig G, Quate CF. Atomic Force Microscope. Phys Rev Lett. 1986;56(9):930933. doi: 10.1103/PhysRevLett.56.930.

37. Piontek MC, Roos WH. Atomic Force Microscopy: An Introduction. Methods Mol Biol. 2018;1665:243-258. doi: 10.1007/978-1-4939-7271-5_13.

38. Zhong Q, Inniss D, Kjoller K, Elings VB. Fractured polymer/silica fiber surface studied by tapping mode atomic force microscopy. Surf Sci Lett. 1993;290(12):L688-L692. doi: 10.1016/0039-6028(93)90582-5.

39. Allison DP, Mortensen NP, Sullivan CJ, Doktycz MJ. Atomic force microscopy of biological samples. Wiley Interdiscip Rev Nanomedicine Nanobiotechnology. 2010;2(6):618-634. doi: 10.1002/wnan.104.

40. Jarvis SP. Resolving intra- and inter-molecular structure with non-contact atomic force microscopy. Int J Mol Sci. 2015;16(8):19936-19959. doi: 10.3390/ijms160819936.

41. de Oteyza DG, Gorman P, Chen Y-C, et al. Direct Imaging of Covalent Bond Structure in Single-Molecule Chemical Reactions. Science (80- ). 2013;340(6139):1434-1437. doi: 10.1126/science.1238187.

42. Putman CA, van der Werf KO, de Grooth BG, van Hulst NF, Greve J. Viscoelasticity of living cells allows high resolution imaging by tapping mode atomic force microscopy. Biophys J. 1994;67(4):1749-1753. doi: 10.1016/S00063495(94)80649-6.

43. Stylianou A, Kontomaris SV, Grant C, Alexandratou E. Atomic force microscopy on biological materials related to pathological conditions. Scanning. 2019;2019. doi: $10.1155 / 2019 / 8452851$.

44. Li M, Xiao X, Liu L, Xi N, Wang Y. Rapid recognition and functional analysis of membrane proteins on human cancer cells using atomic force microscopy. $J$ Immunol Methods. 2016;436:41-49. doi: 10.1016/j.jim.2016.06.006.

45. Li M, Dang D, Liu L, Xi N, Wang Y. Imaging and Force Recognition of Single Molecular Behaviors Using Atomic Force Microscopy. Sensors (Basel). 2017;17(1):1-20. doi: 10.3390/s17010200.

46. Schillers H, Medalsy I, Hu S, Slade AL, Shaw JE. PeakForce Tapping resolves individual microvilli on living cells. J Mol Recognit. 2016;29(2):95-101. doi: $10.1002 / \mathrm{jmr} .2510$.

47. Kroeger ME, Sorenson BA, Thomas JS, Stojković EA, Tsonchev S, Nicholson $\mathrm{KT}$. Atomic force microscopy of red-light photoreceptors using peakforce quantitative nanomechanical property mapping. J Vis Exp. 2014;(92):e52164. doi: $\underline{10.3791 / 52164 .}$. 
48. Kaemmar SB. Introduction to Bruker's ScanAsyst and PeakForce Tapping AFM Technology. Appl note. 2011;133(Rev. A0):12.

https://www.bruker.com/products/surface-and-dimensional-analysis/atomic-forcemicroscopes/afm-application-notes/an133-introduction-to-brukers-scanasyst-andpeakforce-tapping.html

49. Alexander J, Belikov S, Magonov S. AFM-Based Characterization of Electrical Properties of Materials. Methods Mol Biol. 2018;1814:99-127. doi: 10.1007/978-14939-8591-3_7.

50. Marlière $\mathrm{C}$, Dhahri S. An in vivo study of electrical charge distribution on the bacterial cell wall by atomic force microscopy in vibrating force mode. Nanoscale. 2015;7(19):8843-8857. doi: 10.1039/c5nr00968e.

51. Price DM, Reading M, Hammiche A, Pollock HM. Micro-thermal analysis: Scanning thermal microscopy and localised thermal analysis. Int J Pharm. 1999;192(1):85-96. doi: 10.1016/S0378-5173(99)00275-6.

52. Pereira MJ, Amaral JS, Silva NJO, Amaral VS. Nano-Localized Thermal Analysis and Mapping of Surface and Sub-Surface Thermal Properties Using Scanning Thermal Microscopy (SThM). Microsc Microanal. 2016;22(6):1270-1280. doi: 10.1017/S1431927616011867.

53. Chen J, Sun Y, Zhong L, et al. Scalable Fabrication of Multiplexed Plasmonic Nanoparticle Structures Based on AFM Lithography. Small. 2016;12(42):58185825. doi: 10.1002/smll.201602250.

54. Wu CC, Reinhoudt DN, Otto C, Subramaniam V, Velders AH. Strategies for patterning biomolecules with dip-pen nanolithography. Small. 2011;7(8):9891002. doi: $10.1002 / \mathrm{smll} .201001749$.

55. Ikai A, Afrin R, Saito M, Watanabe-Nakayama T. Atomic force microscope as a nano- and micrometer scale biological manipulator: A short review. Semin Cell Dev Biol. 2018;73:132-144. doi: 10.1016/j.semcdb.2017.07.031.

56. Zhang Y, Hu X, Sun J, et al. High-resolution imaging and nano-manipulation of biological structures on surface. Microsc Res Tech. 2011;74(7):614-626. doi: 10.1002/jemt.20925.

57. Riener CK, Stroh CM, Ebner A, et al. Simple test system for single molecule recognition force microscopy. Anal Chim Acta. 2003;479(1):59-75. doi: 10.1016/S0003-2670(02)01373-9.

58. Barattin R, Voyer N. Chemical modifications of AFM tips for the study of molecular recognition events. Chem Commun. 2008;(13):1513-1532. doi: 10.1039/b614328h.

59. Zemła J, Danilkiewicz J, Orzechowska B, Pabijan J, Seweryn S, Lekka M. Atomic force microscopy as a tool for assessing the cellular elasticity and adhesiveness to identify cancer cells and tissues. Semin Cell Dev Biol. 2018;73:115-124. doi: 10.1016/j.semcdb.2017.06.029.

60. Grobelny J, Pradeep N, Kim DI, Ying ZC. Quantification of the meniscus effect in adhesion force measurements. Appl Phys Lett. 2006;88(9):2005-2007. doi: $\underline{10.1063 / 1.2181200 .}$.

61. Toca-Herrera JL. Atomic Force Microscopy Meets Biophysics, Bioengineering, Chemistry, and Materials Science. ChemSusChem. 2019;12(3):603-611. doi: $\underline{10.1002 / \text { cssc. } 201802383 \text {. }}$ 
62. Butt HJ. Measuring electrostatic, van der Waals, and hydration forces in electrolyte solutions with an atomic force microscope. Biophys $J$. 1991;60(6):1438-1444. doi: 10.1016/S0006-3495(91)82180-4.

63. Butt H-J, Jaschke M. Calculation of thermal noise in atomic force microscopy. Nanotechnology. 1995;6(1):1-7. doi:10.1088/0957-4484/6/1/001.

64. Lévy R, Maaloum M. Measuring the spring constant of atomic force microscope cantilevers: Thermal fluctuations and other methods. Nanotechnology. 2002;13(1):33-37. doi:10.1088/0957-4484/13/1/307.

65. Guckenberger R, Kösslinger C, Gatz R, Breu H, Levai N, Baumeister W. A scanning tunneling microscope (STM) for biological applications: design and performance. Ultramicroscopy. 1988;25(2):111-121. doi: 10.1016/03043991(88)90218-5.

66. Hansma PK, Elings VB, Marti O, Bracker CE. Scanning tunneling microscopy and atomic force microscopy: application to biology and technology. Science. 1988;242(4876):209-216. doi:10.1126/science.3051380.

67. Kim KW. High-resolution imaging of the microbial cell surface. 2016;54(11):703708. doi:10.1007/s12275-016-6348-5.

68. Braet F, De Zanger R, Wisse E. Drying cells for SEM, AFM and TEM by hexamethyldisilazane: a study on hepatic endothelial cells. J Microsc. 1997;186(1):84-87. doi: 10.1046/j.1365-2818.1997.1940755.x.

69. Shibata M, Nishimasu H, Kodera N, et al. Real-space and real-Time dynamics of CRISPR-Cas9 visualized by high-speed atomic force microscopy. Nat Commun. 2017;8(1):1-9. doi: 10.1038/s41467-017-01466-8.

70. Henderson E, Haydon PG, Sakaguchi DS. Actin filament dynamics in living glial cells imaged by atomic force microscopy. Science. 1992;257(5078):1944-1946. doi: $\underline{10.1126 / \text { science. } 1411511 .}$.

71. Radmacher M, Tillamnn RW, Fritz M, Gaub HE. From molecules to cells: imaging soft samples with the atomic force microscope. Science. 1992;257(5078):1900-1905. doi:10.1126/science.1411505.

72. Weisenhorn AL, Khorsandi M, Kasas S, Gotzos V, Butt H-J. Deformation and height anomaly of soft surfaces studied with an AFM. Nanotechnology. 1993;4(2):106-113. doi:10.1088/0957-4484/4/2/006.

73. Yamagishi A, Susaki M, Takano Y, et al. The Structural Function of Nestin in Cell Body Softening is Correlated with Cancer Cell Metastasis. Int J Biol Sci. 2019;15(7):1546-1556. doi: 10.7150/ijbs.33423.

74. $\mathrm{Ku}$ M, Kim HJ, Yau SY, et al. Microsphere-Based Nanoindentation for the Monitoring of Cellular Cortical Stiffness Regulated by MT1-MMP. Small. 2018;14(41):1-10. doi: 10.1002/smll.201803000.

75. Sun J, Luo Q, Liu L, Song G. Low-level shear stress induces differentiation of liver cancer stem cells via the Wnt/ $\beta$-catenin signalling pathway. Exp Cell Res. 2019;375(1):90-96. doi: 10.1016/j.yexcr.2018.12.023.

76. Pei W, Chen J, Wang C, et al. Regional biomechanical imaging of liver cancer cells. J Cancer. 2019;10(19):4481-4487. doi: 10.7150/jca.32985.

77. Cross SE, Jin YS, Rao J, Gimzewski JK. Nanomechanical analysis of cells from cancer patients. Nat Nanotechnol. 2007;2(12):780-783. doi: $\underline{10.1038 / \text { nnano.2007.388. }}$. 
78. Lekka M, Gil D, Pogoda K, et al. Cancer cell detection in tissue sections using AFM. Arch Biochem Biophys. 2012;518(2):151-156. doi:

10.1016/j.abb.2011.12.013.

79. Swaminathan V, Mythreye K, O’Brien ET, Berchuck A, Blobe GC, Superfine R. Mechanical stiffness grades metastatic potential in patient tumor cells and in cancer cell lines. Cancer Res. 2011;71(15):5075-5080. doi: 10.1158/00085472.CAN-11-0247.

80. Cascione M, Leporatti S, Dituri F, Giannelli G. Transforming growth factor- $\beta$ promotes morphomechanical effects involved in epithelial to mesenchymal transition in living hepatocellular carcinoma. Int J Mol Sci. 2019;20(1):7-9. doi: 10.3390/ijms20010108.

81. Holenstein CN, Horvath A, Schär B, et al. The relationship between metastatic potential and in vitro mechanical properties of osteosarcoma cells. Mol Biol Cell. 2019;30(7):887-898. doi: 10.1091/mbc.E18-08-0545.

82. Bobrowska J, Awsiuk K, Pabijan J, et al. Biophysical and Biochemical Characteristics as Complementary Indicators of Melanoma Progression. Anal Chem. 2019;91(15):9885-9892. doi: 10.1021/acs.analchem.9b01542.

83. Nguyen A V, Nyberg KD, Scott MB, et al. Stiffness of pancreatic cancer cells is associated with increased invasive potential. Integr Biol (Camb). 2016;8(12):12321245. doi: 10.1039/c6ib00135a.

84. Kulkarni AH, Chatterjee A, Kondaiah P, Gundiah N. TGF- $\beta$ induces changes in breast cancer cell deformability. Phys Biol. 2018;15(6). doi: $\underline{10.1088 / 1478-}$ 3975/aac3ba.

85. Stylianou A, Gkretsi V, Stylianopoulos T. Transforming growth factor- $\beta$ modulates pancreatic cancer associated fibroblasts cell shape, stiffness and invasion. Biochim Biophys Acta - Gen Subj. 2018;1862(7):1537-1546. doi: 10.1016/j.bbagen.2018.02.009.

86. Rice AJ, Cortes E, Lachowski D, et al. Matrix stiffness induces epithelialmesenchymal transition and promotes chemoresistance in pancreatic cancer cells. Oncogenesis. 2017;6(7). doi: 10.1038/oncsis.2017.54.

87. Wang H-C, Lin Y-L, Hsu C-C, et al. Pancreatic stellate cells activated by mutant KRAS-mediated PAI-1 upregulation foster pancreatic cancer progression via IL-8. Theranostics. 2019;9(24):7168-7183. doi: 10.7150/thno.36830.

88. Robinson BK, Cortes E, Rice AJ, Sarper M, Hernañdez ADR. Quantitative analysis of 3D extracellular matrix remodelling by pancreatic stellate cells. Biol Open. 2016;5(6):875-882. doi: 10.1242/bio.017632.

89. Zhao J, Wang H, Hsiao CH, et al. Simultaneous inhibition of hedgehog signaling and tumor proliferation remodels stroma and enhances pancreatic cancer therapy. Biomaterials. 2018;159:215-228. doi: 10.1016/j.biomaterials.2018.01.014.

90. Cao Y, Hoeppner LH, Bach S, et al. Neuropilin-2 promotes extravasation and metastasis by interacting with endothelial $\alpha 5$ integrin. Cancer Res. 2013;73(14):4579-4590. doi: 10.1158/0008-5472.CAN-13-0529.

91. Egawa N, Maillet B, VanDamme B, De Grève J, Klöppel G. Differentiation of pancreatic carcinoma induced by retinoic acid or sodium butyrate: a morphological and molecular analysis of four cell lines. Virchows Arch. 1996;429(1):59-68. doi:

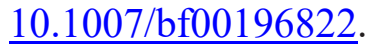


92. Jögi A, Vaapil M, Johansson M, Påhlman S. Cancer cell differentiation heterogeneity and aggressive behavior in solid tumors. Ups J Med Sci. 2012;117(2):217-224. doi: 10.3109/03009734.2012.659294.

93. Conant JL, Peng Z, Evans MF, Naud S, Cooper K. Sarcomatoid renal cell carcinoma is an example of epithelial-mesenchymal transition. J Clin Pathol. 2011;64(12):1088-1092. doi: 10.1136/jclinpath-2011-200216.

94. Hafeez BB, Ganju A, Sikander M, et al. Ormeloxifene suppresses prostate tumor growth and metastatic phenotypes via inhibition of oncogenic $\beta$-catenin signaling and EMT progression. Mol Cancer Ther. 2017;16(10). doi: 10.1158/15357163.MCT-17-0157.

95. Russell R, Perkhofer L, Liebau S, et al. Loss of ATM accelerates pancreatic cancer formation and epithelial-mesenchymal transition. Nat Commun. 2015;6:7677. doi: $10.1038 /$ ncomms 8677.

96. Aiello NM, Maddipati R, Norgard RJ, et al. EMT Subtype Influences Epithelial Plasticity and Mode of Cell Migration. Dev Cell. 2018;45(6):681-695.e4. doi: 10.1016/j.devcel.2018.05.027.

97. Lee Y, Koay EJ, Zhang W, et al. Human equilibrative nucleoside transporter-1 knockdown tunes cellular mechanics through epithelial-mesenchymal transition in pancreatic cancer cells. PLoS One. 2014;9(10). doi:

10.1371/journal.pone.0107973.

98. Nakajima S, Doi R, Toyoda E, et al. N-cadherin expression and epithelialmesenchymal transition in pancreatic carcinoma. Clin Cancer Res. 2004;10(12 I):4125-4133. doi: 10.1158/1078-0432.CCR-0578-03.

99. Adamska A, Elaskalani O, Emmanouilidi A, et al. Molecular and cellular mechanisms of chemoresistance in pancreatic cancer. Adv Biol Regul. 2017;(October):0-1. doi: 10.1016/i.jbior.2017.11.007.

100. Lamouille S, Xu J, Derynck R. Molecular mechanisms of epithelial-mesenchymal transition. Nat Rev Mol Cell Biol. 2014;15(3):178-196. doi: 10.1038/nrm3758.

101. Lee KM, Nguyen C, Ulrich AB, Pour PM, Ouellette MM. Immortalization with telomerase of the Nestin-positive cells of the human pancreas. Biochem Biophys Res Commun. 2003;301(4):1038-1044. doi: 10.1016/S0006-291X(03)00086-X.

102. Deer EL, González-Hernández J, Coursen JD, et al. Phenotype and genotype of pancreatic cancer cell lines. Pancreas. 2010;39(4):425-435. doi: 10.1097/MPA.0b013e3181c15963.

103. Chen WH, Horoszewicz JS, Leong SS, et al. Human pancreatic adenocarcinoma: in vitro and in vivo morphology of a new tumor line established from ascites. In Vitro. 1982;18(1):24-34. doi: 10.1007/BF02796382.

104. Massey AE, Doxtater KA, Yallapu MM, Chauhan SC. Biophysical changes caused by altered MUC13 expression in pancreatic cancer cells. Micron. 2020;130(December 2019):102822. doi:10.1016/i.micron.2019.102822.

105. Haase K, Pelling AE. Investigating cell mechanics with atomic force microscopy. J R Soc Interface. 2015;12(104):20140970. doi: 10.1098/rsif.2014.0970.

106. Shroff SG, Saner DR, Lal R. Dynamic micromechanical properties of cultured rat atrial myocytes measured by atomic force microscopy. Am J Physiol. 1995;269(1 Pt 1):C286-92. doi: 10.1152/ajpcell.1995.269.1.C286. 
107. Nagayama M, Haga H, Takahashi M, Saitoh T, Kawabata K. Contribution of cellular contractility to spatial and temporal variations in cellular stiffness. Exp Cell Res. 2004;300(2):396-405. doi: 10.1016/j.yexcr.2004.07.034.

108. Stylianou A, Lekka M, Stylianopoulos T. AFM assessing of nanomechanical fingerprints for cancer early diagnosis and classification: from single cell to tissue level. Nanoscale. 2018. doi: 10.1039/C8NR06146G.

109. Lekka M. Discrimination Between Normal and Cancerous Cells Using AFM. Bionanoscience. 2016;6(1):65-80. doi: 10.1007/s12668-016-0191-3.

110. Ramos JR, Pabijan J, Garcia R, Lekka M. The softening of human bladder cancer cells happens at an early stage of the malignancy process. Beilstein J Nanotechnol. 2014;5:447-457. doi:10.3762/bjnano.5.52.

111. Abduljauwad SN, Ahmed H ur R. Enhancing cancer cell adhesion with clay nanoparticles for countering metastasis. Sci Rep. 2019;9(1):1-12. doi:10.1038/s41598-019-42498-y.

112. Wang H, Unternaehrer JJ. Epithelial-mesenchymal Transition and Cancer Stem Cells: At the Crossroads of Differentiation and Dedifferentiation. Dev Dyn. 2019;248(1):10-20. doi: 10.1002/dvdy.24678.

113. Karlsson MC, Gonzalez SF, Welin J, Fuxe J. Epithelial-mesenchymal transition in cancer metastasis through the lymphatic system. Mol Oncol. 2017;11(7):781-791. doi: $10.1002 / 1878-0261.12092$.

114. Masuda Y, Inami W, Miyakawa A, Kawata Y. Cell culture on hydrophilicitycontrolled silicon nitride surfaces. World J Microbiol Biotechnol. 2015;31(12):1977-1982. doi: 10.1007/s11274-015-1946-7.

115. Rossi ML, Rehman AA, Gondi CS. Therapeutic options for the management of pancreatic cancer. World J Gastroenterol. 2014;20(32):11142-11159. doi: 10.3748/wig.v20.i32.11142.

116. Von Hoff DD, Ervin T, Arena FP, et al. Increased survival in pancreatic cancer with nab-paclitaxel plus gemcitabine. N Engl J Med. 2013;369(18):1691-1703. doi: 10.1056/NEJMoa1304369.

117. Conroy T, Desseigne F, Ychou M, et al. FOLFIRINOX versus gemcitabine for metastatic pancreatic cancer. $N$ Engl J Med. 2011;364(19):1817-1825. doi: 10.1056/NEJMoa1011923.

118. Kanai M. Therapeutic applications of curcumin for patients with pancreatic cancer. World J Gastroenterol. 2014;20(28):9384-9391. doi:10.3748/wjg.v20.i28.9384.

119. Dhillon N, Aggarwal BB, Newman RA, et al. Phase II trial of curcumin in patients with advanced pancreatic cancer. Clin Cancer Res. 2008;14(14):4491-4499. doi:10.1158/1078-0432.CCR-08-0024.

120. Weaver BA. How Taxol/paclitaxel kills cancer cells. Mol Biol Cell. 2014;25(18):2677-2681. doi: 10.1091/mbc.E14-04-0916.

121. Frese KK, Neesse A, Cook N, et al. Nab-paclitaxel potentiates gemcitabine activity by reducing cytidine deaminase levels in a mouse model of pancreatic cancer. Cancer Discov. 2012;2(3):260-269. doi: 10.1158/2159-8290.CD-11-0242.

122. Mini E, Nobili S, Caciagli B, Landini I, Mazzei T. Cellular pharmacology of gemcitabine. Ann Oncol Off J Eur Soc Med Oncol. 2006;17 Suppl 5:v7-12. doi: 10.1093/annonc/mdj941. 
123. Burris HA, Moore MJ, Andersen J, et al. Improvements in survival and clinical benefit with gemcitabine as first-line therapy for patients with advanced pancreas cancer: a randomized trial. J Clin Oncol. 1997;15(6):2403-2413. doi: 10.1200/JCO.1997.15.6.2403.

124. Zhang Y-J, Wen C-L, Qin Y-X, et al. Establishment of a human primary pancreatic cancer mouse model to examine and investigate gemcitabine resistance. Oncol Rep. 2017;38(6):3335-3346. doi: 10.3892/or.2017.6026.

125. Marasini B, Sahu RP. Natural Anti-Cancer Agents: Implications in GemcitabineResistant Pancreatic Cancer Treatment. Mini Rev Med Chem. 2017;17(11):920927. doi: $10.2174 / 1389557517666170315124438$.

126. Sasaki H, Sunagawa Y, Takahashi K, et al. Innovative preparation of curcumin for improved oral bioavailability. Biol Pharm Bull. 2011;34(5):660-665. doi: $10.1248 / \mathrm{bpb} .34 .660$.

127. Bimonte $\mathrm{S}$, Barbieri A, Leongito $\mathrm{M}$, et al. Curcumin anticancer studies in pancreatic cancer. Nutrients. 2016;8(7):1-12. doi: 10.3390/nu8070433.

128. Tomeh MA, Hadianamrei R, Zhao X. A Review of Curcumin and Its Derivatives as Anticancer Agents. Int J Mol Sci. 2019;20(5). doi: 10.3390/ijms20051033.

129. Khan S, Setua S, Kumari S, et al. Superparamagnetic iron oxide nanoparticles of curcumin enhance gemcitabine therapeutic response in pancreatic cancer. Biomaterials. 2019;208:83-97. doi: 10.1016/j.biomaterials.2019.04.005.

130. Yallapu MM, Ebeling MC, Khan S, et al. Novel curcumin-loaded magnetic nanoparticles for pancreatic cancer treatment. Mol Cancer Ther. 2013;12(8):14711480. doi: 10.1158/1535-7163.MCT-12-1227.

131. Massey AE, Sikander M, Chauhan N, et al. Next-generation paclitaxelnanoparticle formulation for pancreatic cancer treatment. Nanomedicine Nanotechnology, Biol Med. 2019;20. doi: 10.1016/j.nano.2019.102027.

132. Awasthi N, Zhang C, Schwarz AM, et al. Comparative benefits of Nab-paclitaxel over gemcitabine or polysorbate-based docetaxel in experimental pancreatic cancer. Carcinogenesis. 2013;34(10):2361-2369. doi: 10.1093/carcin/bgt227.

133. Amrutkar M, Gladhaug IP. Pancreatic Cancer Chemoresistance to Gemcitabine. Cancers (Basel). 2017;9(11). doi: 10.3390/cancers9110157.

134. Matsuo K, Mandelbaum RS, Machida H, et al. Association of tumor differentiation grade and survival of women with squamous cell carcinoma of the uterine cervix. $J$ Gynecol Oncol. 2018;29(6):e91. doi: 10.3802/jgo.2018.29.e91.

135. Alexander $\mathrm{D}$, Jhala $\mathrm{N}$, Chatla $\mathrm{C}$, et al. High-grade tumor differentiation is an indicator of poor prognosis in African Americans with colonic adenocarcinomas. Cancer. 2005;103(10):2163-2170. doi: 10.1002/cncr.21021.

136. Wasif N, Ko CY, Farrell J, et al. Impact of tumor grade on prognosis in pancreatic cancer: should we include grade in AJCC staging? Ann Surg Oncol. 2010;17(9):2312-2320. doi: 10.1245/s10434-010-1071-7.

137. Leary M, Heerboth S, Lapinska K, Sarkar S. Sensitization of Drug Resistant Cancer Cells: A Matter of Combination Therapy. Cancers (Basel). 2018;10(12). doi: 10.3390/cancers10120483.

138. Prieto-Vila M, Takahashi R-U, Usuba W, Kohama I, Ochiya T. Drug Resistance Driven by Cancer Stem Cells and Their Niche. Int J Mol Sci. 2017;18(12). doi: $\underline{10.3390 / \mathrm{ijms} 18122574 .}$. 
139. Olugbami JO, Damoiseaux R, France B, et al. Atomic force microscopy correlates antimetastatic potentials of HepG2 cell line with its redox/energy status: effects of curcumin and Khaya senegalensis. $J$ Integr Med. 2017;15(3):214-230. doi:10.1016/S2095-4964(17)60337-6.

140. Ren J, Huang H, Liu Y, Zheng X, Zou Q. An Atomic Force Microscope Study Revealed Two Mechanisms in the Effect of Anticancer Drugs on Rate-Dependent Young's Modulus of Human Prostate Cancer Cells. Dague E, ed. PLoS One. 2015;10(5):e0126107. doi:10.1371/journal.pone.0126107.

141. Saab M, Bec N, Martin M, et al. Differential Effect of Curcumin on the Nanomechanics of Normal and Cancerous Mammalian Epithelial Cells. Cell Biochem Biophys. 2013;65(3):399-411. doi:10.1007/s12013-012-9443-1.

142. Rotsch C, Radmacher M. Drug-induced changes of cytoskeletal structure and mechanics in fibroblasts: an atomic force microscopy study. Biophys $J$. 2000;78(1):520-535. doi: 10.1016/S0006-3495(00)76614-8.

143. Kashyap VK, Wang Q, Setua S, et al. Therapeutic efficacy of a novel $\beta \mathrm{III} / \beta \mathrm{IV}$ tubulin inhibitor (VERU-111) in pancreatic cancer. J Exp Clin Cancer Res. 2019;38(1):29. doi: 10.1186/s13046-018-1009-7.

144. McIntyre LJ, Kim YS. Effects of sodium butyrate and dimethylsulfoxide on human pancreatic tumor cell lines. Eur J Cancer Clin Oncol. 1984;20(2):265-271. doi: 10.1016/0277-5379(84)90194-9.

145. Cross SE, Jin Y-S, Lu Q-Y, Rao J, Gimzewski JK. Green tea extract selectively targets nanomechanics of live metastatic cancer cells. Nanotechnology. 2011;22(21):215101. doi: 10.1088/0957-4484/22/21/215101.

146. Suganuma M, Takahashi A, Watanabe T, et al. Biophysical approach to mechanisms of cancer prevention and treatment with green tea catechins. Molecules. 2016;21(11):1-17. doi: 10.3390/molecules21111566.

147. Pi J, Cai H, Jin H, et al. Qualitative and quantitative analysis of ROS-mediated oridonin-induced oesophageal cancer KYSE-150 cell apoptosis by atomic force microscopy. PLoS One. 2015;10(10):1-18. doi: 10.1371/journal.pone.0140935.

148. Mezencev R, Wang L, Xu W, et al. Molecular analysis of the inhibitory effect of $\mathrm{N}$-acetyl-L-cysteine on the proliferation and invasiveness of pancreatic cancer cells. Anticancer Drugs. 2013;24(5):504-518. doi: 10.1097/CAD.0b013e32836009d7.

149. Iturri J, Weber A, Moreno-Cencerrado A, et al. Resveratrol-induced temporal variation in the mechanical properties of MCF- 7 breast cancer cells investigated by atomic force microscopy. Int J Mol Sci. 2019;20(13). doi: 10.3390/ijms20133275.

150. Dokukin ME, Guz N V., Sokolov I. Mechanical properties of cancer cells depend on number of passages: Atomic force microscopy indentation study. Jpn J Appl Phys. 2017;56(8). doi: 10.7567/JJAP.56.08LB01.

151. Gupta BK, Maher DM, Ebeling MC, et al. Increased expression and aberrant localization of mucin 13 in metastatic colon cancer. $J$ Histochem Cytochem. 2012;60(11):822-831. doi: 10.1369/0022155412460678.

152. Li M, Liu L, Xi N, Wang Y. Atomic force microscopy studies on cellular elastic and viscoelastic properties. Sci China Life Sci. 2018;61(1):57-67. doi: $\underline{10.1007 / \mathrm{s} 11427-016-9041-9 .}$. 
153. Yallapu MM, Katti KS, Katti DR, et al. The roles of cellular nanomechanics in cancer. Med Res Rev. 2015;35(1):198-223. doi: 10.1002/med.21329.

154. Luo Q, Kuang D, Zhang B, Song G. Cell stiffness determined by atomic force microscopy and its correlation with cell motility. Biochim Biophys Acta - Gen Subj. 2016;1860(9):1953-1960. doi: 10.1016/j.bbagen.2016.06.010.

155. Park S, Lee YJ. AFM-based dual nano-mechanical phenotypes for cancer metastasis. J Biol Phys. 2014;40(4):413-419. doi: 10.1007/s10867-014-9353-0.

156. Kim H, Yamagishi A, Imaizumi M, et al. Quantitative measurements of intercellular adhesion between a macrophage and cancer cells using a cup-attached AFM chip. Colloids Surfaces B Biointerfaces. 2017;155:366-372. doi: 10.1016/j.colsurfb.2017.04.039.

157. Lin HH, Lin HK, Lin IH, et al. Mechanical phenotype of cancer cells: Cell softening and loss of stiffness sensing. Oncotarget. 2015;6(25):20946-20958. doi: 10.18632/oncotarget.4173.

158. Peñuela LA, Fulcheri E, Vellone VG, et al. Atomic force microscopy: a promising aid in diagnosis of uterine smooth muscle neoplasms. Am J Obstet Gynecol. 2019;(October):362-364. doi: 10.1016/j.ajog.2019.05.013.

159. Kulkarni T, Tam A, Mukhopadhyay D, Bhattacharya S. AFM study: Cell cycle and probe geometry influences nanomechanical characterization of Panc1 cells. Biochim Biophys Acta - Gen Subj. 2019;1863(5):802-812. doi: 10.1016/j.bbagen.2019.02.006.

160. Liu H, Wang N, Zhang Z, Wang H, Du J, Tang J. Effects of Tumor Necrosis Factor- $\alpha$ on Morphology and Mechanical Properties of HCT116 Human Colon Cancer Cells Investigated by Atomic Force Microscopy. Scanning. 2017;2017:2027079. doi: 10.1155/2017/2027079.

161. Khan S, Sikander M, Ebeling MC, et al. MUC13 interaction with receptor tyrosine kinase HER2 drives pancreatic ductal adenocarcinoma progression. Oncogene. 2016;(May):1-10. doi: 10.1038/onc.2016.218.

162. Kumari S, Khan S, Gupta SC, et al. MUC13 contributes to rewiring of glucose metabolism in pancreatic cancer. Oncogenesis. 2018;7(2). doi: 10.1038/s41389$\underline{018-0031-0 .}$. 

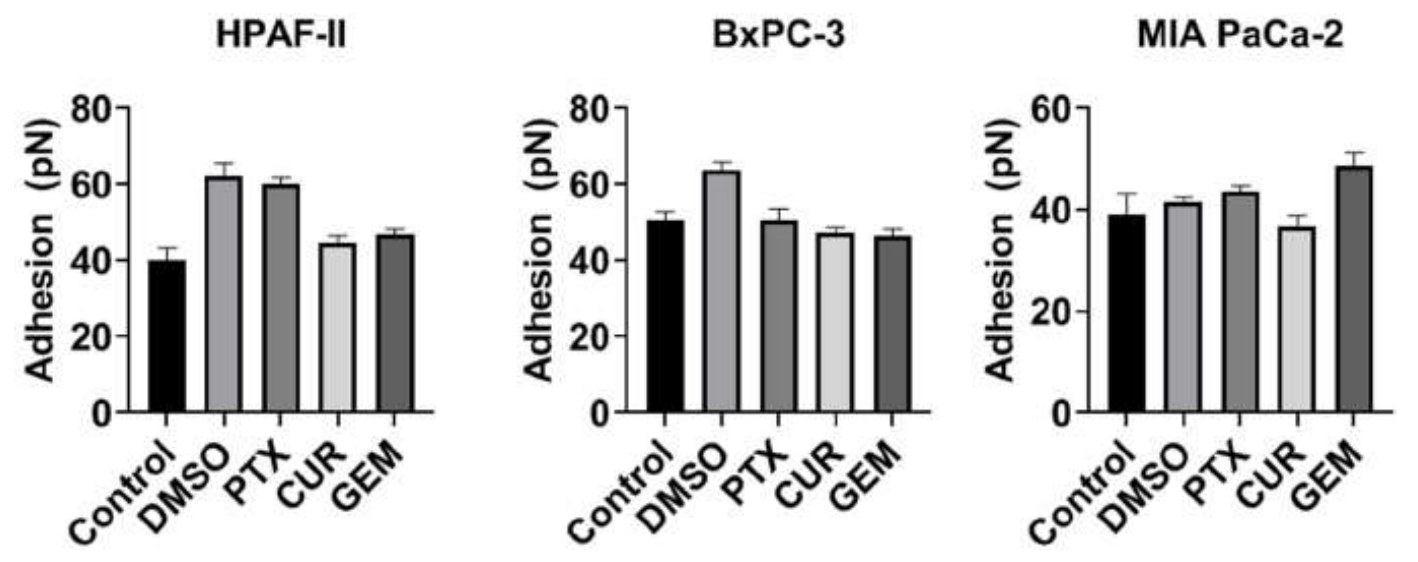

AsPC-1

Panc-1
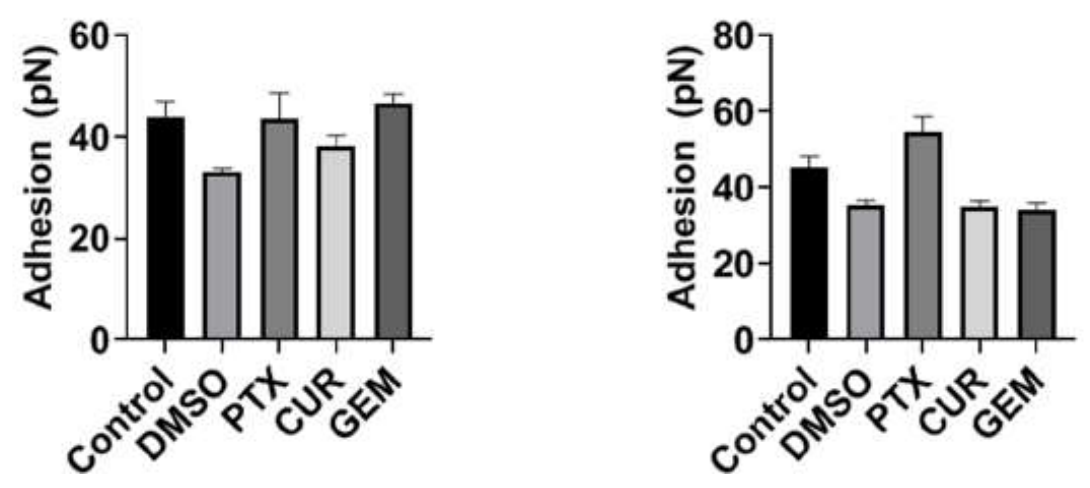

Figure A-1. Overall analysis of chemotherapeutic treatments on adhesive properties of PDAC cells. 

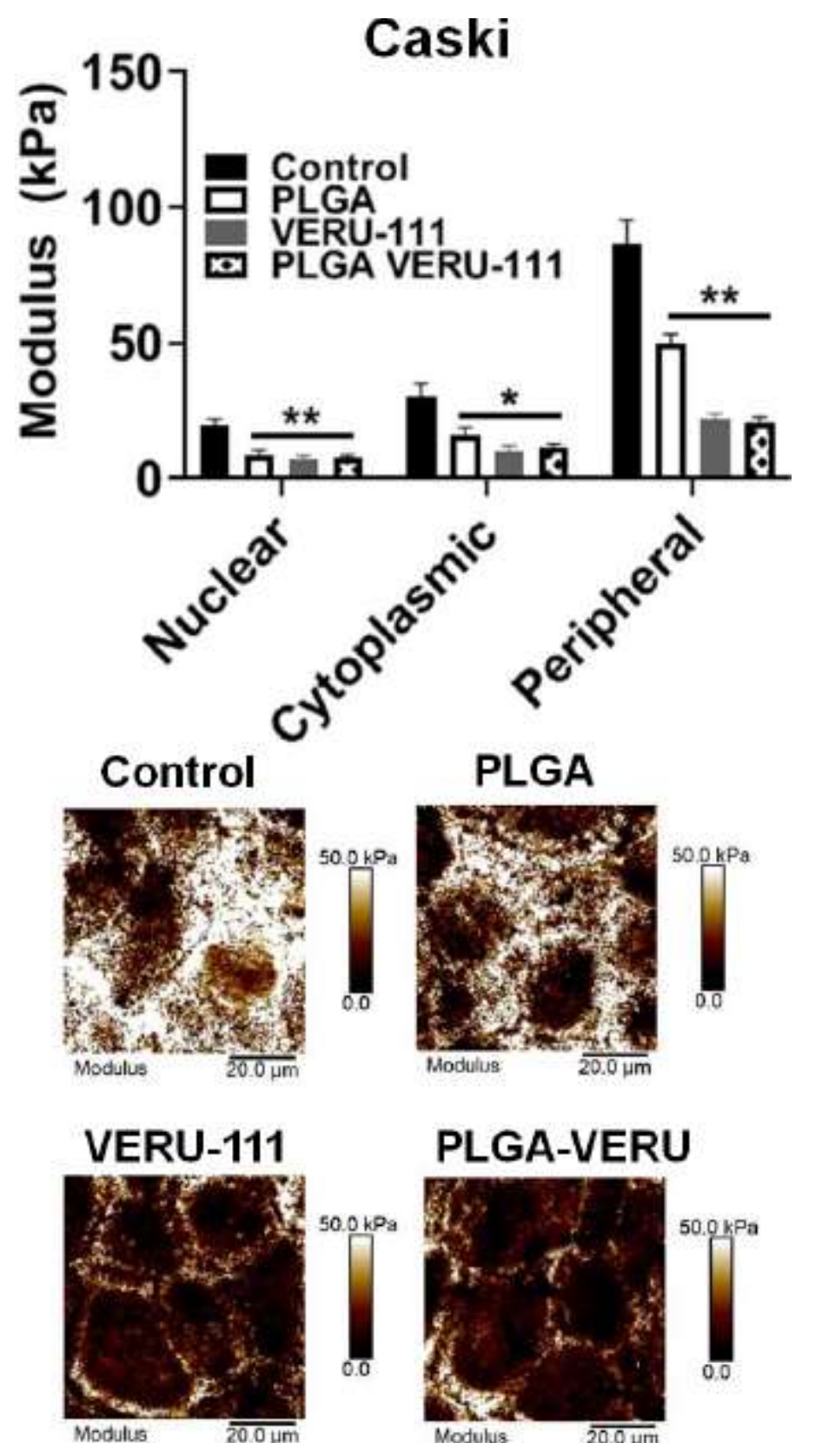

Figure A-2. Biophysical effects of VERU-111 (free drug and PLGA nanoformulations) on Caski cervical cancer cells.

Cells were treated with $10 \mathrm{nM}$ of both free VERU and nanoparticle formulation. Cells were analyzed in the same method described in Chapter 3. 

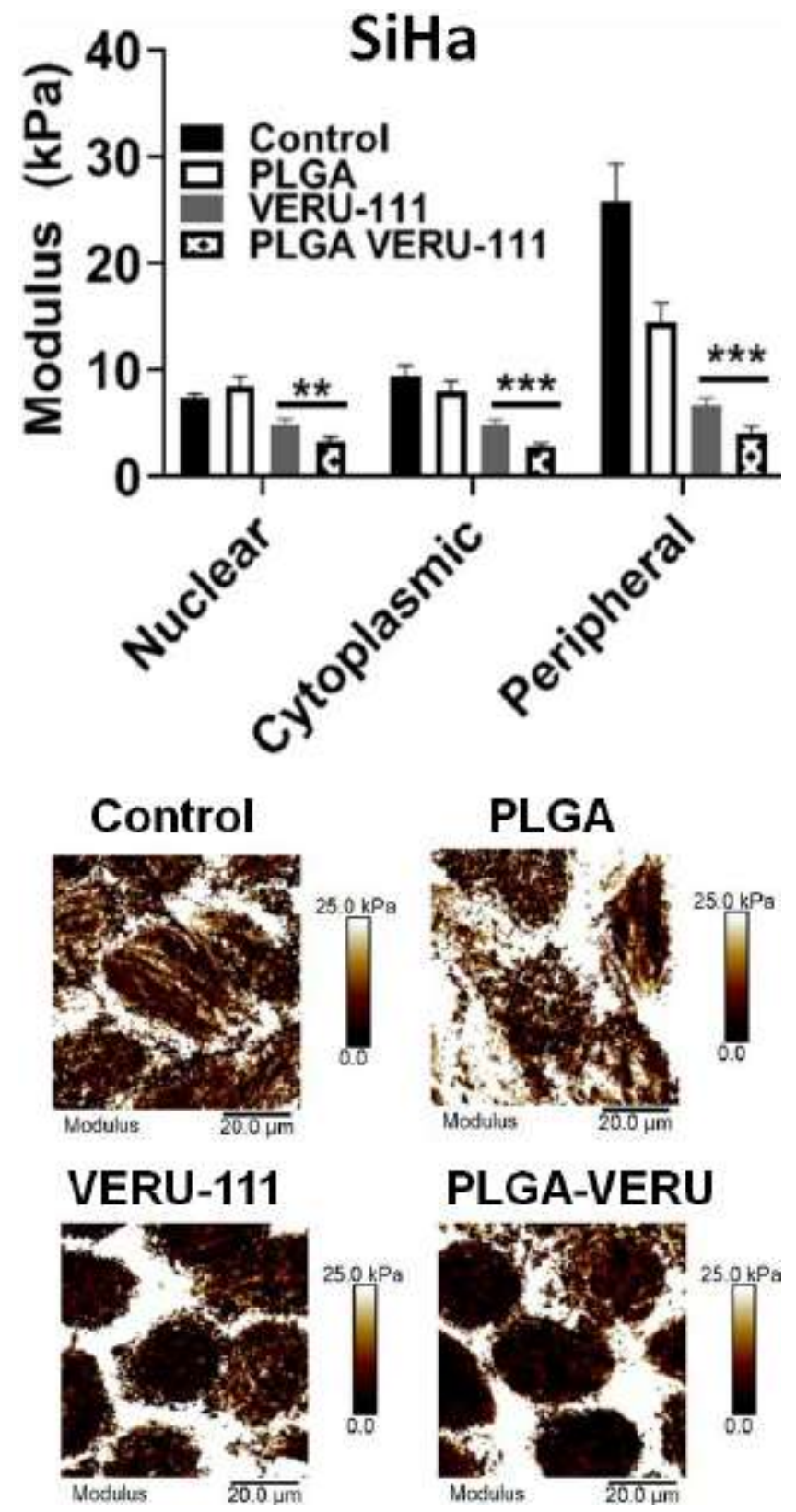

Figure A-3. Biophysical effects of VERU-111 (free drug and PLGA nanoformulations) on SiHa cervical cancer cells.

Cells were treated with $10 \mathrm{nM}$ of both free VERU and nanoparticle formulation. Cells were analyzed in the same method described in Chapter 3. 

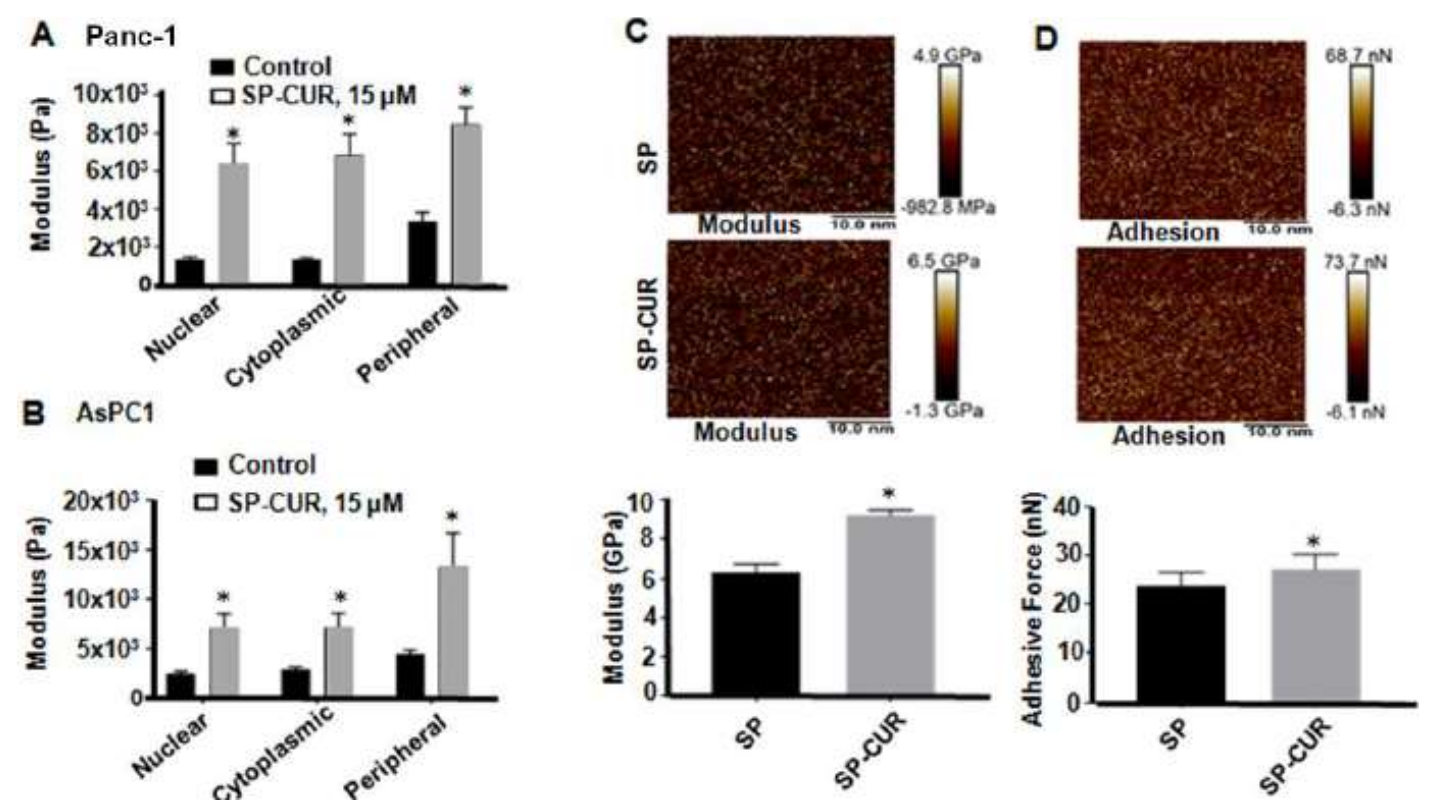

Figure A-4. Biophysical effects of curcumin-loaded magnetic nanoparticles on PDAC cells and tissues.

(A and B) Graphs depicting changes in elastic properties of Panc-1 (A) AsPC-1 (B) cells on treatment with SP-CUR $(\mathrm{p}<0.05)$. (C and D) Representative images and corresponding graphs comparing elastic modulus $(p=0.0006)(C)$ and adhesion properties $(\mathrm{p}=0.2385)(\mathrm{D})$ of FFPE tumor tissues from SP and SP-CUR treated orthotopic nude mice. $\mathrm{P}$ values as $\mathrm{p}<0.05$ are considered significant and are denoted as * symbol.

Modified from final submission with permission from Elsevier. Khan S, Setua S, Kumari $\mathrm{S}$, et al. Superparamagnetic iron oxide nanoparticles of curcumin enhance gemcitabine therapeutic response in pancreatic cancer. Biomaterials. 2019;208:83-97. doi:10.1016/j.biomaterials.2019.04.005. [125]. 
Figure A-5. Synthesis and characterization of PLGA-PTX nanoparticles (PPNPs).

(A) Schematic overview of PPNPs synthesis. (B) DLS characterization of PLGA and PPNPs. (C) DLS characterization of zeta potential for PLGA and PPNPs. (D) FTIR spectra for free PTX, PLGA, and PPNPs. (E) XRD spectra for free PTX, PLGA, and PPNPs. (F) Topographical and physical analysis of PLGA and PPNPs by atomic force microscopy (AFM). Representative 2D and 3D images $\left(2 \times 2 \mu \mathrm{m}^{2}\right)$ of PLGA and PPNPs (i-ii). Modulus data for two separate samples (iii-iv).

Reprinted from final submission with permission from Elsevier. Massey AE, Sikander M, Chauhan N, et al. Next-generation paclitaxel-nanoparticle formulation for pancreatic cancer treatment. Nanomedicine Nanotechnology, Biol Med. 2019;20.

doi:10.1016/j.nano.2019.102027. [127]. 

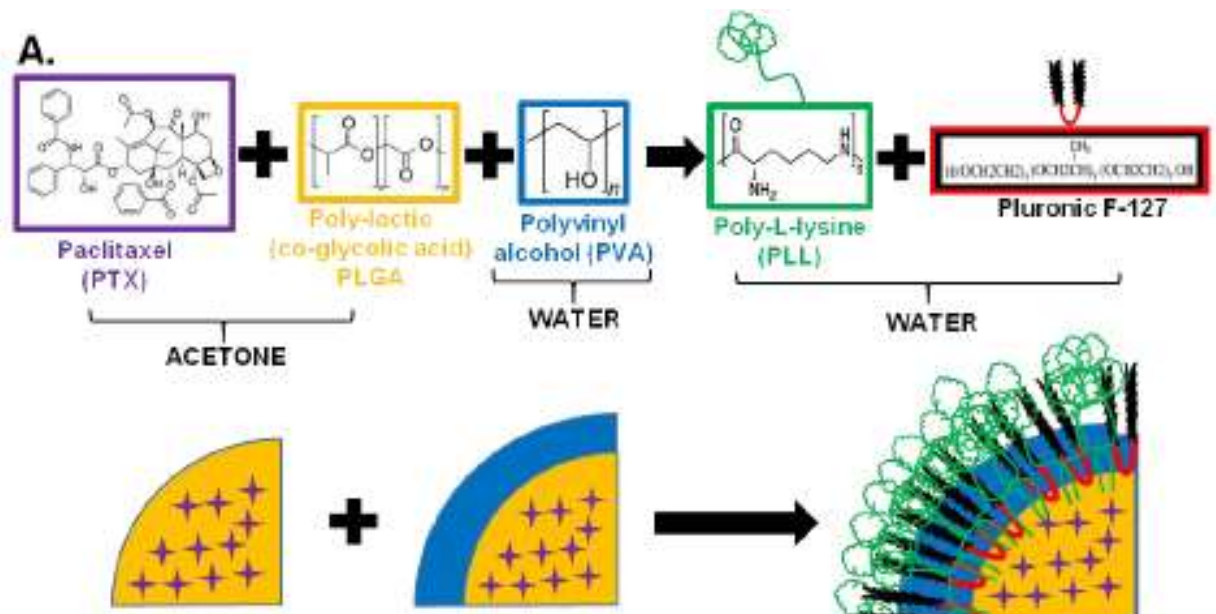

B.

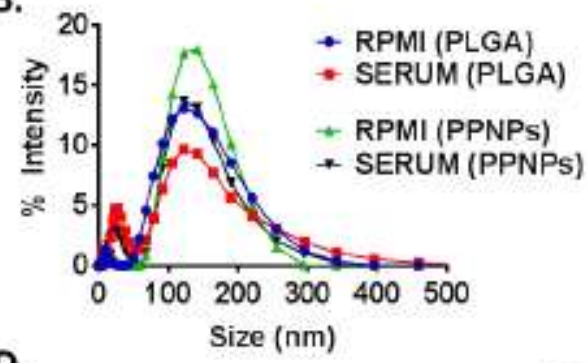

C.

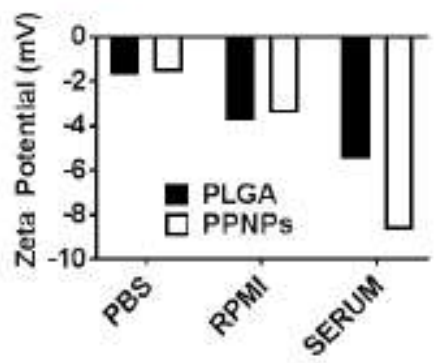

F.
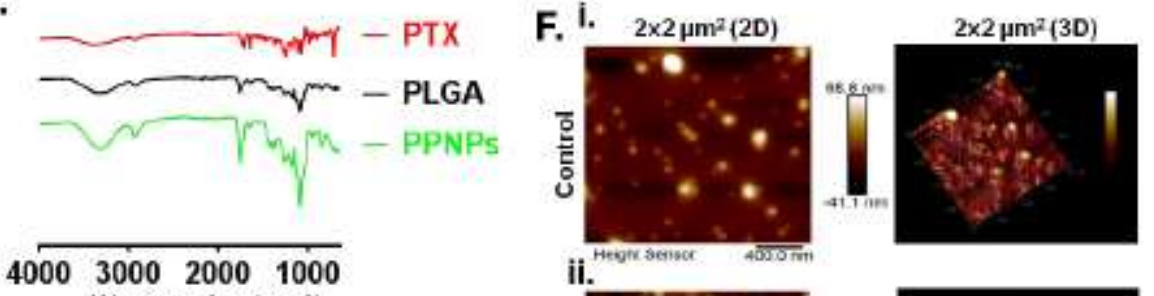

Wavenumber $\left(\mathrm{cm}^{-1}\right)$

E.

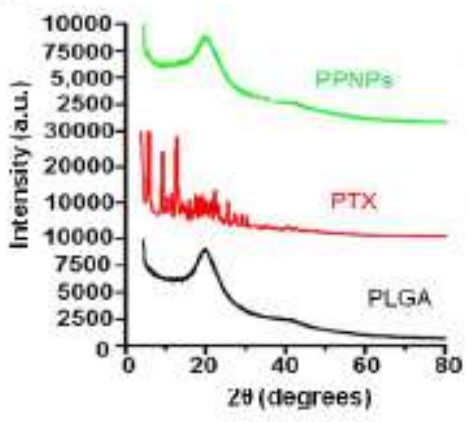

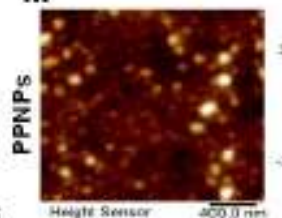

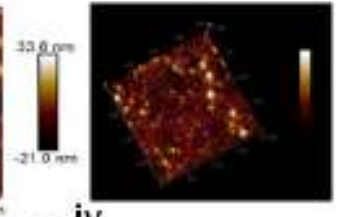

iii.

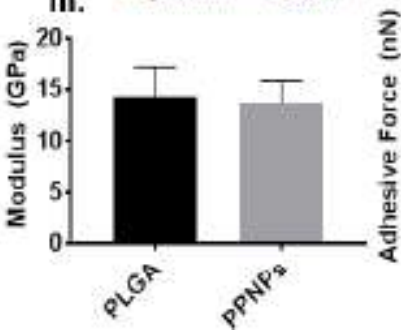

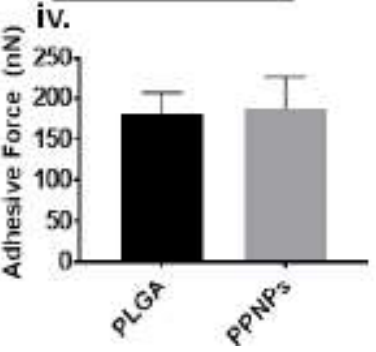


Figure A-6. Physical characteristics of living cells after treatment with PPNPs.

(A) Analysis of ASPC1 cells. Three-dimensional images of of untreated (i) and PPNPstreated (ii) cells showing morphological changes with treatment (10nM for 24 hours). (iii) Summary of physical data collected by AFM force analysis showing changes in modulus and adhesion with PPNP treatment. (B) Analysis of Panc1 cells. Three-dimensional images of of untreated (i) and PPNPs-treated (ii) cells showing morphological changes with treatment (10nM for 24 hours). (iii) Summary of physical data collected by AFM force analysis showing changes in modulus and adhesion with PPNP treatment.

Reprinted from final submission with permission from Elsevier. Massey AE, Sikander M, Chauhan N, et al. Next-generation paclitaxel-nanoparticle formulation for pancreatic cancer treatment. Nanomedicine Nanotechnology, Biol Med. 2019;20.

doi:10.1016/j.nano.2019.102027. [127]. 


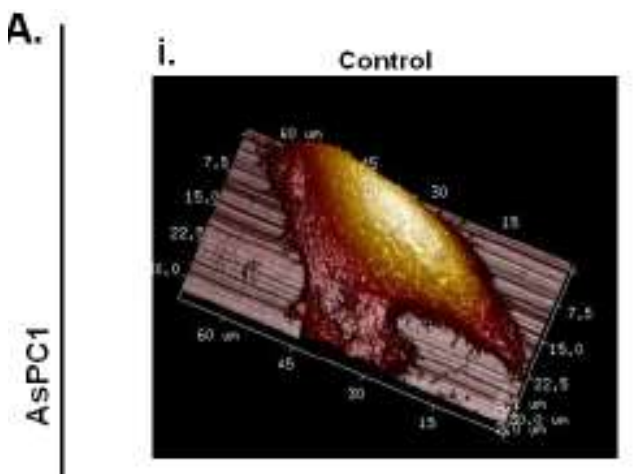

iii.
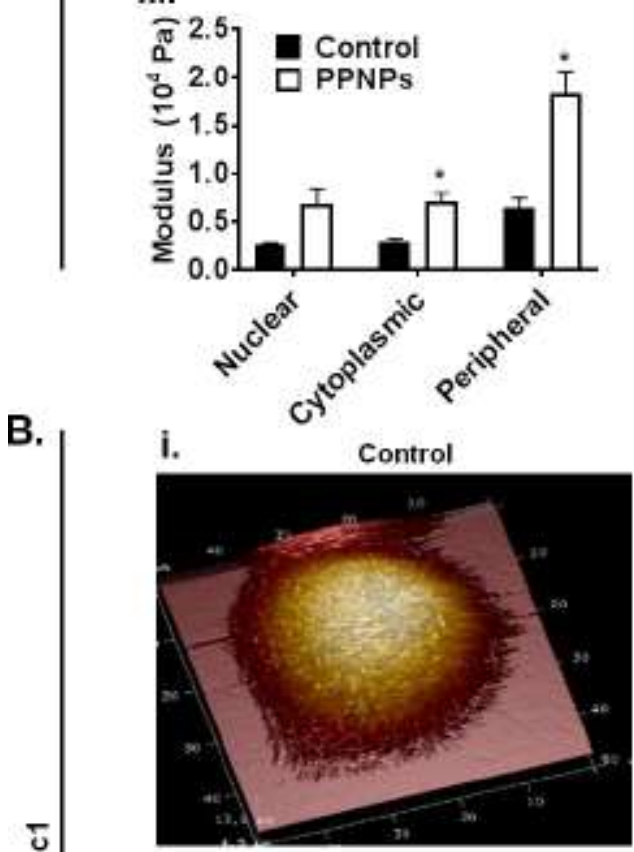

ธุ๊

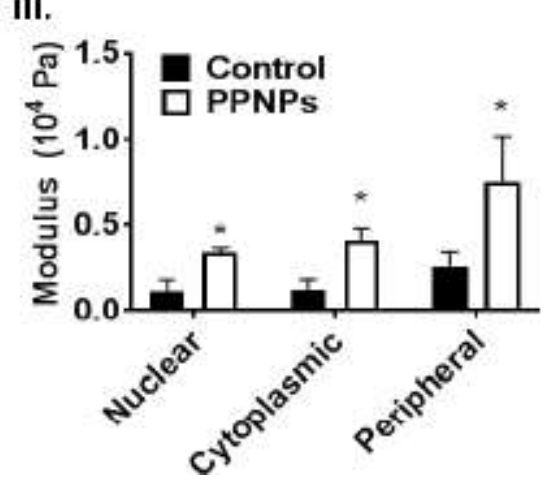

ii.

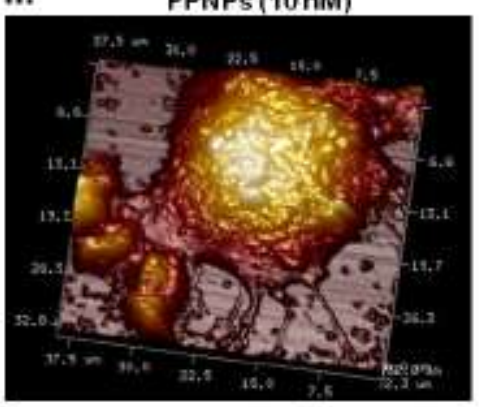

iv.

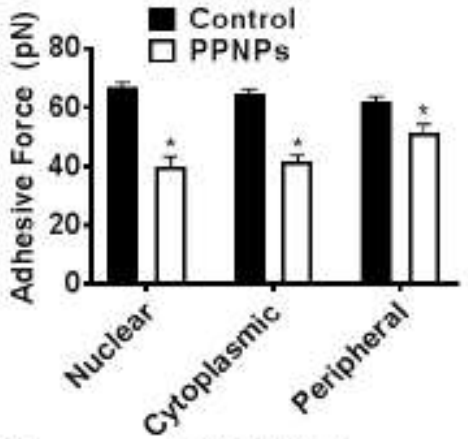

ii.

PPNPS (10nM)

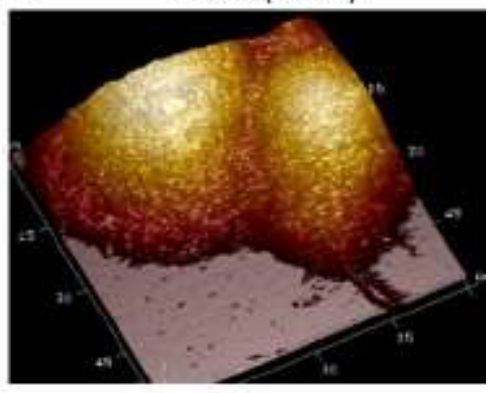

iv.

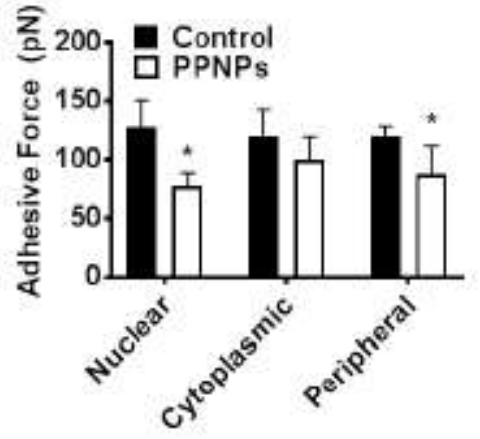




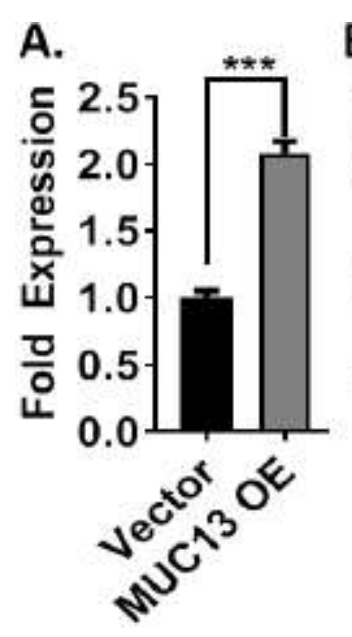

B.
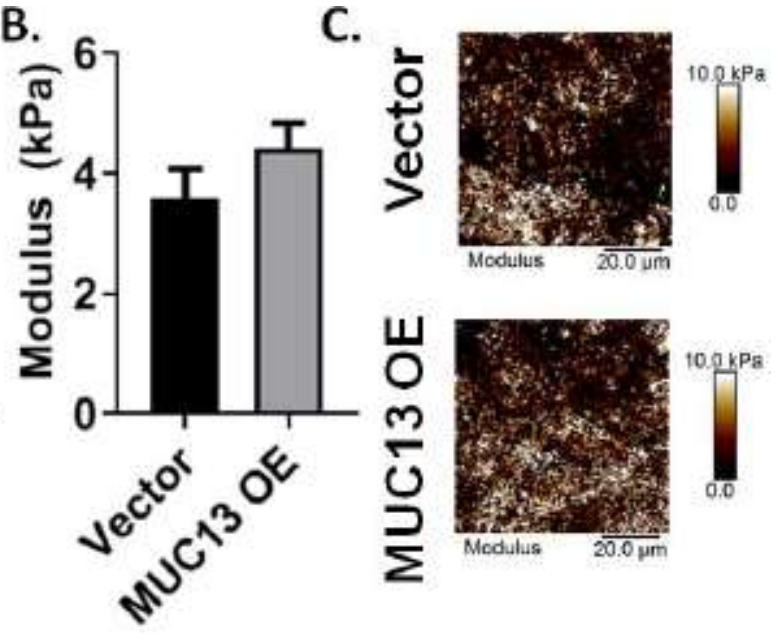

D.

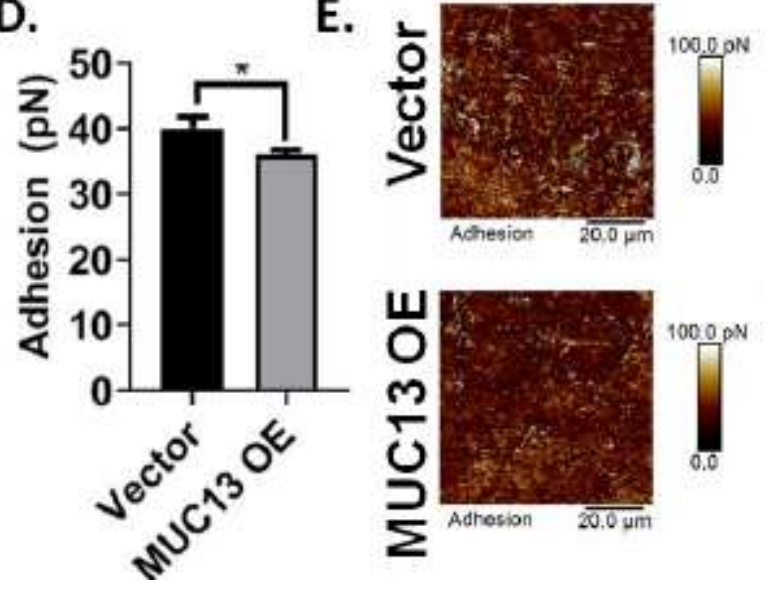

Figure B-1. Biophysical effects of MUC13 overexpression on SW480 colorectal cells.

(A) Confirmation of MUC13 expression with PCR analysis. (B) Change in modulus with MUC13 overexpression. (C) Representative modulus images with MUC13 overexpression. (D) Changes in membrane adhesion with MUC13 overexpression. (E) Representative images of adhesion with MUC13 overexpression. 

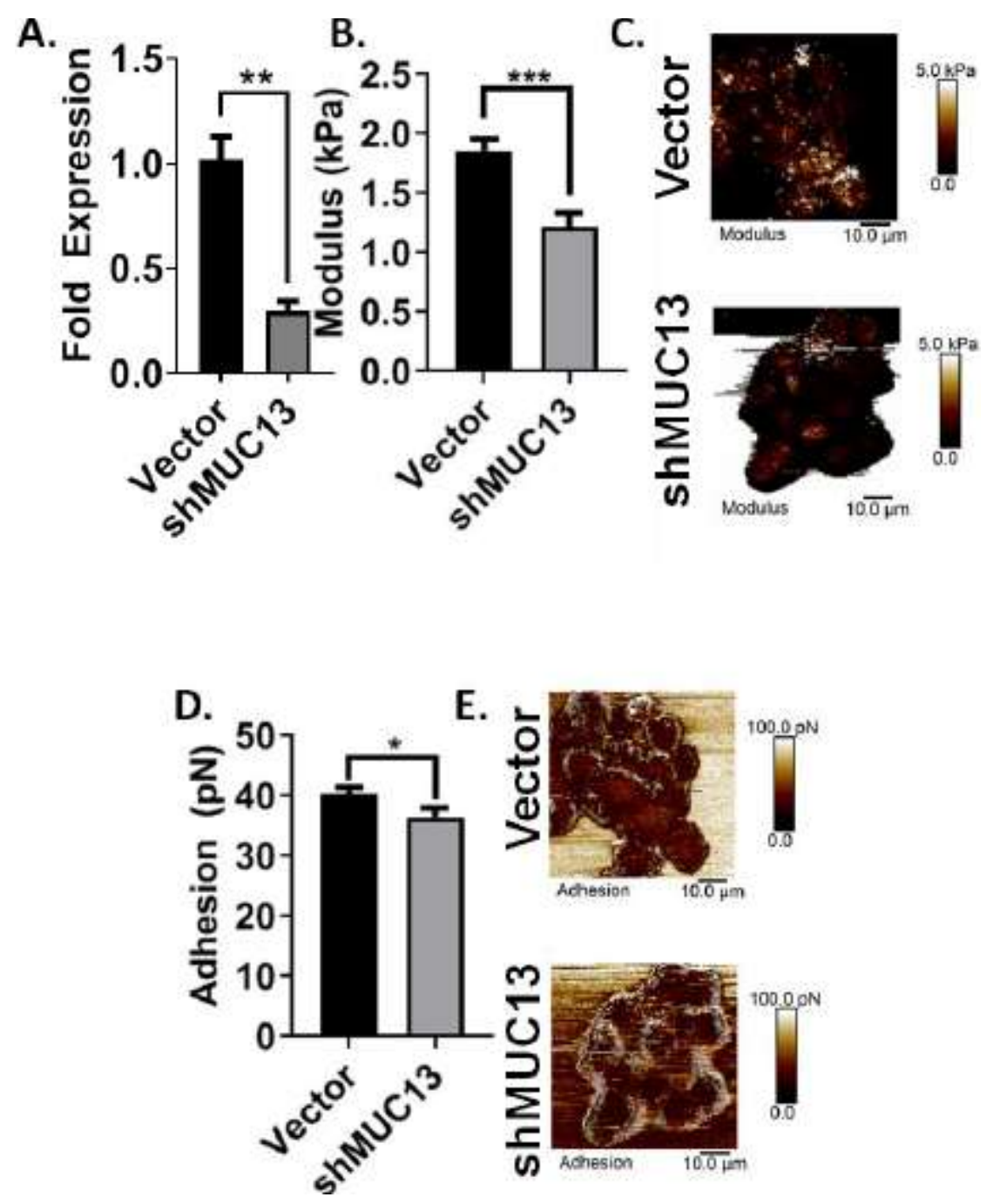

Figure B-2. Biophysical effects of MUC13 knockdown on SW620 colorectal cells.

(A) Confirmation of MUC13 expression with PCR analysis. (B) Change in modulus with MUC13 knockdown. (C) Representative modulus images with MUC13 knockdown. (D) Changes in membrane adhesion with MUC13 knockdown. (E) Representative images of adhesion with MUC13 knockdown 

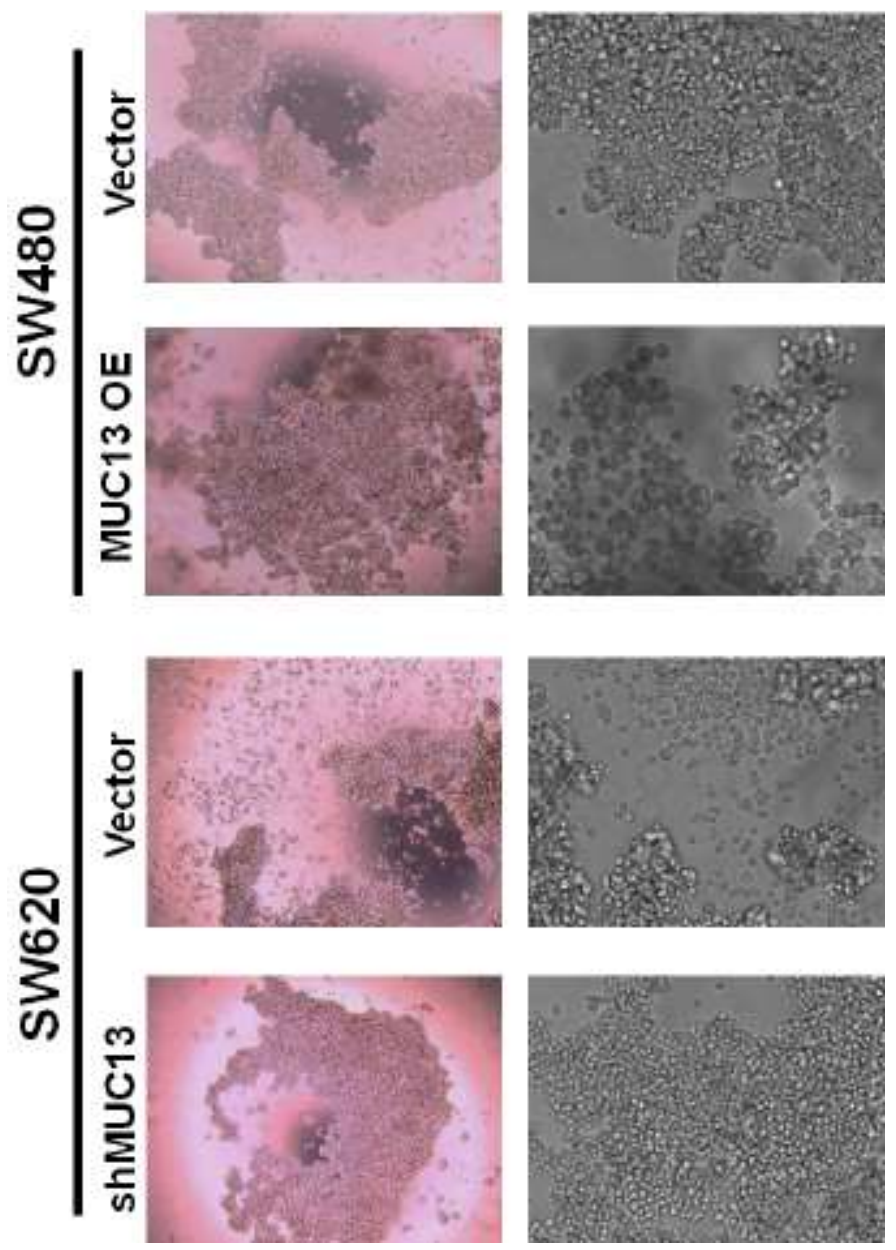

Figure B-3. Representative aggregation assay results showing effects of MUC13 modulation on aggregative potential in colorectal cancer cells. 

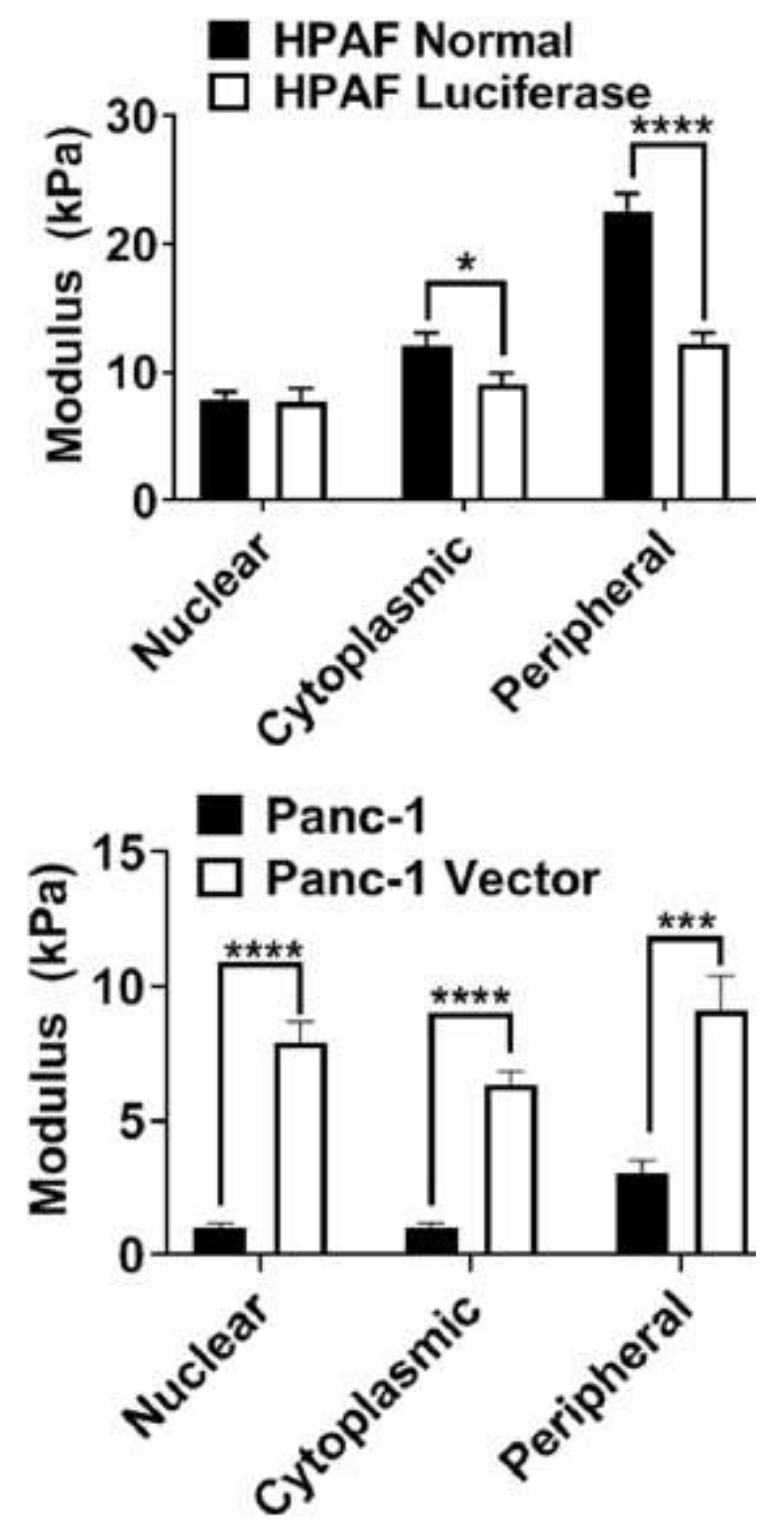

Figure B-4. Biophysical effects of cellular transfection on pancreatic cancer cells. 


\section{VITA}

Andrew Massey was born in Shreveport, Louisiana in 1988. He graduated from Louisiana Tech University with a Bachelor of Science in Nanosystems Engineering in 2012. In 2016, he earned his Doctor of Pharmacy (Pharm.D.) from the University of Louisiana at Monroe. The same year he joined the University of Tennessee Health Science Center (UTHSC) at Memphis and joined Dr. Subhash Chauhan's lab. He anticipates receiving his $\mathrm{PhD}$ in Pharmaceutical Sciences in May 2020 from UTHSC. 